\title{
The Effect of Social Presence on Students' Perceived Learning and Satisfaction in Online Courses
}

Joseph Nyandusi Nyachae

West Virginia University

Follow this and additional works at: https://researchrepository.wvu.edu/etd

\section{Recommended Citation}

Nyachae, Joseph Nyandusi, "The Effect of Social Presence on Students' Perceived Learning and Satisfaction in Online Courses" (2011). Graduate Theses, Dissertations, and Problem Reports. 4761. https://researchrepository.wvu.edu/etd/4761

This Dissertation is protected by copyright and/or related rights. It has been brought to you by the The Research Repository @ WVU with permission from the rights-holder(s). You are free to use this Dissertation in any way that is permitted by the copyright and related rights legislation that applies to your use. For other uses you must obtain permission from the rights-holder(s) directly, unless additional rights are indicated by a Creative Commons license in the record and/ or on the work itself. This Dissertation has been accepted for inclusion in WVU Graduate Theses, Dissertations, and Problem Reports collection by an authorized administrator of The Research Repository @ WVU.

For more information, please contact researchrepository@mail.wvu.edu. 
The Effect of Social Presence on Students' Perceived Learning and Satisfaction in Online Courses.

\author{
Joseph Nyandusi Nyachae
}

Dissertation submitted to the College of Human Resources and Education at West Virginia University in partial fulfillment of the requirements for the degree of

Doctor of Education

In

Technology Education

\author{
Terence C. Ahern, Ph.D., Chair \\ Daniel Hursh, Ph.D. \\ Neal Shambaugh, Ph.D. \\ Sebastian Diaz, Ph.D., J.D. \\ Ugur Kale, PhD.
}

Department of Technology, Learning \& Culture, Morgantown, West Virginia 2011

Keywords: Synchronous \& Asynchronous Communication, Distance Education, Computer Mediated Communication, Community of Inquiry, Social Presence 


\begin{abstract}
The Effect of Social Presence on Students' Perceived Learning and Satisfaction in Online Courses

Joseph Nyandusi Nyachae

This study investigated the effects of social presence on students' perceived learning and satisfaction in online courses. The participants for this study were 81 graduate students enrolled in four special education online courses offered at a major higher education institution located in a Mid-Atlantic state. Two research questions were used to conduct the research:

1. Can we predict in a statistically significant fashion using linear regression students' perceived learning in a course based on their perceived level of social presence and number of interactive elements in the course?

2. Can we predict in a statistically significant fashion using linear regression students' satisfaction in a course based on their perceived level of social presence and number of interactive elements in the course?

The results indicated that there positive correlation between perceived learning and the two independent variables (number of interactive elements and social presence). Social presence had a positive relationship with perceived learning. There was no statistically significant relationship between interactive elements and perceived learning. Results also showed that there was a positive correlation between satisfaction and the two independent variables (number of interactive elements and social presence). Social presence had a positive relationship satisfaction. There was no statistically significant relationship between interactive elements and satisfaction. The study demonstrated that interactive elements alone did not have an impact on students' perceived learning and satisfaction.
\end{abstract}




\section{BIOGRAPHICAL SKETCH}

Joseph Nyandusi Nyachae was born on October 12th 1975 in Kisii, Kenya and grew up in Nyosia, a small town in Kisii District, located in Nyanza Province of Kenya. Right from when he was little boy, Nyandusi's parents strongly stressed the value of education and the importance of working hard. Between 1981 and 1989, he attended Sakagwa primary school before joining Cardinal Otunga High School for his secondary education from 1990 to 1993. In 1994 he moved to the United States of America for further studies and attended State University of New York (SUNY), College at Buffalo where he graduated with an Economics and a Master's degree in Educational Computing. In 2003, Nyandusi's livelong dream became a reality when he was admitted in a doctoral program at West Virginia University to major in Technology Education and minor in Instructional Design. In 2007, he was offered a job at West Virginia University as an Instructional Designer. Nyandusi currently resides in Morgantown, West Virginia. He can be reached at Joseph.Nyachae@,mail.wvu.edu or nyandusi@yahoo.com. 


\section{DEDICATION}

I want to dedicate this dissertation to my parents, Mr. Simeon Nyachae and Mrs. Martha Mwango Nyachae, and members of my beloved family, who provided me with endless love, encouragement, advice and support throughout my life. To my late grandmother, Mrs. Paulina Bosibori Nyandusi, who continuously encouraged me to keep on pursuing my studies and to keep my trust in God at all times. To my late friend and colleague, Dr. Francis Ndwiga Murage, for his support and encouragement. Without you, my friend I would probably have not started this journey.

I dedicate this dissertation to you all. 


\section{ACKNOWLEDGEMENTS}

The task of writing this dissertation was not an individual endeavor; it would not have been achieved without the guidance and support of esteemed personalities. To all of you, I truly give my deepest heartfelt thank you. In particular, I would like to express my deepest gratitude to members of my doctoral committee. I would like to thank my dissertation chair and advisor, Dr. Terence C. Ahern for his advice, valuable feedback, support, and guidance in this process. Special thanks to Dr. Daniel Hursh for his counsel, guidance, insight and encouragement during the writing of this dissertation. Equally, I would like to really thank Dr. Neal Shambaugh for his receptiveness and encouragement. I really enjoyed and truly gained valuable knowledge from attending your Instructional Design class. In the same breath, I would like to express special gratitude to Dr. Sebastian Diaz for his invaluable guidance in the data analysis process. I thank you for taking time from your busy schedule to counsel me with the statistics section of my dissertation. Likewise, I would like to sincerely thank Dr. Ugur Kale for agreeing to serve on my doctoral committee in the later phase of writing this dissertation. His valuable knowledge, advice and assistance were essential for the completion of this dissertation.

Many thanks to the participants who took valuable time to complete the survey instrument. Also, I want to give many thanks to the Department of Special Education, particularly Dr. Barbara Ludlow for assisting me to dispense the survey instruments. I would also like to thank my colleagues who have supported and encouraged me on several occasions. I would like to recognize members of the Instructional Technology Resource Center (ITRC) especially Carla, Chrys, Kelley, Lydia, Pat and Tarannum for their inconceivable support. I would like to single out Ms. Lucinda Hart, my immediate supervisor, for her advice and guidance and for giving me the opportunity to be part of an amazing team. Being part of ITRC 
has given me an opportunity to express my ideas freely, to grow and contribute to a dynamic, creative and cooperative environment. Similarly, many thanks to Dr. David McCrory, Dr. John Wells, Dr. Dan Hartley, Benson Njoroge, Sophia Baisie, Daniel Richter, Mr. Jackson Omoi, and Adam Flack, for their advice and guidance. I would also like to thank Dr. Chifundu Lemani for his invaluable guidance in the data analysis process. In particular, I cannot overlook the support of Ian Kahoro who has remained to be a great friend. On many occasions, I have consulted him whenever different obstacles overwhelmed me. In the same breath, I truly give my deepest heartfelt thank you to Ms. Daton Dean for being my number one cheerleader and best friend. You always reminded me to take time out to rest and have some fun. Your unconditional love, encouragement and friendship have been invaluable all the way through my doctoral studies.

I am deeply indebted to members of my immediate family. Most importantly, I truly give my deepest heartfelt thank you to my dear parents, Mr. Simeon Nyachae and Mrs. Martha Mwango Nyachae for their unselfish love and unconditional support. From the time when I was a little boy, you taught me a lot about discipline, hard work, spirituality and preserving humility while achieving great heights. Dad, you are one of the most important people in my life, an exceptional man of ethics, morals and devotion to his family. Mum, I thank you for all your prayers and encouragement. You've always been there for me and I don't tell you often enough how very much you mean to me. On the same breath, I would like to recognize my brother, Michael Moragia Nyachae, who has been my mentor and role model. His encouragement, insights, advice and assistance has been invaluable throughout my entire life. Many thanks to all my siblings and their families for their prayers and support. Likewise, I would like to sincerely thank my sister in-law, Grace Atebe for her brilliant advice. Her valuable advice and assistance 
were very essential for the completion of this dissertation. To my nieces and nephews, I hope this work motivates you as well as instill the desire to pursue academic excellence.

Finally yet importantly, I would like to thank the Colloquium and the Chancellor's Scholars program, the College of Human Resources and Education, WVU Extended Learning and the Office of Information Technology for supporting me financially. My deepest heartfelt thank you to Jennifer McIntosh, Executive Officer for Social Justice for your encouragement and financial support, particularly my first semester at West Virginia University. I would like to sincerely thank Ann Crabtree of the Department of Technology, Learning, \& Culture at WVU. Her efficiency, friendliness, and professionalism are greatly appreciated. 


\section{TABLE OF CONTENTS}

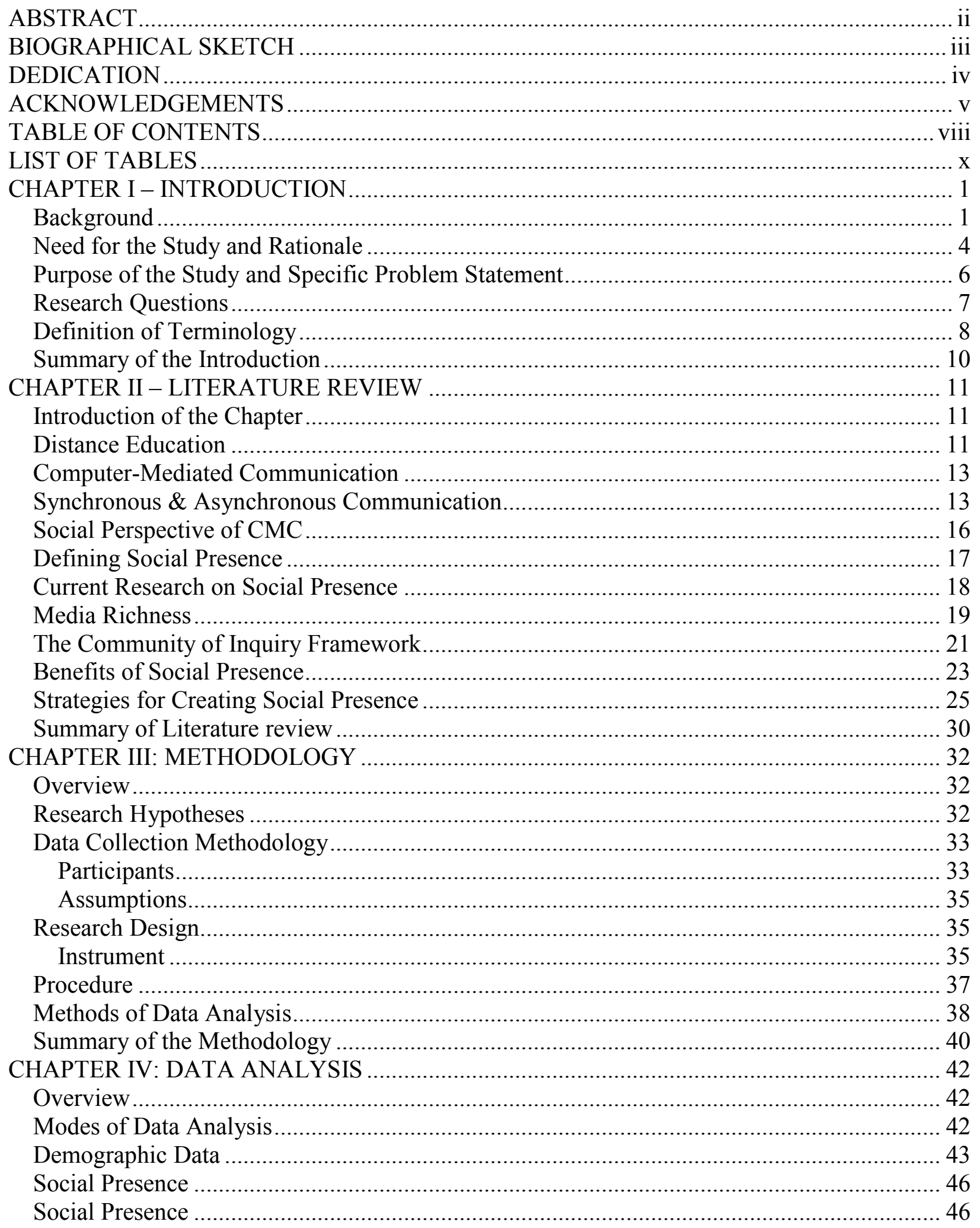




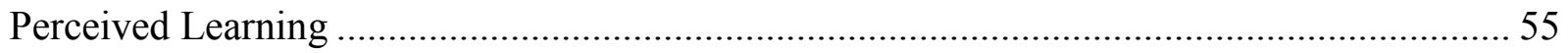

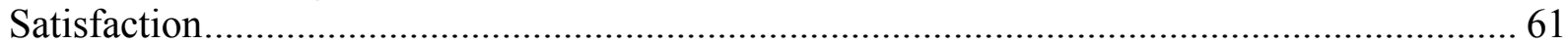

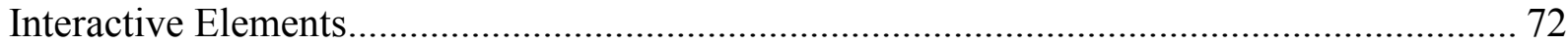

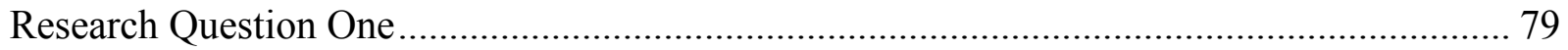

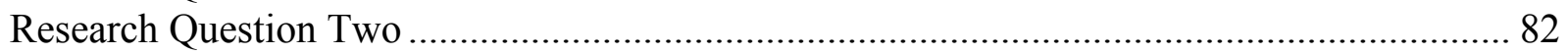

As part of a check for the assumption of linearity, plots were produced for each of the two main regression analyses conducted in which standardized residuals were plotted against standardized predicted values of the dependent variable. For the regression involving perceived learning as the dependent variable, the following plot was obtained........................ 85

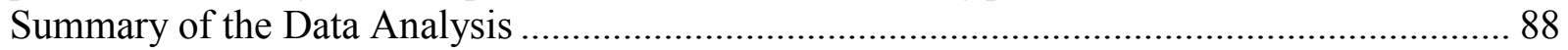

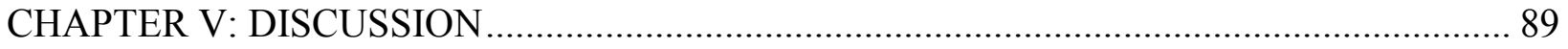

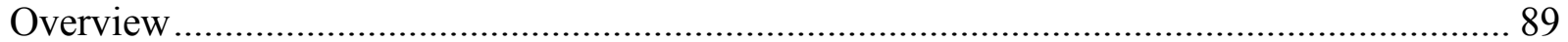

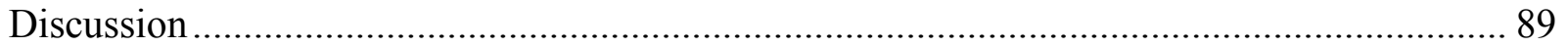

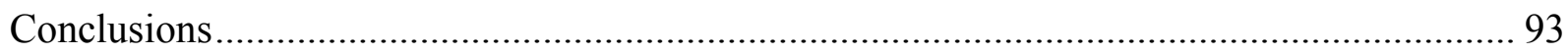

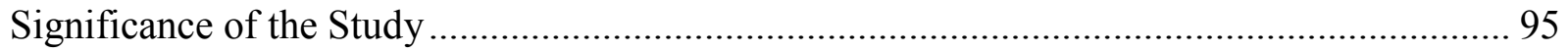

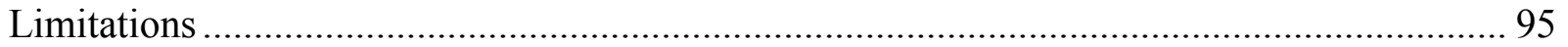

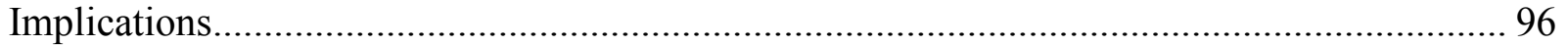

Recommendations for Further Research.......................................................................... 97

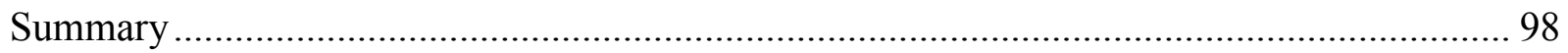

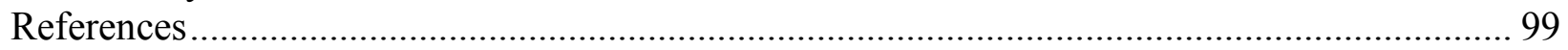

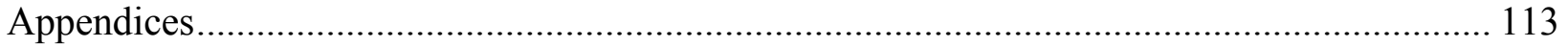

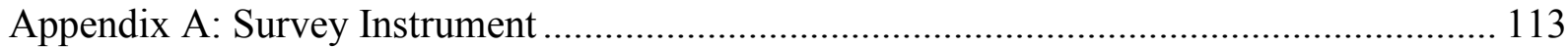

Appendix B: IRB Cover Letter Sent to Participants........................................................... 120

Appendix C: Cover Letter Sent to Faculty Requesting Assistance in Sending Survey to

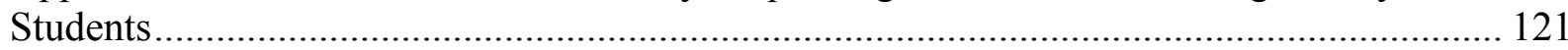

Appendix D: Follow-Up E-Mails to Survey Participants .................................................... 122

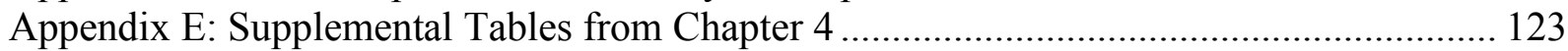

Appendix F: Perceived Learning Regression Analysis Output ........................................... 141

Appendix G: Satisfaction Regression Analysis Output ....................................................... 143

Appendix H: Regression Analysis without Using Interactive Elements ............................... 145

Appendix I: Comments the Respondents Submitted In Response ........................................ 148 


\section{LIST OF TABLES}

Table 1 When, why, and how to use asynchronous versus synchronous e-learning. ................... 15

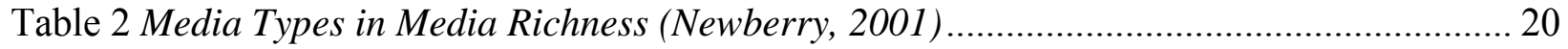

Table 3 Strategies to Creating Social Presence (Aragon, 2003)................................................. 29

Table 4 Number of college credits completed towards degree .................................................. 44

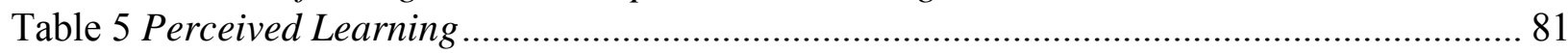

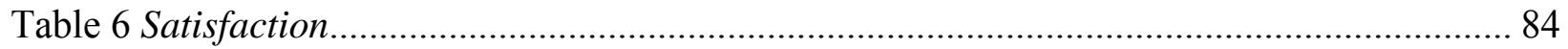

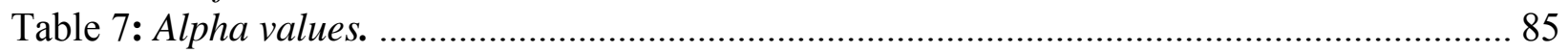

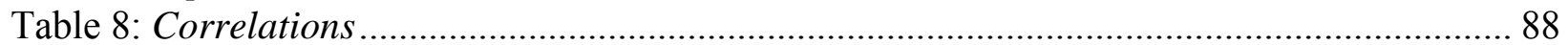

Table 9: Getting to know other course participants gave me a sense of belonging in the course.

Table 10: I was able to form distinct impressions of some course participants. ........................ 123

Table 11: Online or web-based communication is an excellent medium for social interaction. 124

Table 12: I felt comfortable conversing through the online medium........................................ 124

Table 13: I felt comfortable participating in the course discussions......................................... 125

Table 14: I felt comfortable interacting with other course participants..................................... 125

Table 15: I felt comfortable disagreeing with other course participants while still maintaining a

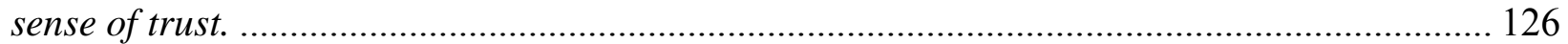

Table 16: I felt that my point of view was acknowledged by other course participants............. 126

Table 17: Online discussions help me to develop a sense of collaboration................................ 127

Table 18: I learned to interrelate the important issues in the course material .......................... 128

Table 19: I gained a good understanding of the basic concepts of the material........................ 128

Table 20: I learned to identify the central issues of the course. ............................................... 129

Table 21: I developed the ability to communicate clearly about the subject............................. 129

Table 22: I improved my ability to integrate facts and develop generalizations from the course

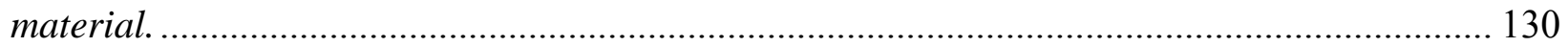

Table 23: I learned concepts and principles in this course. .................................................. 130

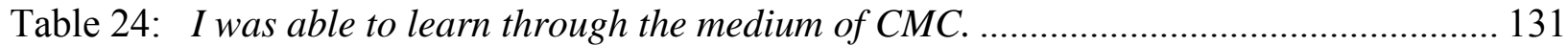

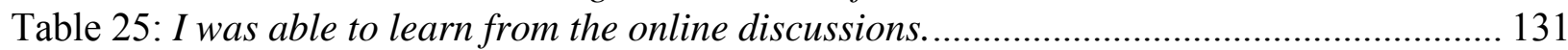

Table 26: I felt motivated to explore content related questions.............................................. 132

Table 27: I utilized a variety of information sources to explore problems posed in this course. 132 Table 28: I was stimulated to do additional reading or research on topics discussed in the online

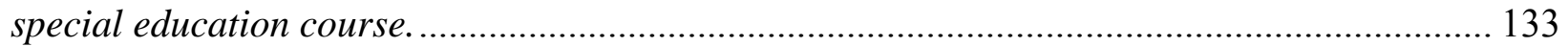

Table 29: I learned to value other points of view. ....................................................................... 133

Table 30: As a result of my experience with the online special education course, I would like to participate in another online course in the future. ............................................................... 134

Table 31: The online course was a useful learning experience. .................................................... 134

Table 32: As a result of my participation in the online course, I made acquaintances electronically in other parts of the country/world. ............................................................... 135

Table 33: The diversity of topics in the online course prompted me to participate in the

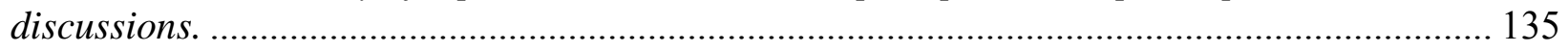

Table 34: I put a great deal of effort to learn the CMC system to participate in the online course.

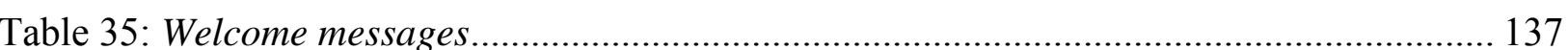




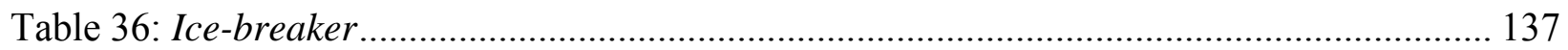

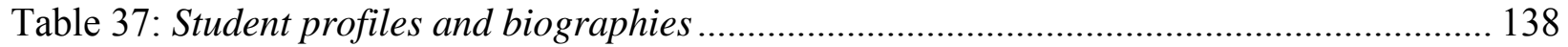

Table 38: Addressing students' using their names ................................................................ 138

Table 39: Social area in the discussion board (Sandbox) ................................................... 139

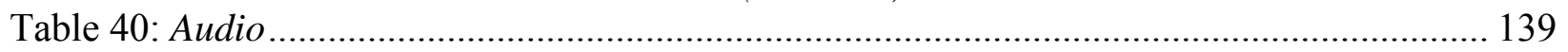

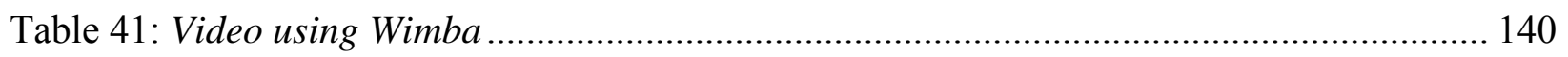




\section{LIST OF FIGURES}

Figure 1: Community of Inquiry Framework ....................................................................... 22

Figure 2 Gilly Salmon's five-stage model (Salmon, 2004).................................................. 30

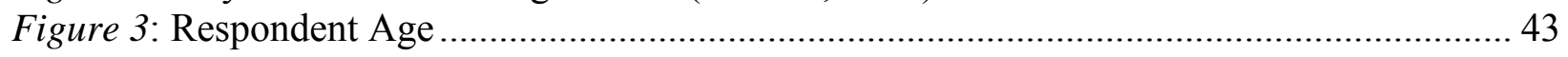

Figure 4: Number of online college courses taken ......................................................... 45

Figure 5: Getting to know other course participants gave me a sense of belonging in the course.

Figure 6: I was able to form distinct impressions of some course participants........................ 46

Figure 7: Online or web-based communication is an excellent medium for social interaction. .. 48

Figure 8: I felt comfortable conversing through the online medium....................................... 49

Figure 9: I felt comfortable participating in the course discussions....................................... 50

Figure 10: I felt comfortable interacting with other course participants. ................................ 51

Figure 11: I felt comfortable disagreeing with other course participants while still maintaining a

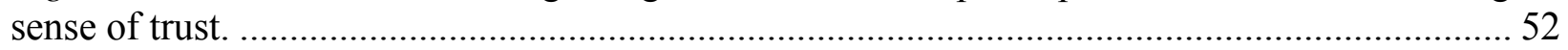

Figure 12: I felt that my point of view was acknowledged by other course participants............ 53

Figure 13: Online discussions help me to develop a sense of collaboration........................... 53

Figure 14: I learned to interrelate the important issues in the course material.......................... 55

Figure 15: I gained a good understanding of the basic concepts of the material. ..................... 56

Figure 16: I learned to identify the central issues of the course ............................................. 57

Figure 17: I developed the ability to communicate clearly about the subject........................... 58

Figure 18: I improved my ability to integrate facts and develop generalizations from the course

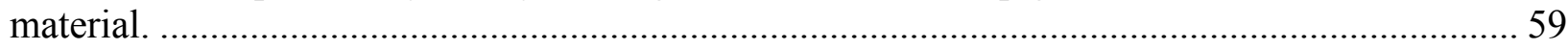

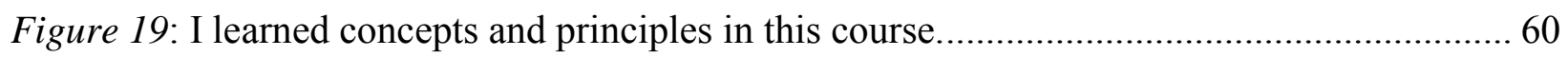

Figure 20: I was able to learn through the medium of CMC ............................................ 61

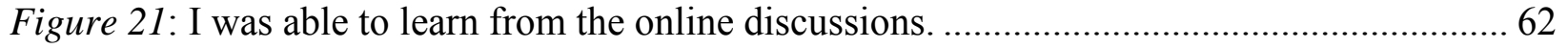

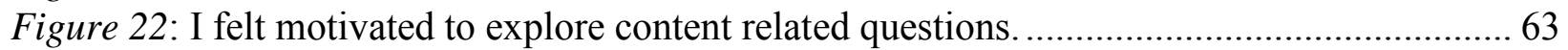

Figure 23: I utilized a variety of information sources to explore problems posed in this course. 64

Figure 24: I was stimulated to do additional reading or research on topics discussed in the online

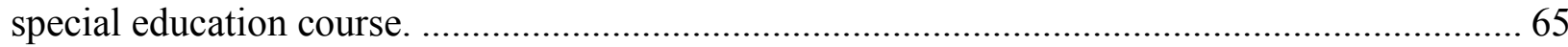

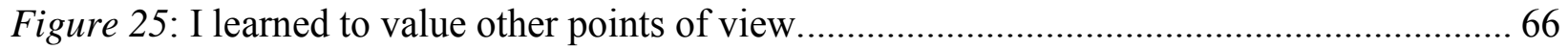

Figure 26: As a result of my experience with the online special education course, I would like to

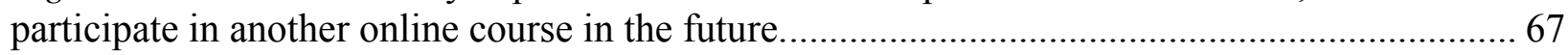

Figure 27: The online course was a useful learning experience........................................... 68

Figure 28: As a result of my participation in the online course, I made acquaintances

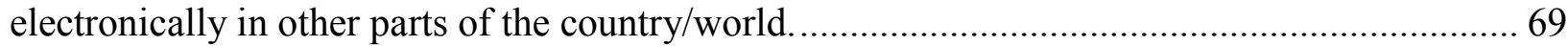

Figure 29: The diversity of topics in the online course prompted me to participate in the

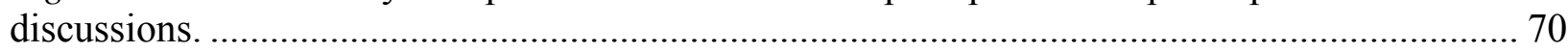

Figure 30: I put a great deal of effort to learn the CMC system to participate in the online course.

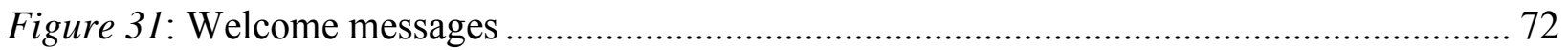

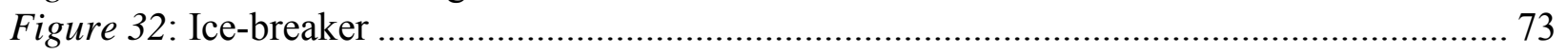

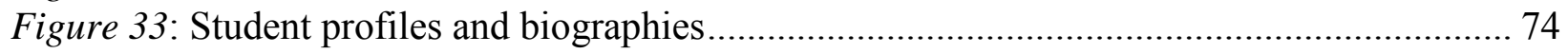

Figure 34: Addressing students' using their names........................................................... 75

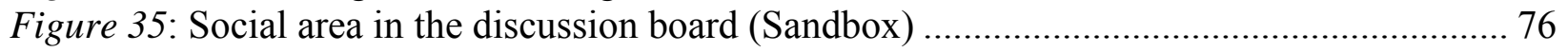

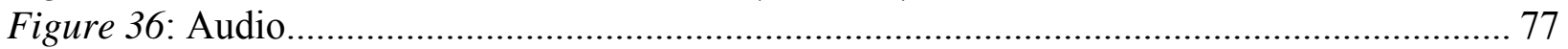




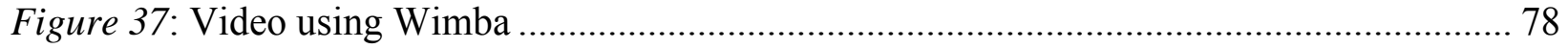

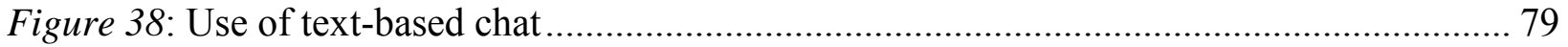

Figure 39: Perceived Learning Assumption Linearity Plot .................................................... 86

Figure 40: Perceived Learning Assumption Linearity Plot............................................... 87 


\section{CHAPTER I - INTRODUCTION}

\section{Background}

While technology has influenced virtually every aspect of society, it has had its greatest effect on educational opportunities. Within the last generation technology development and the demand for higher education has created a great migration towards distance education. According to Tallent-Runnels et al (2006), "rapid development of technology, online instruction has emerged as an alternative mode of teaching and learning and a substantial supplement to traditional teaching" (p. 93). Allen and Seaman (2003) write that over $80 \%$ of institutions of higher education in the United States offer either completely online or blended/hybrid courses. Conventional teaching methods are being recreated to incorporate web-based components aimed at:

1) changing workloads of faculty,

2) increasing access to courses, and

3) addressing the issues of

a) student-to-student interaction and

b) Teacher-to student interaction (Tiangha, 2003).

Computer-mediated communication (CMC) has improved the way students share and acquire knowledge while living in vastly different geographical areas. As the number of traditional brick and mortar colleges developing and delivering content in distance learning environments increases, so does the need to research and identify the elements that increase student satisfaction and knowledge retention. With the introduction of computer-based distance education, educators have tried to incorporate novel methods of learning in which online learners team up in groups towards a universal similar goal. This is done with the 
confidence that increased communication and collaboration between group members would greatly improve both the learning results and happiness with the experience of students. Current research in distance education has changed its focus from understanding the technology such as computer-mediated communication, to how this technology can be used to enhance how students learn with it. Following this trend, institutions have been evaluating methods to determine which mechanisms work best to support learners' overall retention of material and contentment with their learning experience.

One key area of focus is to understand not only the social processes but also how students learn in computer-mediated communication environments. A major objective of online learning is to create an effective environment for instruction. In order for students to achieve the targeted learning outcome, the environment must assist them to become successful and satisfied learners by helping them to communicate and interact with each other, the content and the instructor. This notion of interaction is a very important part of the educational process and it should be considered when developing online courses (Roberson \& Klotz, 2002).

Social presence is the key facilitator in how students form stronger associations; construct a sense of community, and ultimately increasing their contentment with the whole learning experience (Woods \& Keeler, 2001). Wegerif (1998) also states that "Without a feeling of community people are on their own, likely to be anxious, defensive and unwilling to take the risks involved in learning" (p. 48). Social presence allows learners to emotionally and socially view themselves as part of the online learning community. An online community as defined by Rupert, Hassas, Li, and Sherwood (2007) is "a community of people that communicate and interact socially using the Internet as the medium of communication. 
Online communities are composed of people from different groups who participate in a common social environment." Garrison and Anderson (2003) suggest, "It is inconceivable to think that one could create a community without some degree of social presence" (p. 49). According to Esani (2010) social presence is "the ability of participants within the online learning community to project their personal characteristics into the community and present themselves as real people.” (p. 187). Social presence is when members of a community feel a part of the community and are recognized and appreciated. In order for the online learning to be successful, interactivity is necessary between the instructors and students, and between the students (Sherry, 1996). Salmon (2004) argues that the success of online students is how well the course is designed to encourage interactivity in a learning community. In an online environment, the learners are physically separated from each other and as a result, their channels of communication are constrained by the technology they are using. Efficient and clear channels of communication are necessary for effective learning and interaction among learners.

Even though research has been done regarding distance education, it is imperative to examine different elements of online learning, in particular the role of social presence. According to Russo and Benson (2005), "more investigation of students' assessment of their own presence and its relationship to course outcomes are in order" (p. 60). Social presence as well as its impact on student accomplishment is a subject that is both interesting and is needed in order to gain deeper insight into how social presence effects online learning of students. Saenz (2002) affirms that "these factors may provide insightful information to instructional designers and distance educators" as they design and development of online courses (p. 1). 
Need for the Study and Rationale

More and more higher learning institutions are offering online courses and as a result, there been an increased debate on the effectiveness of these courses, their design, development, and implementation. Even with the constant growth, there are still some criticism coming from the institutions, instructors and students. Some learners in the online environment feel isolated due to lack of face-to-face contact. The majority of these institutions are experiencing a difficult task on how successfully to design, to develop and to implement online courses that provide students an opportunity to have a positive connection between their sense of presence and what they are learning in an online environment. Research has revealed that there are obvious and apparent associations between online learning and their human relations. Because online learners do not necessarily meet in person, it is imperative that they feel socially present while participating and interacting in this new environment. Social presence is critical because human beings naturally want to feel that they are needed, that they have a role to play in something, and are not isolated According to Hiltz (1994), "the social process of developing shared understanding through interaction is the "natural' way for people to learn" (p. 22). There is a need for the learners to comprehend that they are part of this new community.

Unfortunately, not enough research has been devoted to inquire whether learners feel socially present in online communities and how this effects their perceived learning and affects their satisfaction. Social presence is something, which is sometimes overlooked by many institutions of higher learning when implementing online education in their curriculum. Studies on the perception of social presence as it applies to online learning, show that there are researchers who argue that online courses lacks the social distinctiveness required to 
develop social presence. According to Richardson and Swan (2003), “critics claim that webbased or online learning is not as effective as traditional classroom learning because of its lack of face to face interactions" (p. 69). These researchers maintain that computer-mediated communication technologies lack social signals such as non-verbal communication, eye contact, body language, and in some cases voice recognition. According to Berge and Collins (1995), "Lack of social cues and face-to-face interaction increases the sense of isolation for persons using this medium to teach and learn" (p. 13).

Deficiency of social interaction among learners in learning communities makes distance learning appear boring and unexciting for both the learner and the educator. Due to this impression, the research of understanding social presence and how it affects learners is highly complex. Picciano (2002) proposes that the impression of social presence differs from individual to individual, and that these impressions are fundamentally superficial opinions based on personal ideologies. It is therefore essential to understand the relationship of social presence among learners in online learning communities and whether it affects their perceived learning and affects their satisfaction. In addition, the bulk of research on social presence has mainly focused on the perception of social presence. Fewer have looked at the effect of social presence on the learner's perceived learning (Lowenthal, 2009).

Perceived learning is the extent to which learners recognize that they have obtained new knowledge or corrected their shortcomings in their earlier knowledge. Perceived learning is the point of view that a learner has concerning the learning that has taken place. Alavi et al (2002) define perceived learning as "changes in the learner's perceptions of skill and knowledge levels before and after the learning experience" (p.406). It is imperative to look at how students perceive their learning because it offers both instructors and 
instructional designers an opportunity to make revisions or additions to the course with respect to the way the content is delivered, assessments are conducted and how the course tools are used. These changes could improve the quality of the courses as well as enhance the learner's experience.

It is also imperative to further research on whether social presence in online courses improves student satisfaction. Sweeney and Ingram (2001), define student satisfaction as the learner's "perception of enjoyment and accomplishment in the learning environment" (p. 57). Learner satisfaction is a major factor for the growth of online education. Determining learner satisfaction provides beneficial information about the learners general experiences, how attentive were the students, and their exertion to learn. Sloan Consortium reports that "student satisfaction is the most important key to continuing learning." (Sloan, n.d.). The learners satisfaction can help determine the success or failure of online courses.

A comprehensive study will be performed to investigate the role of social presence in a computer-mediated communication environment. Results from this kind of study could assist instructors and instructional designers to better plan, design, develop, manage, and deliver quality online courses in a way that will improve how students perform as well as their satisfaction.

\section{Purpose of the Study and Specific Problem Statement}

The purpose of the study was to investigate the effects of social presence on students' perceived learning and satisfaction in online courses. Specifically, a survey instruments was given to 160 graduate students enrolled in four special education online courses offered in the summer and fall 2010 semesters at a major higher education institution located in a Mid- 
Atlantic state to determine students' perceived learning and satisfaction in an online course based on their perceived level social presence.

\section{Research Questions}

This study consisted of two major research questions. The research questions were:

1. Can we predict in a statistically significant fashion using linear regression students' perceived learning in a course based on their perceived level of social presence and number of interactive elements in the course?

2. Can we predict in a statistically significant fashion using linear regression students' satisfaction in a course based on their perceived level of social presence and number of interactive elements in the course? 


\section{Definition of Terminology}

Cognitive Presence: Garrison, Anderson and Archer (2001) define cognitive presence as "the extent to which participants in any particular configuration of community of inquiry are able to construct meaning through sustained communication" (p. 11).

Collaborative Learning: Harasim (1999) defines collaborative learning as "an interactive, group knowledge building process. Students actively participate in generating, accessing, and organizing the information. They construct knowledge by formulating their ideas into words and images and then develop these ideas/concepts as they react to other students' responses to their formulations" (p. 44).

Community: Mynatt, Adler, Ito, and O’Day refer community as “a multi-dimensional, cohesive social grouping that includes, in varying degrees: shared spatial relations, social conventions, a sense of membership and boundaries, and an ongoing rhythm of social interaction" (p. 3).

Community of Inquiry: Lipman, (2003) defines a community of inquiry as a community founded on "questioning, reasoning, connecting, deliberating, challenging, and developing problem-solving techniques", particularly in the framework of education.

Face-to-Face instruction: Face-to-Face instruction is instruction that is delivered in a traditional classroom setting.

Learning Community: Conrad (2005) defines an online learning community as an "Online community is a general sense of connection, belonging, and comfort that develop, over time, among members of an online (Internet-based) group who share purpose or commitment to a common goal." (p. 2). 
Social presence: According to Short, Williams, and Christie (1976), social presence refers to the "degree of salience of the other person in mediated communication which is interactive by nature" (p. 64). Social presence is defined by Garrison, Anderson and Archer (2000) as "the ability of participants in a community of inquiry to project themselves socially and emotionally, as "real" people (i.e. their full personality), through the medium of communication being used" (p. 94).

Teaching presence: Garrison et al. (2001) identify teaching presence as "the design, facilitation, and direction of cognitive and social processes for the purpose of realizing personally meaningful and educationally worthwhile learning outcomes" (p. 5). 


\section{Summary of the Introduction}

The rationale of this chapter was to present a background of the dissertation research and to briefly describe the research problem. This chapter examines the rationale for this research, along with, the need for the study and the problem statement. It begins with discussing how computer-mediated communication (CMC) has improved the way students share and acquires knowledge while living in vastly different geographical areas. The chapter discusses why it is important to examine different elements of online learning, in particular the role of social presence. It discusses the reason it is imperative to examine the importance of social presence and need to conduct this research. This chapter also introduces the research questions. The chapter concludes by presenting the assumptions before conducting the study and the definition of the terminology. The following chapter covers in detail the literature review that will be used for this study. This chapter will include the history of distance education and Computer-Mediated Communication, defined social presence and strategies of incorporating social presence. 


\section{CHAPTER II - LITERATURE REVIEW}

Introduction of the Chapter

This chapter presents a detailed literature review regarding the role of social presence in online courses. With the aim of better understanding the objectives of this study, it was imperative to carry out a comprehensive review of the related literature. Given that the study entails diverse topics, it was imperative to divide the literature review in the following subsections: 1) Distance Education 2) Computer-Mediated Communication (CMC); 3) Social Perspective of CMC; 4) Defining Social Presence; 5) Current Research on Social Presence; 6) The Community of Inquiry Framework; 7) Benefits of Social Presence and 8) Strategies for Creating Social Presence.

\section{Distance Education}

Distance education has become a very intricate part of today's society. School systems deliver professional developments online. Fortune 500 companies use online courses to train their workforce. The US military has used distance education to further the education and train its members. Distance education is learning that is focused, scheduled, and meaningful learning, that occurs while the learners and instructors are in two different locations. This separation creates a need to employ the use of varying techniques for content delivery, design, and electronic forms of communication (Moore \& Kearsley, 1996). Distance education has the potential to reach a far greater number of students, may be delivered at significantly less cost, and better address their learning needs (Yoakam \& Franklin, 1999). 
Distance education is becoming more and more accepted at traditional higher learning institutions as a vehicle for students to take part in cooperative learning, while bettering their learning experience. This helps create a learning community that is nearly boundless in its variety, learning locations, and access to information. Online instruction has presented a number of learning alternatives for both the student and the instructors. Given the needs and expected standards of both adult and $21^{\text {st }}$ century learners', colleges and universities are being obligated to create innovative means of content delivery to provide for the wants of the learner. $21^{\text {st }}$ century learners are learners who have grow up using digital technologies and they are comfortable using it. According to Pacific Policy Research Center (2010), "21st century learners have the skills and ability to (a) collect and/or retrieve information, (b) organize and manage information, (c) evaluate the quality, relevance, and usefulness of information, and (d) generate accurate information through the use of existing resources" (p. 2).

The investment in online learning for colleges and universities has been substantial. As colleges and universities integrate more distance education courses into their program of study, they are finding both benefits and challenges in this new learning environment. According to Bos and Shami (2006), more and more online faculty members are incorporating activities that are engaging and interactive in their distance education courses in order to improve the students learning. It is imperative that this new learning environment allows students to successfully learn and interact with one another. D'Angelo and Woosley (2007) discuss how higher learning institutions are not looking for ways to duplicate what they do in face-to-face classroom but to discover innovative ways to engage students to learn in this new learning environment. 


\section{Computer-Mediated Communication}

According to Romiszowski and Mason (1996), computer-mediated communication $(\mathrm{CMC})$ is "generic term now commonly used for a variety of systems that enable people to communicate with other people by means of computers and networks" (p. 438). Some examples include email, discussion boards, computer conferencing, chat rooms, instant messaging, social networking such as Facebook and MySpace, blogs, etc. Computermediated communication has played a major role on how people interact or communicate. In the past decade, CMC has transformed the way students learn. Rovai and Jordan (2004) note that, "computer-mediated communication (CMC) that is used by Internet-based e-learning systems for discussion board and e-mail discourse is a powerful tool for group communication and cooperative learning that promotes a level of reflective interaction that is often lacking in a face-to-face, teacher-centered classroom" (p. 8).

\section{Synchronous \& Asynchronous Communication}

Computer -mediated communication tools are separated into two key categories: synchronous and asynchronous. In asynchronous communication, the learners' are not mandated to have an instantaneous response or interaction because communication is neither time nor location dependent. Users in such a system are able to communicate in an online learning environment anywhere or any time through the use of such applications as email or threaded discussion boards. This medium works best for learners who have several other commitments such as work and family.

The characteristics of an asynchronous environment allow learners to participate in a course at any time in order to contribute to a discussion, to respond to messages from peers 
or instructor. The asynchronous nature of the environment also provides students more time to reflect and refine their contributions before posting them to the class.

Synchronous communications, on the other hand requires all learners to be present at the same time. Synchronous communication involves media such as chat and video conferencing. The characteristics of a synchronous medium require learners to communicate in real time hence avoiding frustrations and feelings of isolation.

However, like most technologies, it is important to establish whether synchronous or asynchronous learning is more suitable depending on the desired learning outcomes. According to Hrastinski (2008), it imperative to understand when, why, and how to use asynchronous vs. synchronous communication as opposed to determining which is better. Table 1 summarizes when, why, and how to use asynchronous versus synchronous communication 
Table 1 When, why, and how to use asynchronous versus synchronous e-learning.

\begin{tabular}{|c|c|c|}
\hline & Asynchronous E-Learning & Synchronous E-Learning \\
\hline When? & $\begin{array}{l}\text { - Reflecting on complex issues } \\
\text { - When synchronous meetings cannot be } \\
\text { scheduled because of work, family, and other } \\
\text { commitments }\end{array}$ & $\begin{array}{ll}\text { - } & \text { Discussing less complex } \\
\text { issues } \\
\text { - } \\
\text { - } & \text { Petting acquainted } \\
\end{array}$ \\
\hline Why? & $\begin{array}{l}\text { Students have more time to reflect because } \\
\text { the sender does not expect an immediate } \\
\text { answer. }\end{array}$ & $\begin{array}{l}\text { - Students become more } \\
\text { committed and motivated } \\
\text { because a quick response } \\
\text { is expected. }\end{array}$ \\
\hline How? & $\begin{array}{l}\text { - Use asynchronous means such as e-mail, } \\
\text { discussion boards, and blogs. }\end{array}$ & $\begin{array}{l}\text { Use synchronous means } \\
\text { such as } \\
\text { videoconferencing, } \\
\text { instant messaging and } \\
\text { chat, and complement } \\
\text { with face-to-face } \\
\text { meetings. }\end{array}$ \\
\hline Examples & $\begin{array}{l}\text { Students expected to reflect individually } \\
\text { on course topics may be asked to } \\
\text { maintain a blog. } \\
\text { - Students expected to share reflections } \\
\text { regarding course topics and critically } \\
\text { assess their peers' ideas may be asked to } \\
\text { participate in online discussions on a } \\
\text { discussion board. }\end{array}$ & $\begin{array}{l}\text { - Students expected to } \\
\text { work in groups may } \\
\text { be advised to use } \\
\text { instant messaging as } \\
\text { support for getting to } \\
\text { know each other, } \\
\text { exchanging ideas, } \\
\text { and planning tasks. } \\
\text { - A teacher who wants } \\
\text { to present concepts } \\
\text { from the literature in } \\
\text { a simplified way } \\
\text { might give an online } \\
\text { lecture by } \\
\text { videoconferencing. }\end{array}$ \\
\hline
\end{tabular}




\section{Social Perspective of CMC}

Gunawardena and Zittle (1997) declare that as people connect with others in new settings, they establish a social presence. The challenge for online learning communities is to simplify the process of creating and maintain social presence among instructors and learners. Swan, Shea, Fredericksen, Pickett, Pelz and Maher (2000) propose that communication among learners using group discussions has proven to be an effective strong part of an online course. According to Hiltz (1994), one-way discussions allow learners to think back on what is posted by other members of the learning community before they reply to what the others have posted. She further states that the tendency to reflect serves to boost the level of mindfulness in the learning community of the online course.

Alternatively, Eastmond (1995) argues that computer-mediated communication does not present a natural home for interaction, but instead is reliant on constant postings by students to message boards, email, and in chat in regular intervals. Ruberg, Moore, and Taylor (1996) recognized that CMC is a means of supporting as well as encouraging: information sharing, ideas discussions, collaboration, cooperation, and higher order thinking. They further indicated that the previously mentioned features serve as a means for creating a social environment (Ruberg et. al, 1996). Tallent-Runnels et al (2006) indicate that a direct association is present between social relations among students, instructors and the institutions.

Research has shown that the success or failure of members in a learning environment varies based on how critical they perceive themselves to be to the learning process. According to Ajayi (2009) it is "how students perceive their learning experiences and how they conceptualize their roles in teaching and learning (from students' perspectives) are 
important for designing pedagogies and tasks that meet the learning needs and interests of learners” (p. 87). Social presence as Rovai (2001) points out has gained importance in the understanding the success of online learning. He notes that class size, the time lapse between interactions, teacher communications, equality among users, group leadership, and individual motivation for learning all are a factor in an online learning environment (Rovai, 2001). The idea that social presence shows a positive correlation to the feeling of unity and cooperation of students is essential to their success in an online learning community.

\section{Defining Social Presence}

Social presence can be defined as relating to the way in which participants in online learning communities experience the feeling of community through electronic learning environment. The more learners participate in online learning environments, the more they build up a sense of presence of others within this learning community. Short, Williams and Christie (1976) characterized social presence as the "degree of salience of the other person in a mediated communication and the consequent salience of their interpersonal interactions" (p. 65). Gunawardena and Zittle (1997) stated that social presence is the extent or the amount that a learner has comprehended as an actual being in computer-mediated communication. According to Anderson, Garrison and Archer (1999), social presence is the ability for the members of the learning community to interrelate and emotionally convey themselves within the learning community (p. 50). Tu and McIsaac (2002) defined social presence as the "the degree of feeling, perception, and reaction to another intellectual entity in the CMC environment." (p. 146). 


\section{Current Research on Social Presence}

Current research indicates that the elements needed for social presence are available in an online learning environment. A study on social presence done by Tu and McIsaac (2002) examined the three elements that facilitate a sense of community in an online environment. The three elements included social context, online communication and interactivity. Tu and McIsaac concluded that as the different aspects that create social presence increase so does the interaction in an online learning environment. During this study, Tu and Corry (2002) developed a questionnaire that assessed the use of web boards, email and chatrooms in relation to social presence and privacy. The collection of the data was done through direct observations, interviews, analyzing documents, and informal observations. Tu and Corry (2002) concluded in their study that "social presence is the degree of feeling, perception, and reaction of being connected by CMC to another intellectual entity through a text based encounter" (p. 140) and "social presence is necessary to enhance and foster online social interaction" (p. 146). The data demonstrated that there are additional variables that contributed to the creation of social presence, which means that the notion of social presence is more complex that previously perceived. The study also found that the perceived social presence and privacy in a $\mathrm{CMC}$ environment was higher and social presence had a positive role in the way the learners interacted. On the other hand, the correlation between the rate of learner participation in the CMC environment and social presence did not differ with the level of social presence. A factor analysis was done using five factors: social perspective, online communication, interactivity, privacy and sense of privacy. Analysis of variance (ANOVA) was conducted on the web boards, email and chatrooms as well as the 
five factors and the results indicated significance in the level of social perspective, online communication, interactivity, privacy and sense of privacy.

\section{Media Richness}

One major issue that arises frequently in discussions of distance education is whether the use of electronic media for online education lacks nonverbal cues which are vital for student learning and as a result leading to reduced communication channels, decreased social presence and the learners feeling disconnected. Lack of nonverbal cues can generate problems for both students and teachers. The question on whether the electronic media used in online courses is rich to facilitate outstanding student learning arises. According to Hirschheim (2005), "Students miss the lectures, discussion, questions, assignments, group work, and the professor's views and perspectives—all part of traditional classes." (p. 98).

Media richness theory is defined as the degree with which the communication media can eliminate ambiguity and uncertainty. (Daft \& Lengel, 1986). The communication that takes place face-to-face is deemed to be rich media because it has less ambiguity whereby computer-mediated communication is considered to have not as much of rich media to eliminate uncertainty. Media richness theory explains that computer-mediated communication gets rid of nonverbal cues that exist in a face-to-face environment hence lowering the quality of what was being communicated. The type of media used can either positively or negatively affect the success of what is being communicated. Effective communication is very important because it helps increase the students' self-esteem as well as improve their problem solving skills. 
Newberry (2001) did a study to investigate issues that relate to social presence in an online environment. This study proposed some methods of increasing social presence among learners. The study explored seven media types in relation to their richness. (See Table 2) Table 2 Media Types in Media Richness (Newberry, 2001)

\begin{tabular}{|l|l|l|l|}
\hline \multicolumn{1}{|c|}{ Criteria } & \multicolumn{2}{|c|}{ Media Rating } \\
\cline { 2 - 4 } & $\begin{array}{c}\text { High } \\
\text { Feedback to Face } \\
\text { Video Conferencing } \\
\text { Synchronous Audio } \\
\text { Text Based Chat }\end{array}$ & \multicolumn{1}{|c|}{ Medium } & $\begin{array}{l}\text { Low } \\
\text { E-mail } \\
\text { Threaded Discussion } \\
\text { Asynchronous Audio }\end{array}$ \\
\hline Multiple cues & Face-to Face & Video Conferencing & $\begin{array}{l}\text { Synchronous Audio } \\
\text { Asynchronous Audio } \\
\text { Text Based Chat } \\
\text { E-mail } \\
\text { Threaded Discussion }\end{array}$ \\
\hline Message Tailoring & Face to Face & $\begin{array}{l}\text { Video Conferencing } \\
\text { Synchronous Audio } \\
\text { E-mail }\end{array}$ & $\begin{array}{l}\text { Text Based Chat } \\
\text { Asynchronous Audio } \\
\text { Threaded Discussion }\end{array}$ \\
\hline Emotions & Face to Face & $\begin{array}{l}\text { Video Conferencing } \\
\text { Synchronous Audio } \\
\text { Asynchronous Audio }\end{array}$ & $\begin{array}{l}\text { Text Based Chat } \\
\text { E-mail } \\
\text { Threaded Discussion }\end{array}$ \\
\hline
\end{tabular}

This study merged the theory of social presence with media richness. Newberry (2001) used a criterion to rate media richness based on whether the media has the ability to provide immediate feedback, convey several cues, for example body language, permit the message to be produced or changed specifically for an intended receiver, and relay the feelings or emotions. Newberry (2001) proposed a method to increase social presence in an online environment, which includes the use of interactive elements such as student pictures, use of voice tools and using synchronous tools such as chat and audio to generate greater social presence, student group work which allows the learners to collaborate in projects and 
assignments hence building their relationships. Interactive elements are essential to improve the learning experience

\section{The Community of Inquiry Framework}

In the past decade, higher education institutions have focused on ways of constructing communities of learners. These institutions have the notion that a community of learners is a very important part of maintaining collaboration among the learners and as a result increasing their levels of learning. While seeking to fully understand the different complexities and properties of online learning, Garrison, Anderson and Archer (2000) developed the Community of Inquiry (COI) framework.

The Community of Inquiry (COI) framework is a model that shows the process and theory of research behind online learning and instruction. According to Lipman a community of inquiry is where "students listen to one another with respect, build on one another's ideas, challenge one another to supply reasons for otherwise unsupported opinions, assist each other in drawing inferences from what has been said, and seek to identify one another's assumptions" (as cited in Garrison \& Anderson, 2003, p. 27). Lipman continues to list the characteristics of a community of inquiry as questioning, reasoning, connecting, deliberating, challenging and developing problem solving techniques. According to Pritchard (2008), an inquiry is a "process that has the aim of augmenting knowledge, resolving doubt, or solving a problem" (p.122). The COI comprises of cognitive presence, teaching presence and social presence. All of these elements are very important in an online learning environment. As shown in Fig. 1, all these elements affect the students and teachers. 
Figure 1: Community of Inquiry Framework

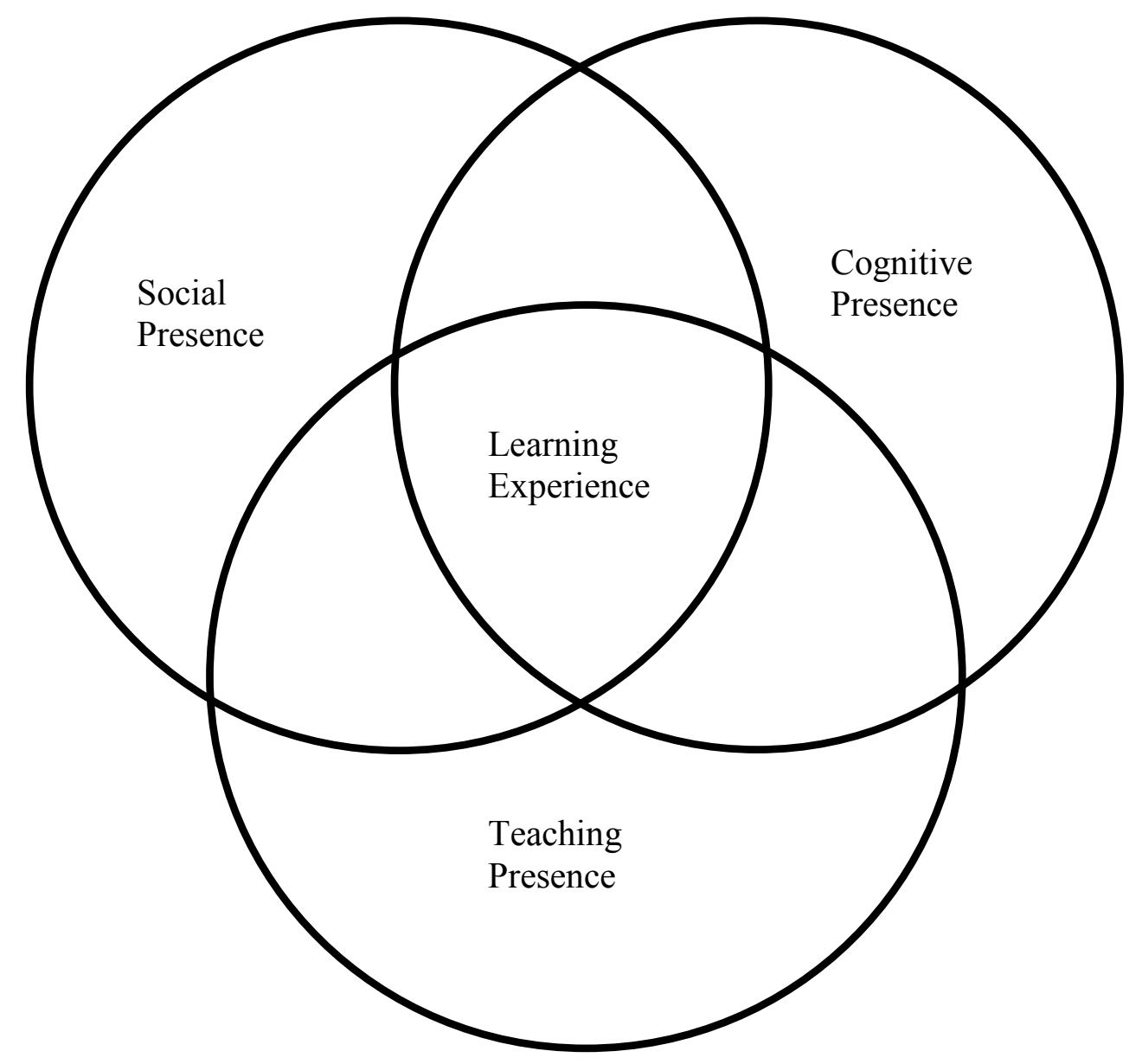

Garrison, Anderson and Archer (2000), researched to see if all the three elements were present in a computer-mediated environment. Garrison et al. (2000) define social presence as "The ability of participants in a community of inquiry to project their personal characteristics into the community thereby presenting themselves to others as real people" (p. 94). Social presence is evident with the signs of emotional demonstration, open communication, and group solidity. Another important component of the Community of Inquiry Framework is teaching presence, which relies mainly with the instructor. According to Garrison et al. (2000), this includes the design of instruction, dialogue facilitation, and direct teaching. The third element is Cognitive presence which Garrison et al. (2000) identify 
as "the extent to which the participants in any particular configuration of a community of inquiry are able to construct meaning through sustained communication” (p. 89).

\section{Benefits of Social Presence}

Dede (1996) determined that the feeling of community both increases the firmness of purpose of learners and the flow of information, learning, and commitment of learners, cooperative activities, and student satisfaction. Wegerif (1998) agrees that if the sense of community is not present, the learners will feel isolated, anxious, self-protective, and reluctant to fully participate in the learning community online. In a more recent study, Rovai (2002) concludes that an important factor in creating social presence in a distance education course is creating a feel of community. Garrison and Anderson remind us that social presence is the capability for students to create their own community and emotional connections that allow them to view each other as actual persons in a community of learners (2003).

The Garrison and Anderson and the Rovai studies demonstrate that social presence is an essential feature of online teaching methods because they encourage student learning, satisfaction, and cooperative learning. Further these studies point out that a deficiency of social presence may be a detriment to student learning leading to frustration and a negative reaction to the learning environment. Although it is known that within the online learning community, social presence is a necessary component for improved learning, the expansion of the social into the online learning environment has its difficulties. Even with the availability of current technologies and the increased use of these technologies in the daily life of online users, the physical separation in the learning community may still be of concern for flourishing within an online environment. 
According to Whiteman (2002), it is the nature of human society to relax in community if there is a belief in human relationship and similar values. Leh (2001) stated that at the times that the online learning environment does not have a sense of social presence, learners perceive it as being rather cold. Therefore, there is reluctance and a decrease in shared information and communication. Yoon (2003) declares that social behaviors makeup 26.3 percent of all behaviors that occur in online learning groups. These behaviors would include salutations, introductions, insight into student personal interest, talking about the course, teaming, and individual support. Whiteman (2002) argues that deeply felt social presence within the online learning experience may lead the student to inclusion, restraint, and fondness. Rouke (1999) agrees and suggests that increased heights of social presence enable the online learning community to be seen as friendly, mutually respectful, and easily assessable for all users. This also helps to incorporate the ability to bring about, keep, and encourage the learning goals.

Gunawardena and Zittle (1997) completed a study on social presence and reviewed its effect on gratification of learners in computer-mediated environments. Shin (2002) ascertained that much of the current research has only begun to delve into the links in the level of social presence, student gratification, and the amount of student learning achievement. The literature indicates that the advantage of social presence may be seen in the levels of student satisfaction, suggesting that it may also serve as an influence on learning outcomes. Because of this, it is of the utmost importance that learners, as well as instructors understand the significance of generating social presence in an online learning community. 


\section{Strategies for Creating Social Presence}

Because social presence plays such a meaningful role in online courses, it is imperative to create strategies that can build an awareness of community among the learner, where learners can learn from one another and also from the instructor. Within an environment that supports the creation of social presence learners are able to share their viewpoints from different angles or perspectives while enhancing the ways they can freely work together without having to monitor each other all the time. It is possible to generate social presence in an online learning community in a variety of ways. The accountability for this lays primary with both the teacher and the students involved in the course are also a factor. This section discusses various strategies that can be used achieve social presence in online courses.

The design of an online course lends itself to the development of social presence. Online courses need to include a welcoming greeting along with an introduction and the opportunity to interact with the material and the community, and the instructor before the course begins or shortly after. According to Winograd (2002), the first thing a student should view when they first enter an online course is a welcome message from the instructor. Just like in a face-to-face situation, first impressions are critical and cannot be easily reversed. The introductory message must be meticulously written because it will set the tone for the rest of the course. "All welcome messages should be warm, friendly and personal, letting the readers know that they are important members of the community and you the moderator are glad they are here" (p. 53). Consider for example a video introduction to both the topic of the course as well as the instructor is especially effective. This video introduction allows students to develop a greater social sense within the course by visually engaging with the instructor. 
Similarly students can post or upload pictures, biographies, or e-portfolios as a means to increase the level of community involvement.

Putting synchronous chat to use as a part of the learning community can also enhance social relations among the students and the instructor in an online course. Because the nature of chat is to be conducted in real-time, chat has the potential for allowing all students to participate with comments and participation in the conversation.

Because the online learning environment may be new to some of the participants, there is a need for emotional and technical support to keep them encouraged. When students become frustrated, particularly with technical issues, it affects how they participate and interact in the course. It is therefore imperative to provide this support in the learning environment. According to Berge (1996), it is recommended to give tutorial sessions to the novice participants as well as have technical support staff to respond to any queries that may arise. Initially, the participants may be adamant or unsure on what to do, therefore the instructor should also be available to respond to any queries or concerns they may have and provide emotional support. Synchronous modes of communication such as chat rooms can be used as an option to personal meetings during the familiarization phase of the online course. Bradshaw, Powell, and Terrell (2002) suggest that during the orientation stage, "Time needs to be given to induction, with specific activities designed to negotiate expectations, provide guidance to the online space, and resolve problems" (p. 7).

As the learners gradually become comfortable with the online environment, there is a need to provide a social area, which they can use to socialize and get to know each other. Working in groups is a central design element of an online learning community because it provides the participants an opportunity to collaborate and to socialize. Bradshaw et al. 
(2002), discuss about the need for a place that can be used for induction and social discussions and where students can "share their thoughts and learning from their module in a more general context.” (p. 6).

It is imperative that any message that is conveyed in an online community through a discussion medium, should have meaning and have connection with the subject being discussed otherwise this would interrupt the students' learning process. Winograd (2002) discusses how some students would post messages in the wrong areas or post messages that have nothing to do with the current topic and as a result, it spoils the flow and organization of a discussion, eventually creating a misunderstanding. Further it is important to have a set of rules that determines the procedure on where and how students post and reply to messages. Other studies mention how online communities develop their own culture as they get to know one another and the importance of having protocols. According to Salmon (2004), "Every grouping of people develops its own culture with formal and informal rules, norms of behavior, ways of operating and sanctions against those who fail to understand or conform. An individual cannot easily replace a familiar culture or values with those of a new community - he or she is more likely to selectively adapt or modify features of a new group that seem attractive or useful" (p. 33).

Typically, first time online participants are nervous or concerned about what they should post in an online discussion or chat, when they should post and how long it takes before they get a reply. It is therefore imperative that the facilitator provides them with some guidance and at least in the initial stages of the course, they should respond promptly. Winograd (2002) suggests, "It is important that first messages receive a response as quickly as possible. In a perfect situation, you would check the conference and e-mail at least every 
two hours during the first week. This, under most circumstances, is not realistic, but during the first week or so, you should be as responsive as possible checking in a number of times during the day and responding to first messages promptly" (p. 55).

According to Hardie (2002), forming an online community takes a lot of time and effort and it is not as trivial as posting commentary on a website or chatting online. In order to develop an online community that is effective, some key factors should be considered. American Psychological Association (1997) discusses the different learner-centered psychological beliefs that guide the learning process such as social influences on learning. Social influences includes how the learners interact and communicate with others, how they respect diversity and care for others in this environment.

Trust is also a very important element when building an online learning community. Rovai (2001) emphasizes that trust "is the feeling that the community can be trusted and feedback will be forthcoming and constructive. Once individuals are accepted as part of a nourishing learning community, they feel safe and trust the community. With safety and trust comes the willingness of community members to speak openly. This candor is important to a learning community because with trust comes the likelihood that members will expose gaps in their learning and feel that other members of the community will respond in supportive ways." (p. 34) According to Preece (2000), "When there is trust among people, relationships flourish; without it, they wither" (p. 191). Further Preeces notes that betrayal in this type of learning environment can be devastating to the community which as a result effects the collaborative interaction. Once the community members feel that they have been accepted and can trust each other, articulating their views becomes naturally easy. 
Although online courses have the capacity to accommodate a large number of students, the creating of social presence is more expected to come about by limiting the number of students. Based on the research of Rovai (2001), the most appropriate class size is 30 student to 1 instructor, further it is recommended that as the student - teacher ratio is increased the level of social presence is decreased. The size of the online community whether large or small is also a key element because it may control how the community members participate and interact with each other when learning. For instance, if the community is large, this might make some of the participants to feel weighed down and inconsequential, while a smaller community will be unappealing to the participants because there are not enough students to participate (Preece, 2000).

Table 3 Strategies to Creating Social Presence (Aragon, 2003)

\begin{tabular}{|c|c|c|}
\hline Course Design: & Instructors: & Participants: \\
\hline $\begin{array}{ll}\text { - } & \text { Develop welcome } \\
\text { - } & \text { Include student } \\
& \text { profiles } \\
\text { - } & \text { Incorporate audio } \\
\text { - } & \text { Limit class size } \\
\text { - } & \text { Structure } \\
& \text { collaborative }\end{array}$ & $\begin{array}{l}\text { - } \text { Contribute to } \\
\text { discussion boards } \\
\text { - Promptly answer e- } \\
\text { mail } \\
\text { - } \text { Provide frequent } \\
\text { feedback } \\
\text { - Strike up a } \\
\text { conversation } \\
\text { - Share personal } \\
\text { - } \text { stories and } \\
\text { - } \text { Usperiences } \\
\text { - Use humor } \\
\text { - Address students by } \\
\text { - } \text { name } \\
\text { Allow students } \\
\text { options for } \\
\text { addressing the } \\
\text { instructor }\end{array}$ & $\begin{array}{ll}\text { - } & \text { Contribute to } \\
\text { discussion } \\
\text { - } & \text { boards } \\
\text { - } & \text { Promptly answer e- } \\
\text { mail } \\
\text { - Strike up a } \\
\text { conversation } \\
\text { - Share personal } \\
\text { - } \text { stories and } \\
\text { - } \text { Usperiences } \\
\text { - Use emoticons } \\
\text { - Use appropriate } \\
\text { titles }\end{array}$ \\
\hline
\end{tabular}


Salmon (2000) recommends the use of online activities, which he calls e-tivities, can be used by the participants to increase interaction and develop trust with one another through discussing their individual experiences and thoughts. Salmon also discusses how e-tivities can be used to understand different cultures and to be aware of the significance of having diversity in an online learning community.

Figure 2 Gilly Salmon's five-stage model (Salmon, 2004)

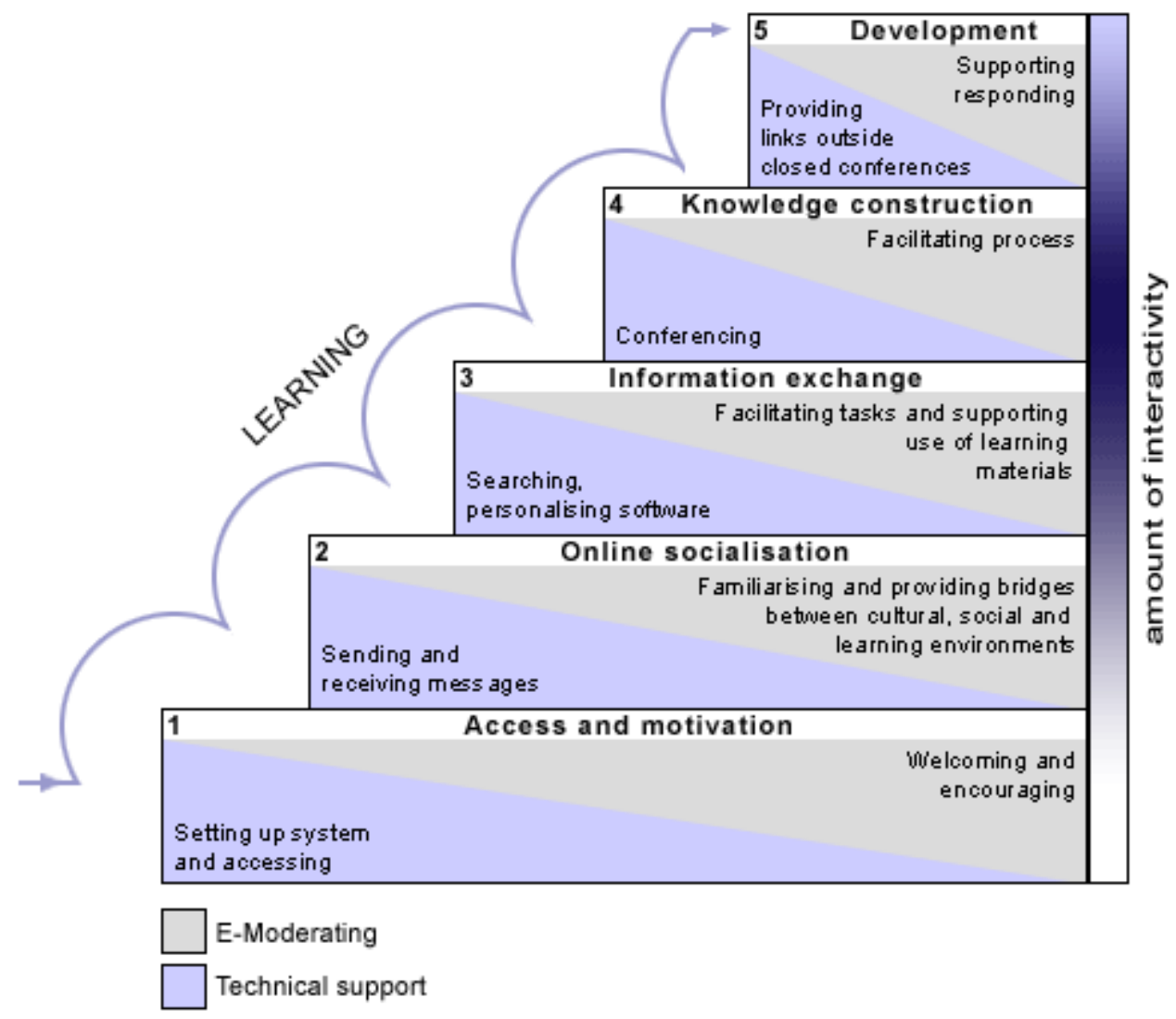

Summary of Literature review

The rationale of this chapter was to provide a review of the literature which dealt with (1) Distance Education (2) Computer Mediated Communication (CMC); (3) Social Perspective of CMC; (4) Defining Social Presence; (5) Current Research on Social Presence; (6) The Community of Inquiry Framework; (7) Benefits of Social Presence and (8) Strategies 
for Creating Social Presence. The literature review discussed the history of distance education and Computer-Mediated Communication. The literature review also defined social presence as the sense of community that the learners feel in an online learning community. It also indicated that social presence is of particular importance as an influencing element in an online learning community. The literature review addressed the topic of social presence, and strategies of incorporating social presence. However, not many studies have looked at the effect of social presence on how students perceived learning and satisfaction in online environments. In addition, the literature review indicated that the few articles written on the subject of social presence do not discuss students' perceived learning presence and their satisfaction with online courses.

Incorporating social presence into online courses presents an opportunity to develop a sound learning atmosphere. It is therefore imperative to recognize how the perception of social presence may influence student satisfaction and quality of learning in the courses as well as providing instructional designers with vital information on how to retain the students in online courses. The following chapter covers in detail the methodology that will be used for this study. This chapter will include information on how the participants were selected, data collection procedures and data analysis. 


\section{CHAPTER III: METHODOLOGY}

\section{Overview}

The purpose of this study is to investigate and review the role that social presence plays in how students perceived learning and satisfaction in online courses. There was one independent variable in this research, which is social presence. The two dependent variables in this study were student perceived learning and satisfaction.

The research questions to be addressed were:

RQ1 - Can we predict in a statistically significant fashion using linear regression students' perceived learning in a course based on their perceived level of social presence and number of interactive elements in the course?

RQ2 - Can we predict in a statistically significant fashion using linear regression students' satisfaction in a course based on their perceived level of social presence and number of interactive elements in the course?

\section{Research Hypotheses}

The research hypotheses for the first research question (RQ1) are:

$\mathrm{H}_{0}$ : There is no statistically significant regression model when trying to predict student's perceived learning from a combination of their social presence score and number of interactive elements in the course.

$\mathrm{H}_{\mathrm{a}}$ : There is a statistically significant regression model when trying to predict student's perceived learning from a combination of their social presence score and number of interactive elements in the course.

The research hypotheses for the first research question (RQ2) are: 
$\mathrm{H}_{0}$ : There is no statistically significant regression model when trying to predict student's satisfaction from a combination of their social presence score and number of interactive elements in the course.

$\mathrm{H}_{\mathrm{a}}$ : There is a statistically significant regression model when trying to predict student's satisfaction from a combination of their social presence score and number of interactive elements in the course.

\section{Data Collection Methodology}

\section{Participants}

The participants for this study were a total of 160 graduate students from a variety of special education courses offered online during Summer and Fall Semesters 2010 at a major higher education institution located in a Mid-Atlantic state. These courses were

- Classroom/Behavior Management for Special Needs,

- Family/Professional Collaboration: Developmental Disabilities,

- Early Learning Curriculum: Early Intervention,

- Culminating Practicum: Early Intervention,

- Standards-based Curriculum: Severe Disabilities,

- Culminating Practicum: Severe Disabilities,

- Braille Reading and Literacy Development,

- Learning Characteristics: Autism,

- Educational Interventions: Autism,

- Collaborative-Consultative Inclusion Strategies,

- $\quad$ Reading for Special Needs and 
- Introduction to Gifted Education.

These courses are offered completely online throughout the Mid-Atlantic state, throughout the United States, and in certain international regions. Each of these courses was delivered by core program instructors by means of online distance education.

Blackboard Vista (eCampus) was the course management system that was used to deliver course material for these courses. The courses were offered using a combination of synchronous and asynchronous sessions. Synchronous class sessions were conducted using Wimba Live Classroom, a software program used for desktop conferencing.

The courses were organized into six-week learning modules. Materials included a syllabus, weekly objectives, lecture notes, chat, discussions, assignment, assessments, and additional resources. The instructor designated students to facilitate the weekly discussion or chat. At the end of the discussion or chat, the instructors would summarize the topic; respond to any questions that the students may have had. To encourage social presence among the students, the instructors used the following techniques:

- Synchronous audio chat

o All students to participated in the conversation in real time

- A welcome message from the instructor in form of a video introduction was included

o allowing the students to develop a greater social sense by identifying the course instructor 
In addition, a social area - the Sandbox - was built into the discussion board, where the students could socialize in order to get to know each other. Further student profiles and biographies were posted.

While the university offers a variety of distance learning courses, the courses chosen for this study were designed to have high levels of interaction; they were learner-centered, and they made extensive use of CMC tools. It was projected that these courses would provide learners with experiences pertinent to this study e.g. interpersonal communication and social connections.

Assumptions

The following assumptions were made for this study:

1. There were similarities and differences among the learners

2. Participation in this study was not to be selected or rejected based on personal identifiers such as age, ethnicity, gender or economic status however the information collected will be used to identify any probable differences in their responses.

3. All of the learners enrolled in this online course had prior experience with the various components of the course.

4. Due to the confidentiality among the participants, their responses were truthful.

\section{Research Design}

\section{Instrument}

The students were to complete a survey at the end of the course, asking them a series of questions concerning their general experience in relation to social presence, perceived 
learning and satisfaction. According to Isaac and Michael (1995), "Surveys are the most widely used technique in education and behavioral sciences for the collection of data. They are a means of gathering information that describes the nature and extent of a specified set of data ranging from physical counts and frequencies to attitudes and opinions" (p. 128).

The survey included four parts. The first part of the questionnaire dealt with social presence. The questions used in this part of the survey are based on the Community of Inquiry questionnaire, which was developed, by Arbaugh, Cleveland-Innes, Diaz, Garrison, Ice, Richardson, Shea and Swan (2007).

The second part of the questionnaire dealt with perceived learning. The questions used in this part of the survey were also based on the perceived learning questionnaire, which was developed, by Hiltz (1994) and Arbaugh (2000).

The third part of the questionnaire dealt with satisfaction. The questions used in this part were part of a questionnaire which was developed by Gunawardena and Zittle (1997) to assess the learning experience and the value of social presence in predicting satisfaction in an online environment. The final part of the questionnaire dealt with the interactive elements used in the course. Using a Likert scale, the participants were asked to rate several interactive elements available in the course, used for accessing information and communicating with colleagues and instructor.

The survey was constructed of both structured and unstructured items that included a checklist in the form of a Likert-type scale ranging from 1 = strongly disagree, 2 = disagree, $3=$ neutral, $4=$ agree, $5=$ strongly agree, and free response section. The first part of the survey questionnaire included overall demographic items such as course name, course instructor, age, gender, and number of college courses. The second and third part of the 
survey also includes Likert-style questions ranging from 1 = strongly disagree, $2=$ disagree, $3=$ neutral, $4=$ agree, $5=$ strongly agree. Reliability is the degree in which an instrument consistently measures what it is intended to measure. To check the reliability of the survey, Cronbach's Alpha value was used to compute and report each scale for all the items of the questionnaire to test the internal consistency. The widely accepted cut-off Conbach Alpha .70 is considered acceptable.

\section{Procedure}

The study was based on a six-week period during the Summer and Fall Semesters. The course was to be delivered over six weeks (modules). The course content included a syllabus, online lecture notes, reading assignments, weekly discussion questions, and related links. Several techniques and activities were used to promote social presence as well as a sense of community among the participants. A live online meeting for each course took place in the first week of the semester to cover the course requirements as well as show the participants how to use the different CMC tools. An Institutional Review Board (IRB) review was conducted before collecting the data. The instructors from each section were contacted by telephone and email. They were asked to send out an email to the students currently registered in these courses directing the potential respondents to a website containing the questionnaire. By this time, the course instructors had a whole list of the students enrolled in the online courses. During the last two weeks of the semester, a survey was administered to the students.

The survey was conducted using Survey Monkey (http://www.surveymonkey.com). The survey was to be administered following the mid-term exams. The purpose of collecting the data at this point was because the participants would have completed the first half of the 
semester and familiarized themselves with the different interactive elements. A hyperlink to the survey was embedded in the message sent out to the students. When the participants clicked the hyperlink, the survey automatically opened. The students were only allowed to complete one survey.

\section{Methods of Data Analysis}

The quantitative data was analyzed using a linear regression analysis. Regression analysis was to be used to determine how strong the relationship is between the student's perceived learning, satisfaction and social presence, and what was the relative importance of social presence towards that relationship. The general consideration for using linear regression analyses is that regression is best when each independent variable is strongly correlated with the dependent variable but uncorrelated with other independent variables. In addition, the general rule of thumb for sample size for a linear regression analysis is greater than $50+8 \mathrm{~m}$ (where $m$ is the \# of independent variables). The extreme outliers will be taken out of the analysis.

An advantage of using a linear regression is that it lets the researcher be able to quantify and to predict to the future. Its limitations include:

- it assumes normality in the variable

- it assumes constant standard deviation in the independent variable

- it is only valid for the range of the data

- it assumes that the relationship is linear

- it does not imply cause-effect

- the outlier affects the model. 
Survey responses on each of the two research questions were analyzed. For research question 1 (RQ1) a regression analysis was performed to predict students' perceived learning in a course based on their perceived level of social presence and number of interactive elements in the course.

The interactive elements built into the course design included

- welcome message

- an ice-breaker

- student profiles and biographies

- addressing students' using their names

- social interactions area in the discussion board (Sandbox)

- audio and video using Wimba

- use of text-based chat

In order to assess perceived learning, a questionnaire using a five point Likert-type scale to measure the perceived learning (1 " Strongly Agree "to 5 " Strongly Disagree ") was used. Six question items asking students their perceived learning in the areas of interrelating the important issues in the course material, gaining a good understanding of the basic concepts of the material, learning to identify the central issues of the course, developing the ability to communicate clearly about the subject, improving their ability to integrate facts and develop generalizations from the course material, learning concepts and principles in this course, were included.

For research question 2 (RQ2), a regression analysis was also performed to evaluate students' satisfaction in a course based on their perceived level of social presence and number of interactive elements in the course. In order to assess student's satisfaction, a 
questionnaire using a five point Likert-type scale to measure the student's satisfaction (1 " Strongly Agree "to 5 " Strongly Disagree ") was used. Eleven items asking students their satisfaction in the areas of learning through the medium of $\mathrm{CMC}$, learning from the online discussions, motivation to explore content related questions, utilizing a variety of information sources to explore problems posed in this course, stimulated to do additional reading or research on topics discussed, learning to value other points of view, wanting to participate in another online course in the future, finding the online course a positive learning experience, making online connections with learners from different parts of the world, variety of subjects in the online course prompting them to contribute in the discussions and whether they play a major role to in computer mediated communication.

\section{Summary of the Methodology}

This chapter presented the methodology and procedures used in this study. A quantitative study was conducted to investigate the role that social presence plays in how students perceived learning and satisfaction in online courses. The survey included the following parts; demographics, social presence, perceived learning, satisfaction and interactive elements. Other researchers had previously established the content validity. An Institutional Review Board (IRB) review was conducted before collecting the data. The participants for this study were 160 graduate students enrolled in special education online courses offered in the Summer and Fall Semesters 2010 at a major higher education institution located in a Mid-Atlantic state. Course instructors were contacted and requested to administer the survey to the students. The survey was conducted online using a survey monkey. Once collected, the data was to be put into a table using Microsoft Excel and then 
analyzed. The following chapter provides a detailed description and analysis of the data collected. 


\section{CHAPTER IV: DATA ANALYSIS}

\section{Overview}

The purpose of this study was to investigate and review the role that social presence plays in how students perceived learning and satisfaction in online courses. The aim of this chapter is to provide a detailed description and analysis of the data collected from graduate students enrolled in special education online courses at a major higher education institution located in a Mid-Atlantic state. The data collected in this research was to address the following questions:

RQ1 - Can we predict in a statistically significant fashion using linear regression students' perceived learning in a course based on their perceived level of social presence and number of interactive elements in the course?

RQ2 - Can we predict in a statistically significant fashion using linear regression students' satisfaction in a course based on their perceived level of social presence and number of interactive elements in the course?

This chapter was divided into three main sections: 1) modes of data analysis, 2) demographic data, and 3) major findings.

\section{Modes of Data Analysis}

In this study, each research question was addressed while analyzing and presenting the data. The data were imported from Survey Monkey into a Microsoft Excel 2007 spreadsheet, and then moved into the Statistical Package for Social Sciences (SPSS) to be analyzed. Prior to analyzing the data in SPSS, the data was coded in Excel to condense each response into a variable that could be used to analyze the data in SPSS. The data was checked 
for omitted data. Both descriptive and inferential statistical procedures were used in this study. The description of the demographics findings are presented below.

\section{Demographic Data}

The population of this study involved graduate students enrolled in special education online courses at a major higher education institution located in a Mid-Atlantic state. The participants were drawn from online special education courses:. The initial target population was 160 graduates enrolled in special education online courses and of those, $81(50.63 \%)$ participated in this study.

Ages of the respondents ranged from 21 to 54 . Figure 3 presents the breakdown of these demographic data.

Figure 3: Respondent Age

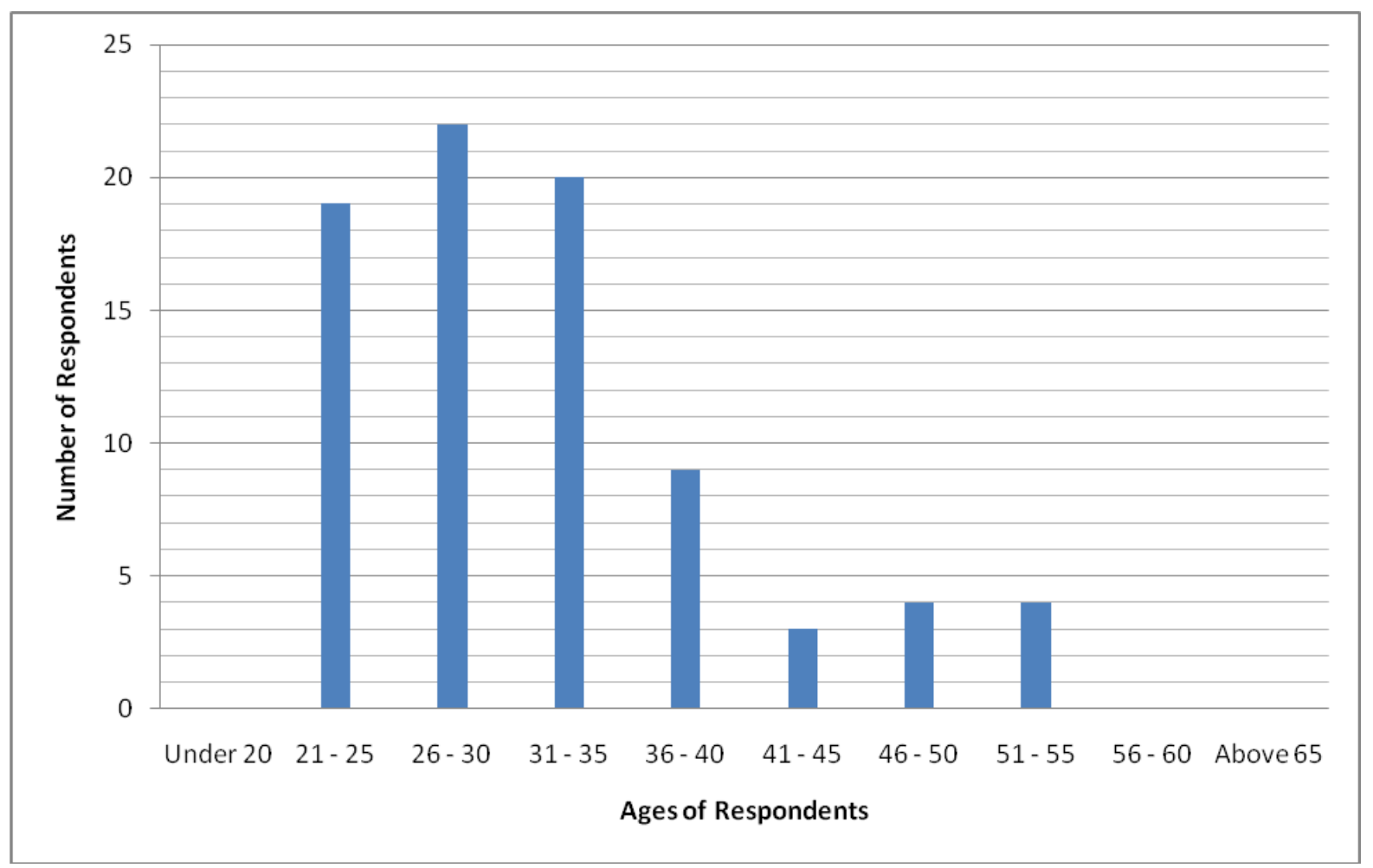


When asked to indicate their gender, of the survey respondents, the majority $(91.4 \%)$ were females, while $8.6 \%$ were males. When asked to indicate the degree program in which they are currently enrolled, 76 of the respondents or $93.8 \%$ of the respondents indicated that they are enrolled in a Master's degree program and only one respondent was enrolled in a Bachelor's degree program. None of the respondents was enrolled in an associate degree or doctorate programs.

The total number of college credits completed towards degree ranged from zero to 41 with a mean number of college credits completed towards degree was 15 (median= 12 , mode $=12$ ). Table 5 presents the breakdown of these demographic data. Table 4 Number of college credits completed towards degree

\begin{tabular}{cccccccc}
\hline Number & Missing & Mean & Median & Mode & $\begin{array}{c}\text { Std. } \\
\text { Deviation }\end{array}$ & Minimum & Maximum \\
\hline 74 & 7 & 15.26 & 12.00 & 12 & 10.708 & 0 & 41 \\
\hline
\end{tabular}

In response to whether this was their first semester taking an online course, 74 of the respondents or $91.4 \%$ indicated that this was not their first semester taking online courses, while 7 respondents or $8.6 \%$ acknowledged that it was their first time taking online courses. For the number of online college courses they have taken, out of 80 respondents, $26.3 \%$ indicated taking between $5-7$ courses, 16 or $20 \%$ took between $8-10$ courses, 12 or $15 \%$ took between $11-15$ courses, 11 or $13.8 \%$ took 2 courses, 8 or $10 \%$ took 4 courses, 5 (representing $6.3 \%$ ) took 3 courses, 3 (representing $3.8 \%$ ) took 1 courses, 2 or $2.5 \%$ took between $21-25$ courses, 1 (representing 1.3\%) took between 16-20 courses and 1 (representing 1.3\%) took more than 25 courses. Figure 4 presents the breakdown of these demographics. 
Figure 4: Number of online college courses taken

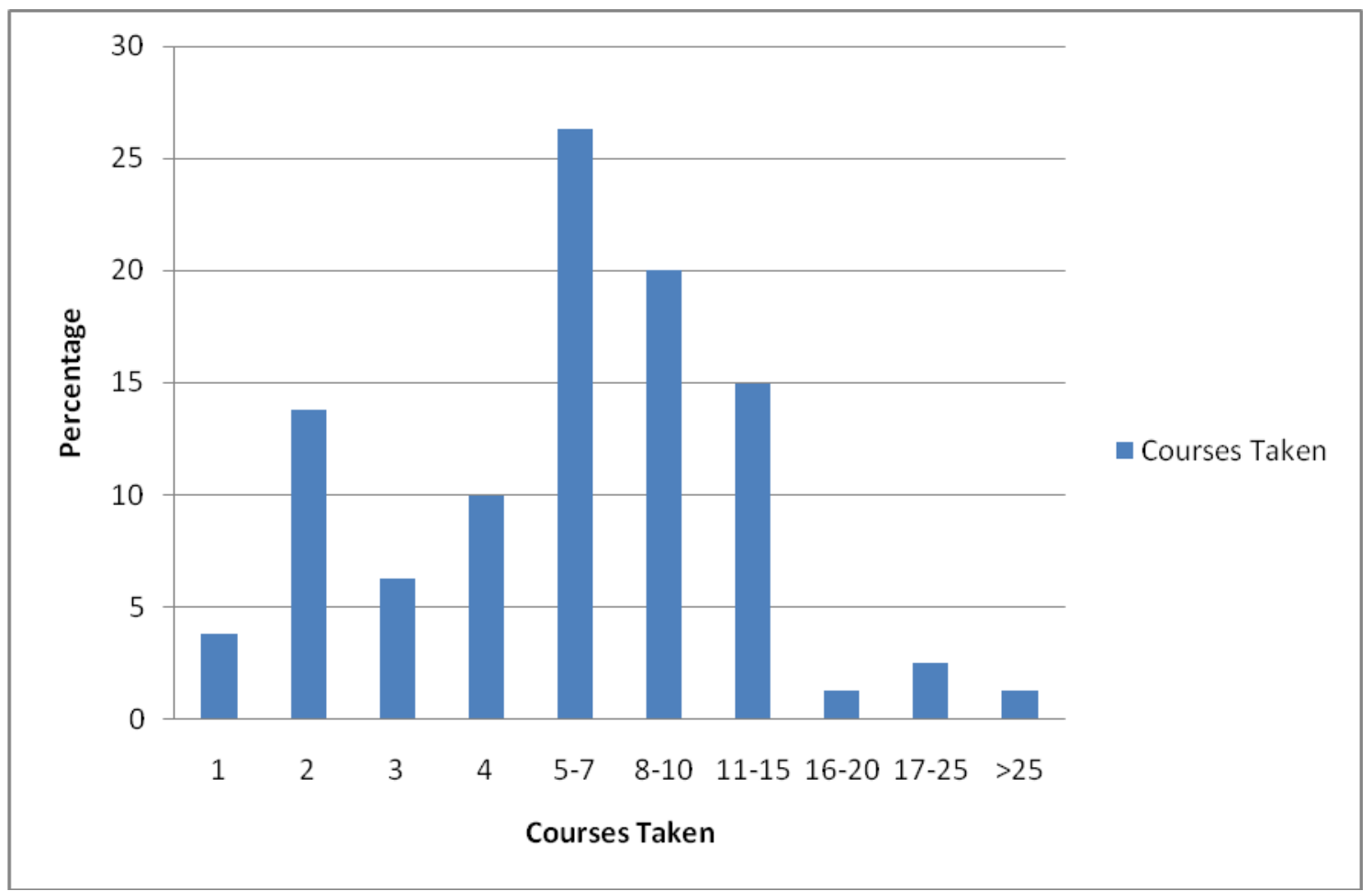




\section{Social Presence}

When responding to whether getting to know other course participants gave them a sense of belonging in the course, $53.9 \%$ of the respondents indicated that they agreed that getting to know other course participants gave them a sense of belonging in the course, while 10 respondents disagreed (representing 13.2\%). However, 15.8\% (12) were neutral. Figure 5 presents the breakdown of these results.

Figure 5: Getting to know other course participants gave me a sense of belonging in the course.

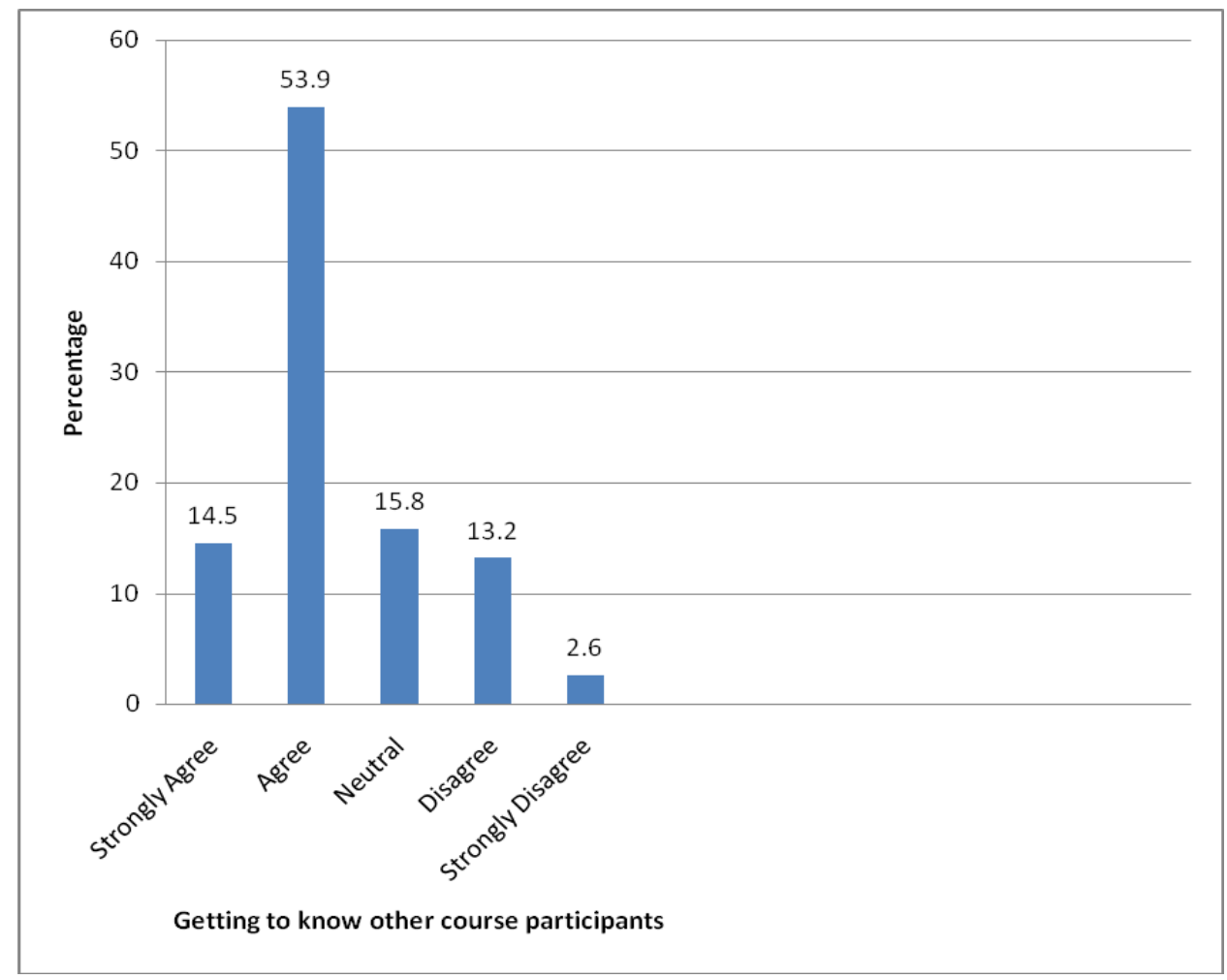

When asked to indicate whether they were able to form distinct impressions of some course participants, 50 of the respondents or $65.8 \%$ indicated that they agreed that they were able to form distinct impressions of some course participants, while 2.6\%) disagreed and 11 or $14.5 \%$ remained neutral. Figure 6 presents the breakdown of these results.

Figure 6: I was able to form distinct impressions of some course participants. 


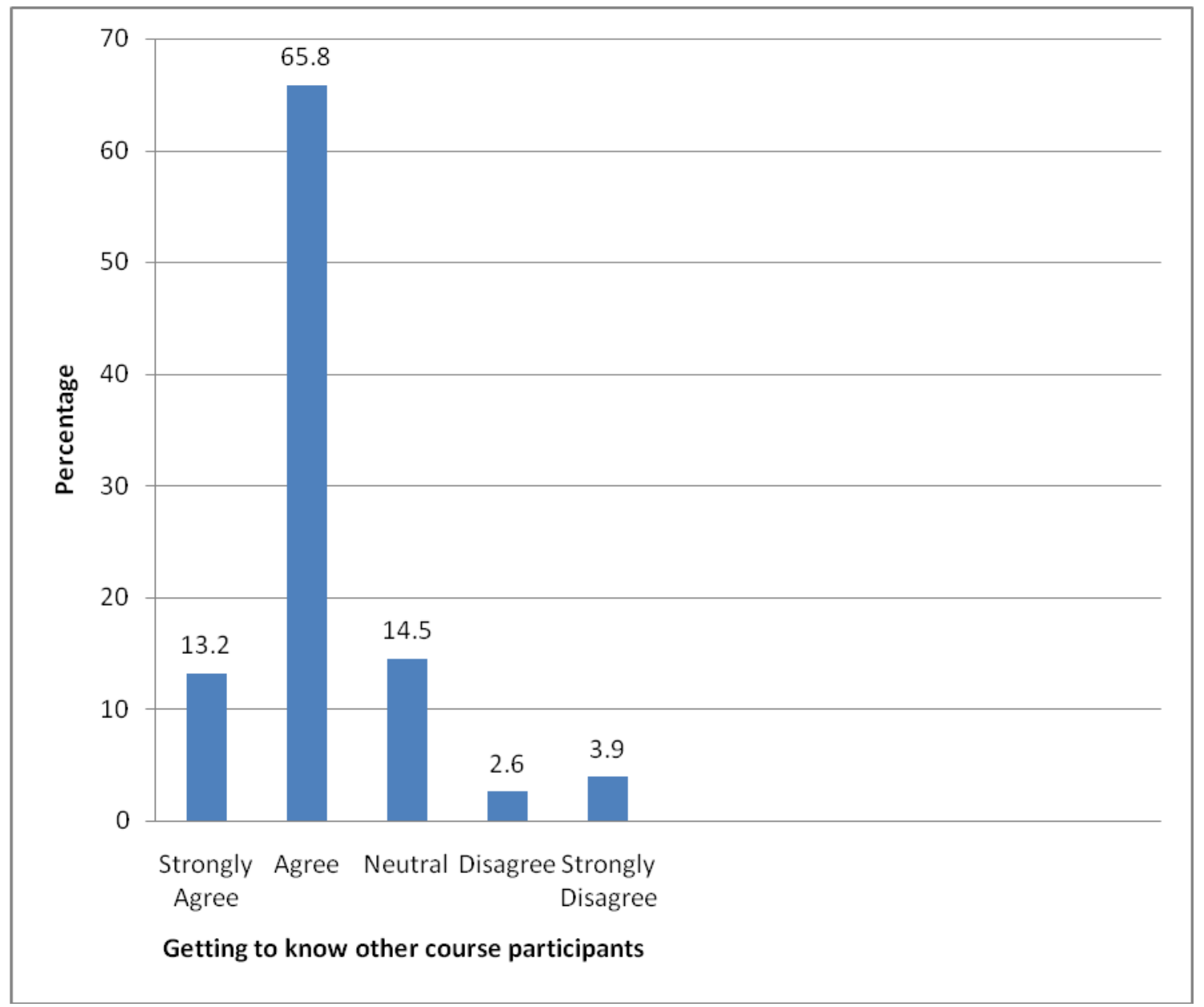

Pertaining to whether online or web-based communication is an excellent medium for social interaction, more than $50 \%$ of the participants agreed that online or web-based communication is an excellent medium for social interaction, whereas only 7 respondents disagreed (representing 9.2\%). However we did get a quarter of the students who remained neutral. Figure 7 presents the breakdown of these results. 
Figure 7: Online or web-based communication is an excellent medium for social interaction.

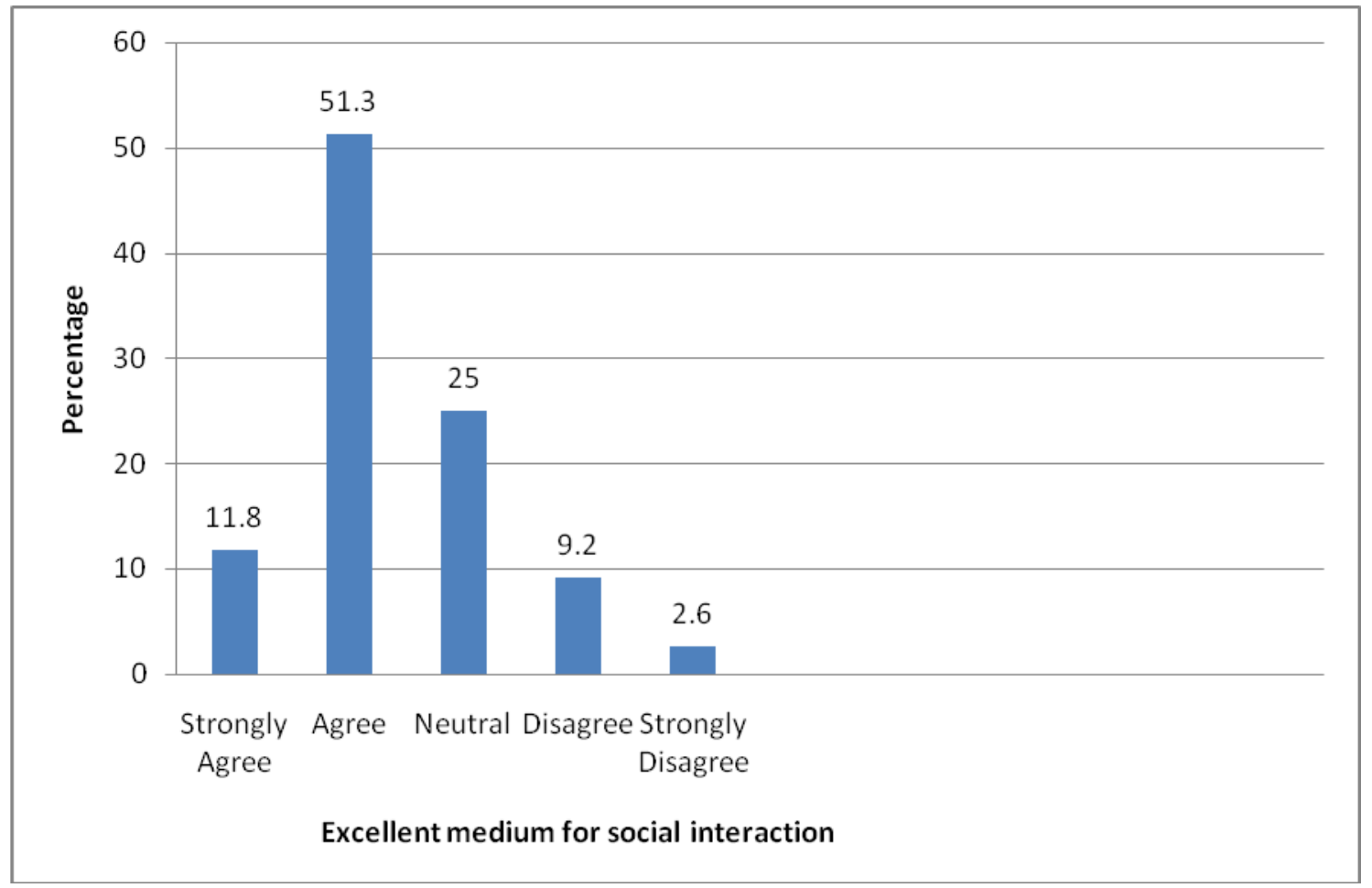

Relating to whether they felt comfortable conversing through the online medium, over half of the respondents agreed that they felt comfortable conversing through the online medium, while 6 or $7.9 \%$ disagreed while $8(10.5 \%)$ were neutral. Figure 8 presents the breakdown of these results. 
Figure 8: I felt comfortable conversing through the online medium.

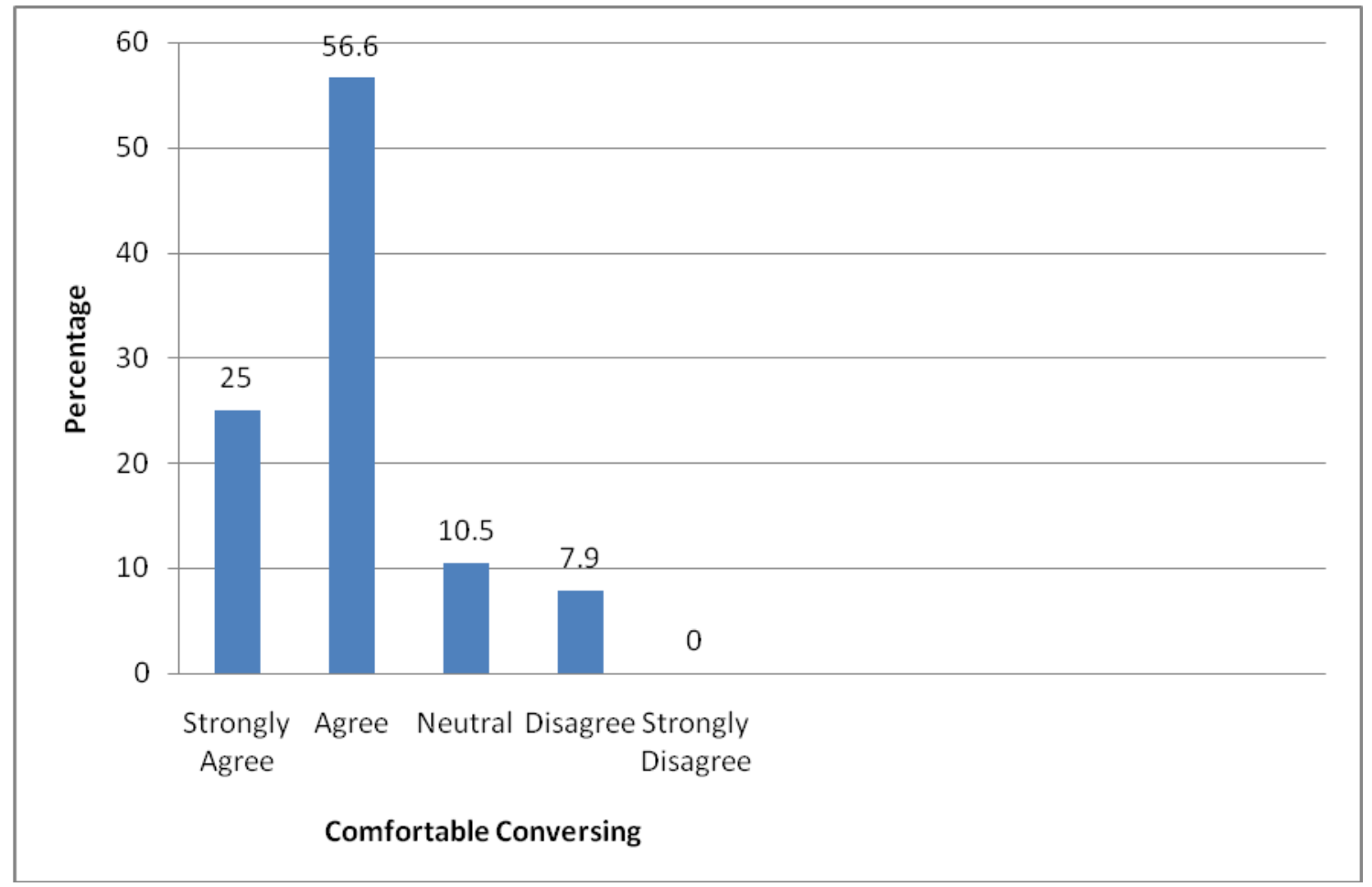

With regard to whether they felt comfortable participating in the course discussions, 49 of the respondents or $64.5 \%$ reported that they felt comfortable participating in the course discussions, while $6(7.9 \%)$ disagreed and $8(10.5 \%)$ were neutral. Figure 9 presents the breakdown of these results. 
Figure 9: I felt comfortable participating in the course discussions.

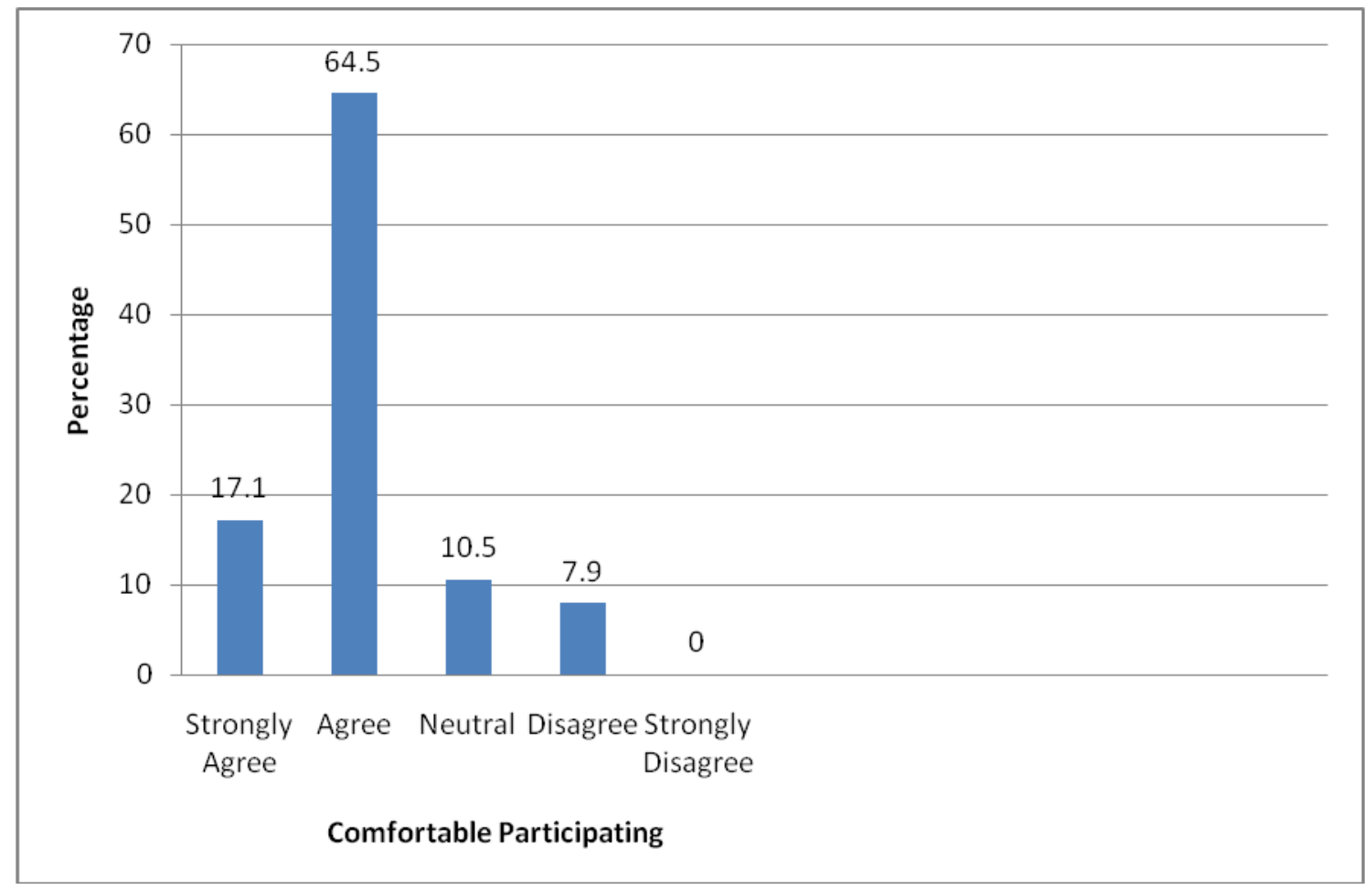

The results of whether they felt comfortable interacting with other course participants, 47 of the respondents or $61.8 \%$ agreed that they felt comfortable participating in the course discussions, while $1.3 \%$ disagreed and 12 or $15.8 \%$ remained neutral. Figure 10 presents the breakdown of these results. 
Figure 10: I felt comfortable interacting with other course participants.

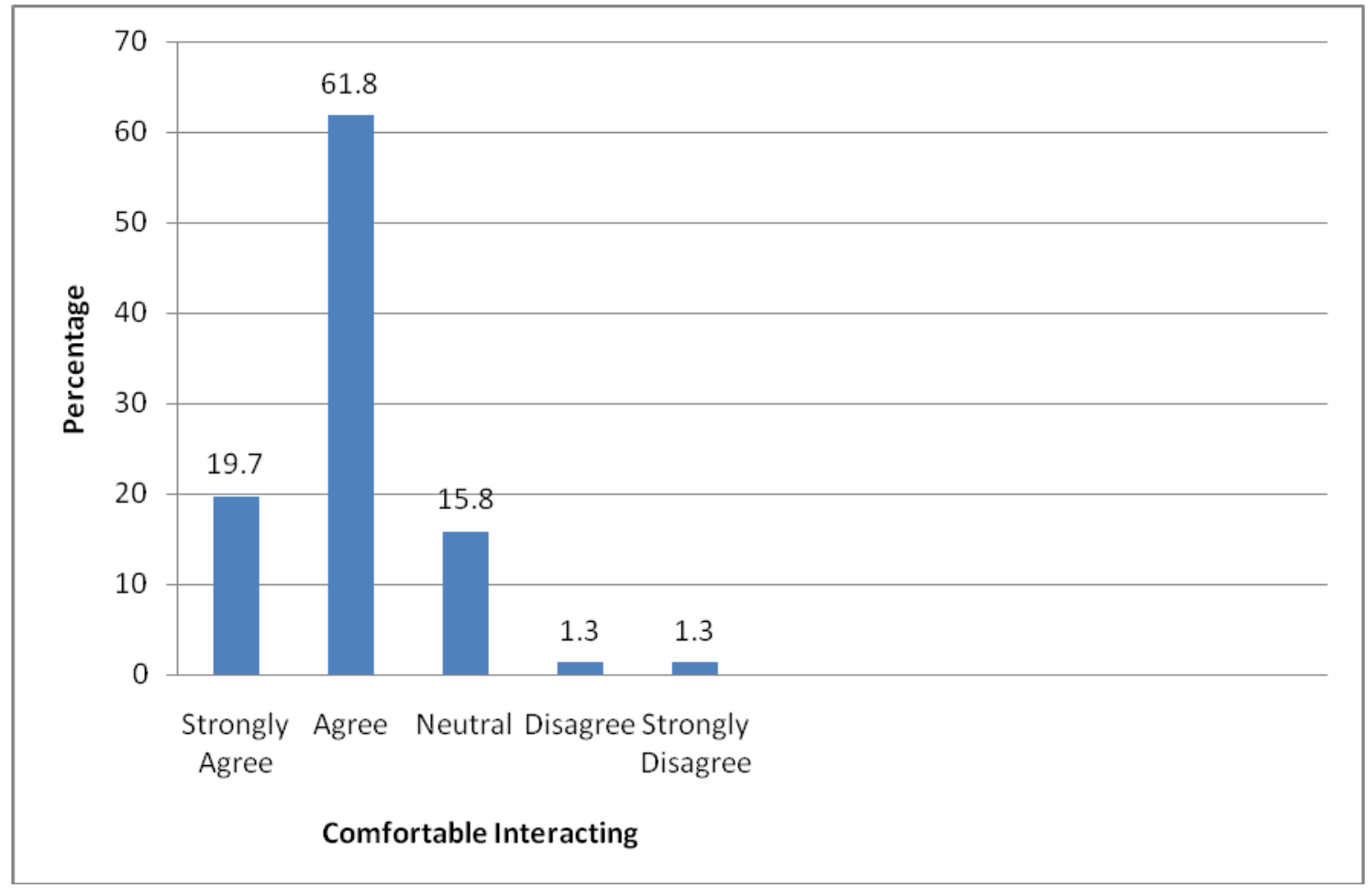

When asked to indicate whether they felt comfortable disagreeing with other course participants while still maintaining a sense of trust, a majority agreed or $56.6 \%$ felt comfortable disagreeing with other course participants while still maintaining a sense of trust, while $14.5 \%$ disagreed and 12 or $15.8 \%$ remained were neutral. Figure 11 presents the breakdown of these results. 
Figure 11: I felt comfortable disagreeing with other course participants while still maintaining a sense of trust.

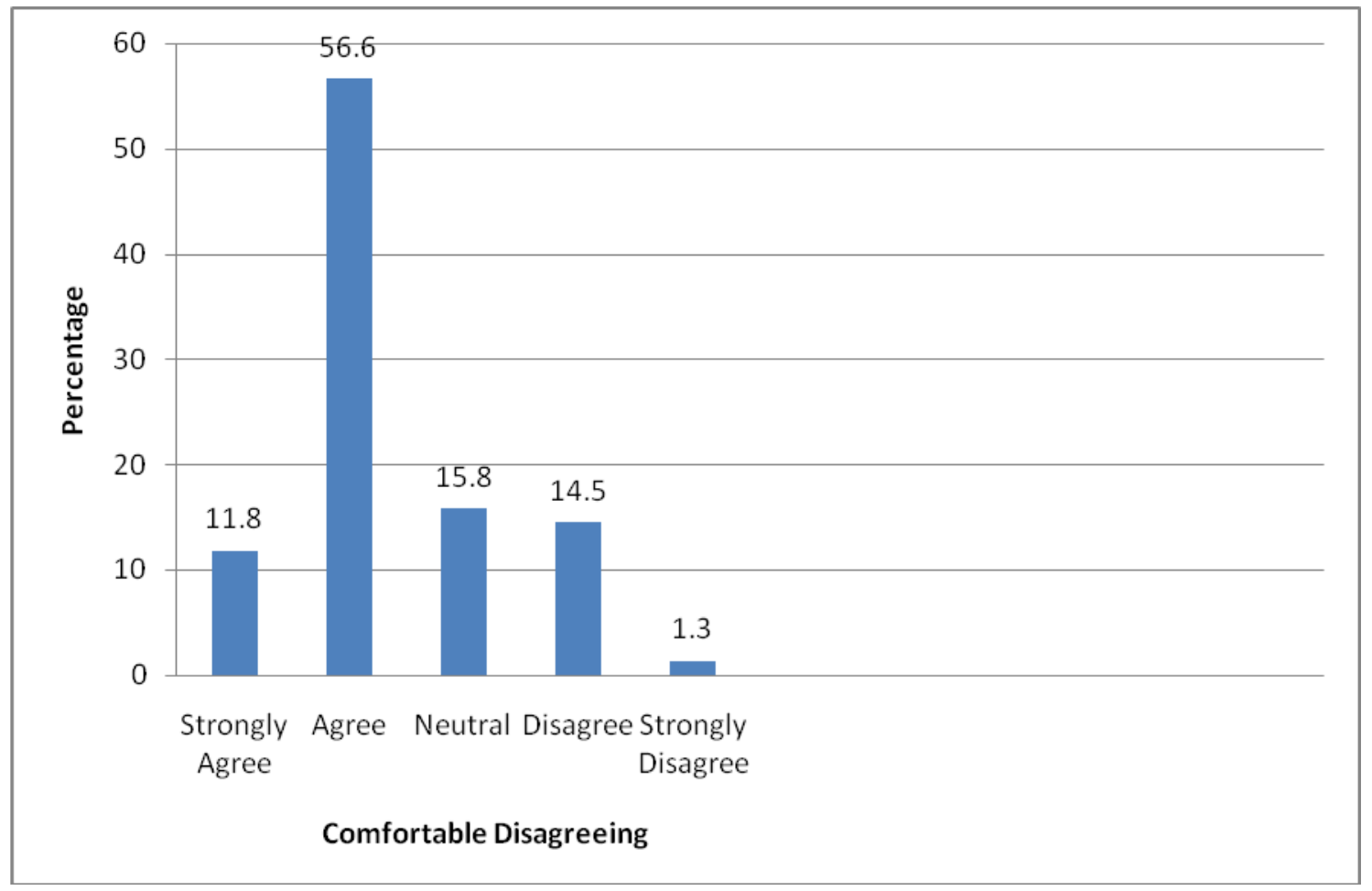

The majority of the respondents indicated that they felt that their point of view was acknowledged by other course participants. Specifically, 53 of the respondents or $70.7 \%$ agreed that they felt that their point of view was acknowledged by other course participants, while $1.3 \%$ disagreed. 8 or $10.7 \%$ remained were neutral. Figure 12 presents the breakdown of these results. 
Figure 12: I felt that my point of view was acknowledged by other course participants.

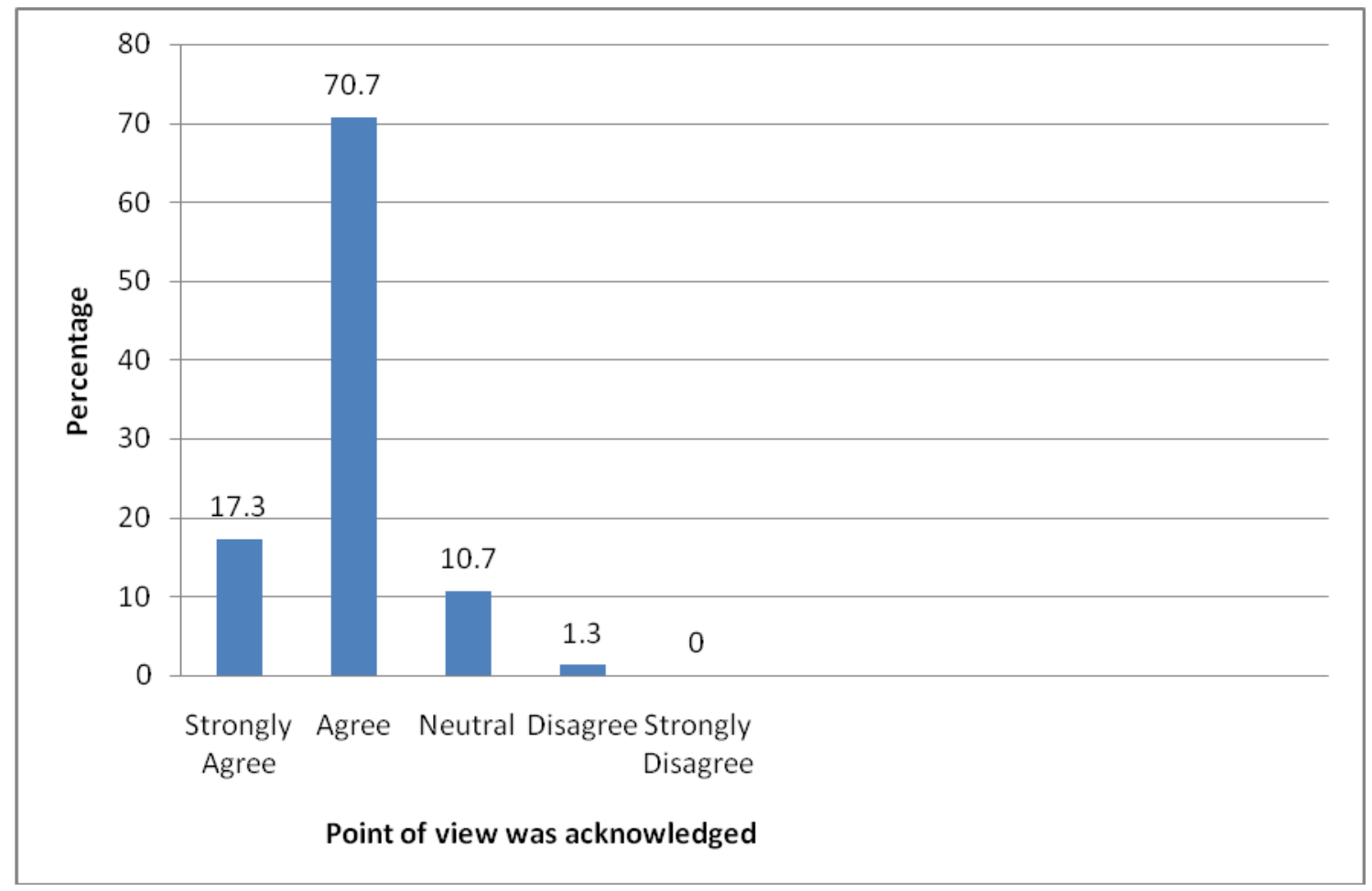

When asked to indicate whether online discussions helped them to develop a sense of collaboration, more than half of the respondents, 47 of the respondents or $61.8 \%$ agreed that they felt that online discussions helped them to develop a sense of collaboration, while $6.6 \%$ disagreed and 12 or $15.8 \%$ were neutral. Figure 13 presents the breakdown of these results.

Figure 13: Online discussions help me to develop a sense of collaboration. 


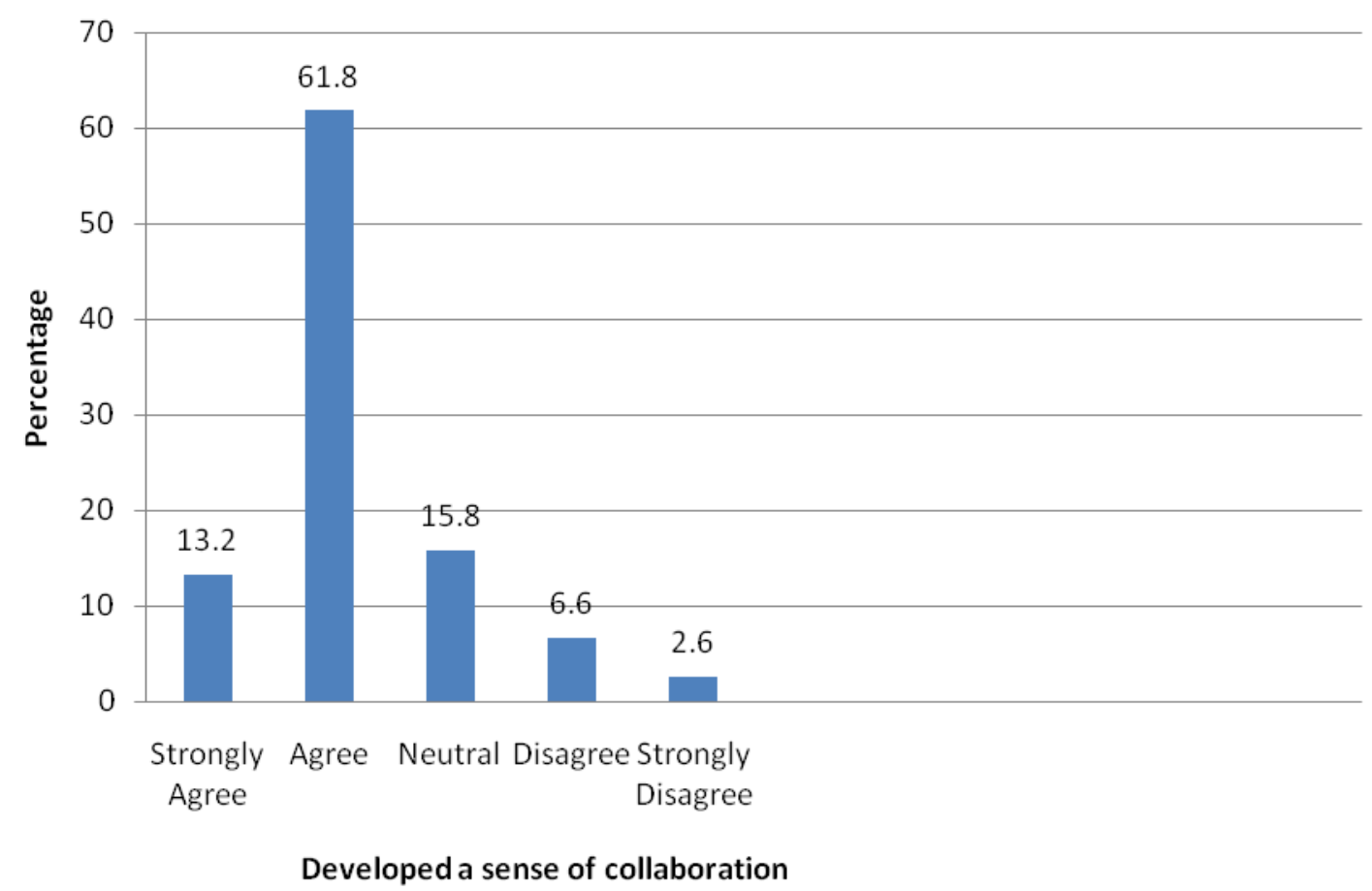




\section{Perceived Learning}

With regard to whether they learned to interrelate the important issues in the course material, slightly less than $70 \%$ of the respondents, agreed that they learned to interrelate the important issues in the course material, while $8.0 \%$ disagreed and 4 or $5.3 \%$ remained neutral. Figure 14 presents the breakdown of these results.

Figure 14: I learned to interrelate the important issues in the course material

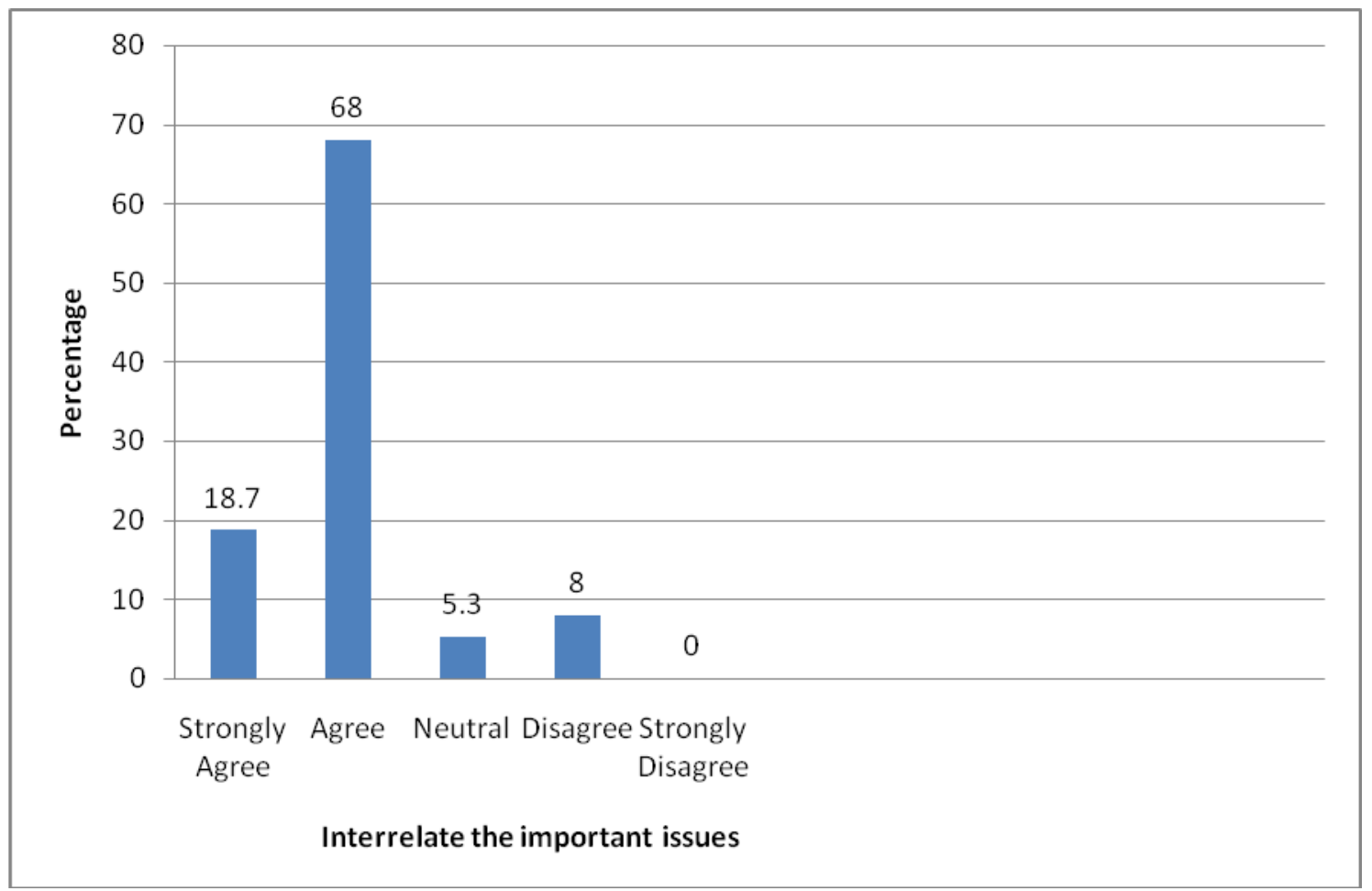

Concerning whether the respondents gained a good understanding of the basic concepts of the material, more than half of the respondents of the respondents, 52 of the respondents or $68.4 \%$ agreed that they gained a good understanding of the basic concepts of the material, while $5.3 \%$ disagreed and $2.6 \%$ remained neutral. Figure 15 presents the breakdown of these results. 
Figure 15: I gained a good understanding of the basic concepts of the material.

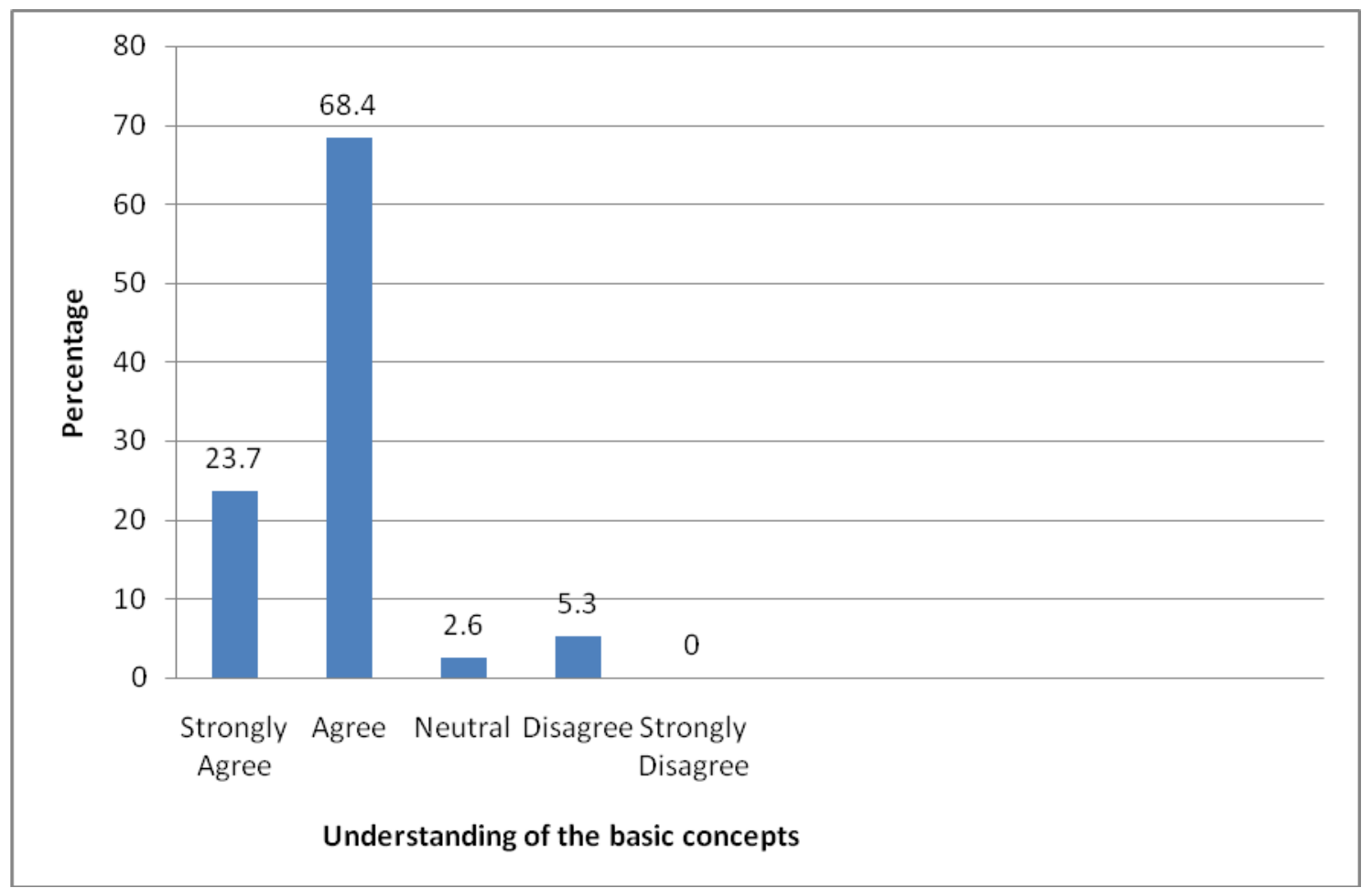

The results of whether the respondents learned to identify the central issues of the course, more than half, 44 of the respondents or (57.9\%) agreed that learned to identify the central issues of the course, while 4 (5.3\%) disagreed and 5.3\% remained neutral. Figure 16 presents the breakdown of these results. 
Figure 16: I learned to identify the central issues of the course.

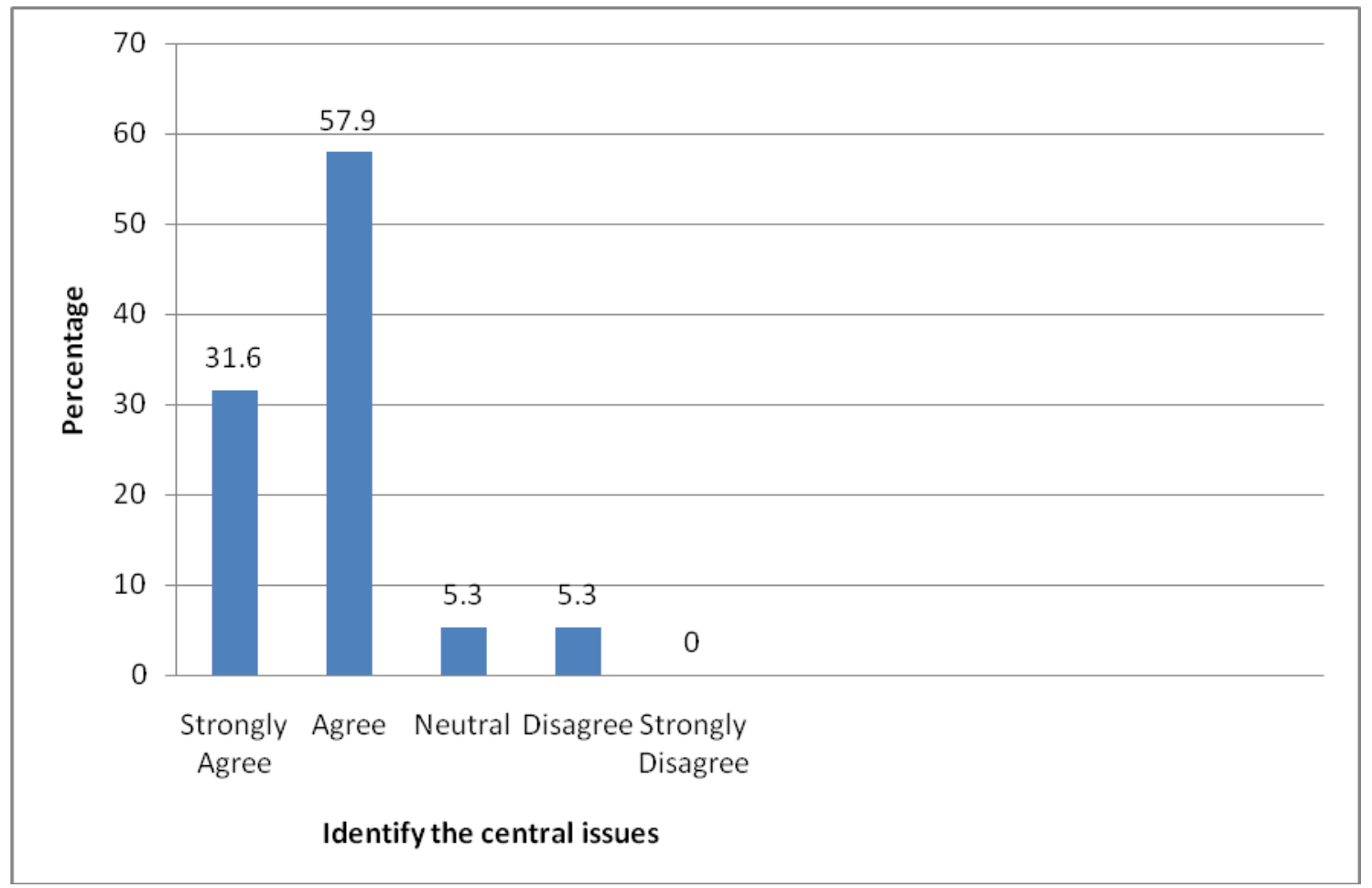

Pertaining to whether they developed the ability to communicate clearly about the subject, approximately $3 / 4$ of the respondents, agreed that they developed the ability to communicate clearly about the subject, while $5.3 \%$ disagreed and 6 or $7.9 \%$ were neutral. Figure 17 presents the breakdown of these results. 
Figure 17: I developed the ability to communicate clearly about the subject.

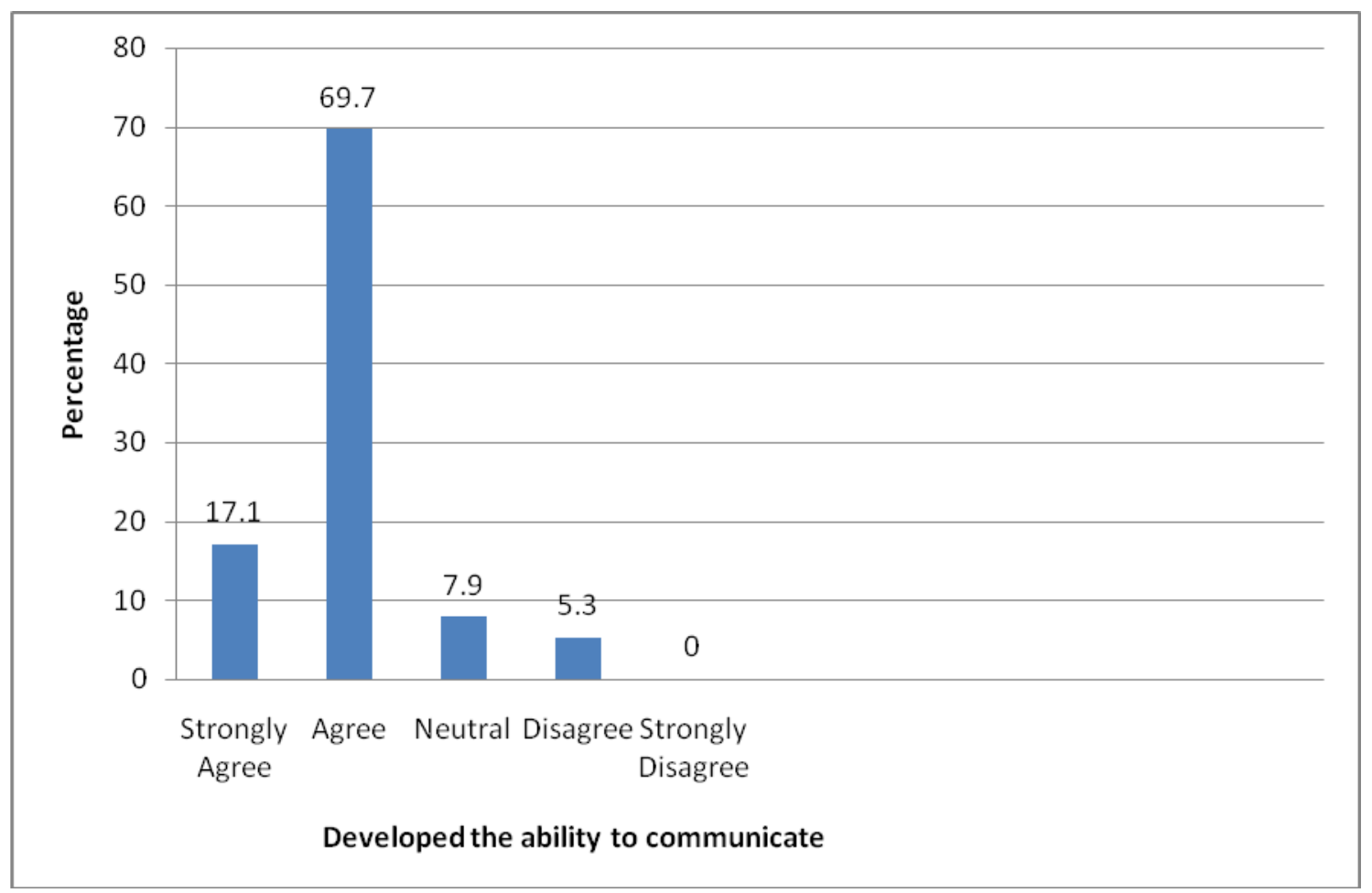

Most of the participants indicated that they improved their ability to integrate facts and develop generalizations from the course material. Specifically, 50 of the respondents or $65.8 \%$ agreed that they improved their ability to integrate facts and develop generalizations from the course material, while 3 disagreed and 6 or $7.9 \%$ were neutral. Figure 18 presents the breakdown of these results. 
Figure 18: I improved my ability to integrate facts and develop generalizations from the course material.

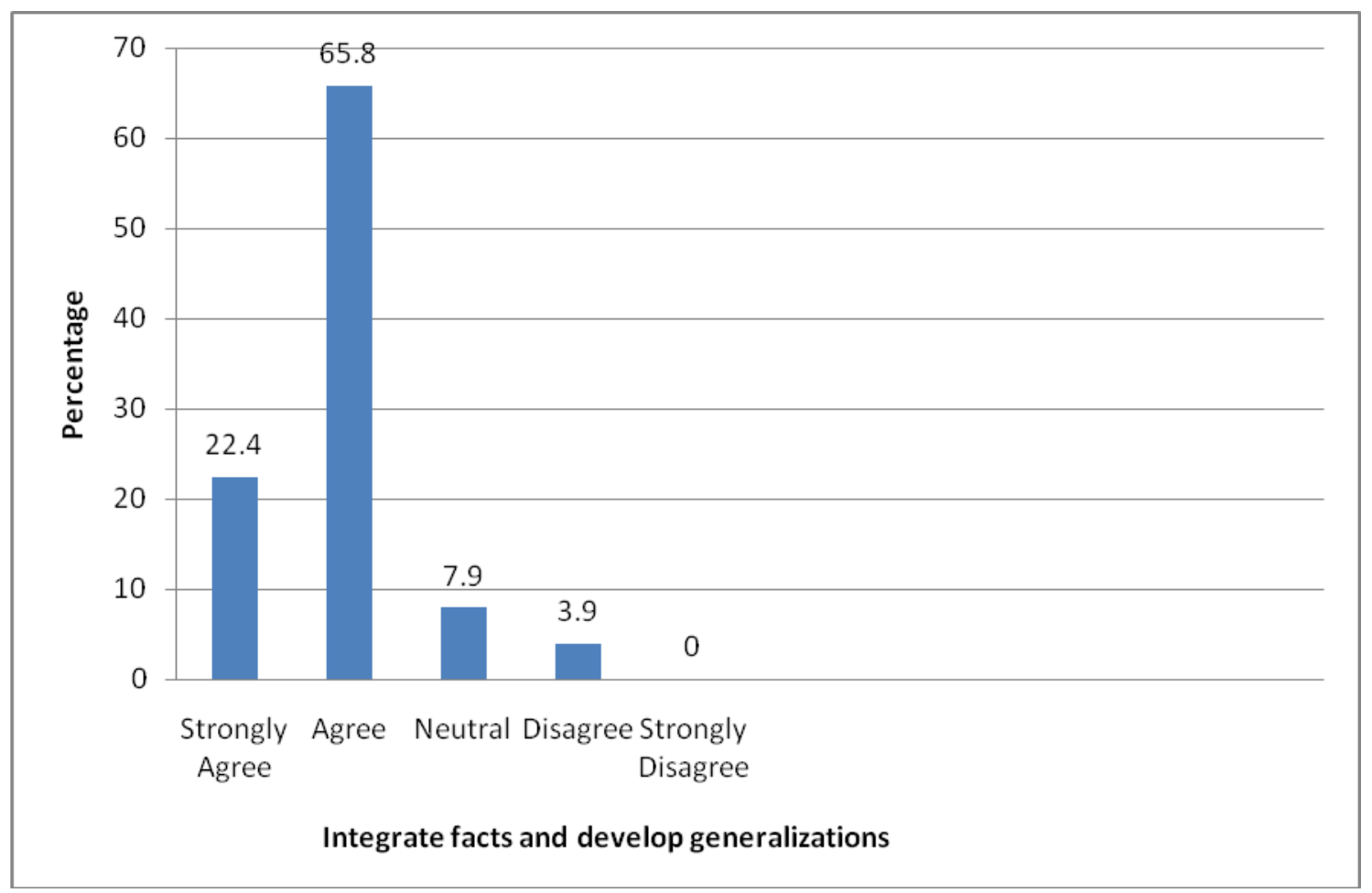

In regards to whether they learned concepts and principles in this course, the data showed that $63.2 \%$ of the participants indicated that they learned concepts and principles in this course, 1 respondent disagreed while 4 or $5.3 \%$ remained neutral. Figure 19 presents the breakdown of these results. 
Figure 19: I learned concepts and principles in this course.

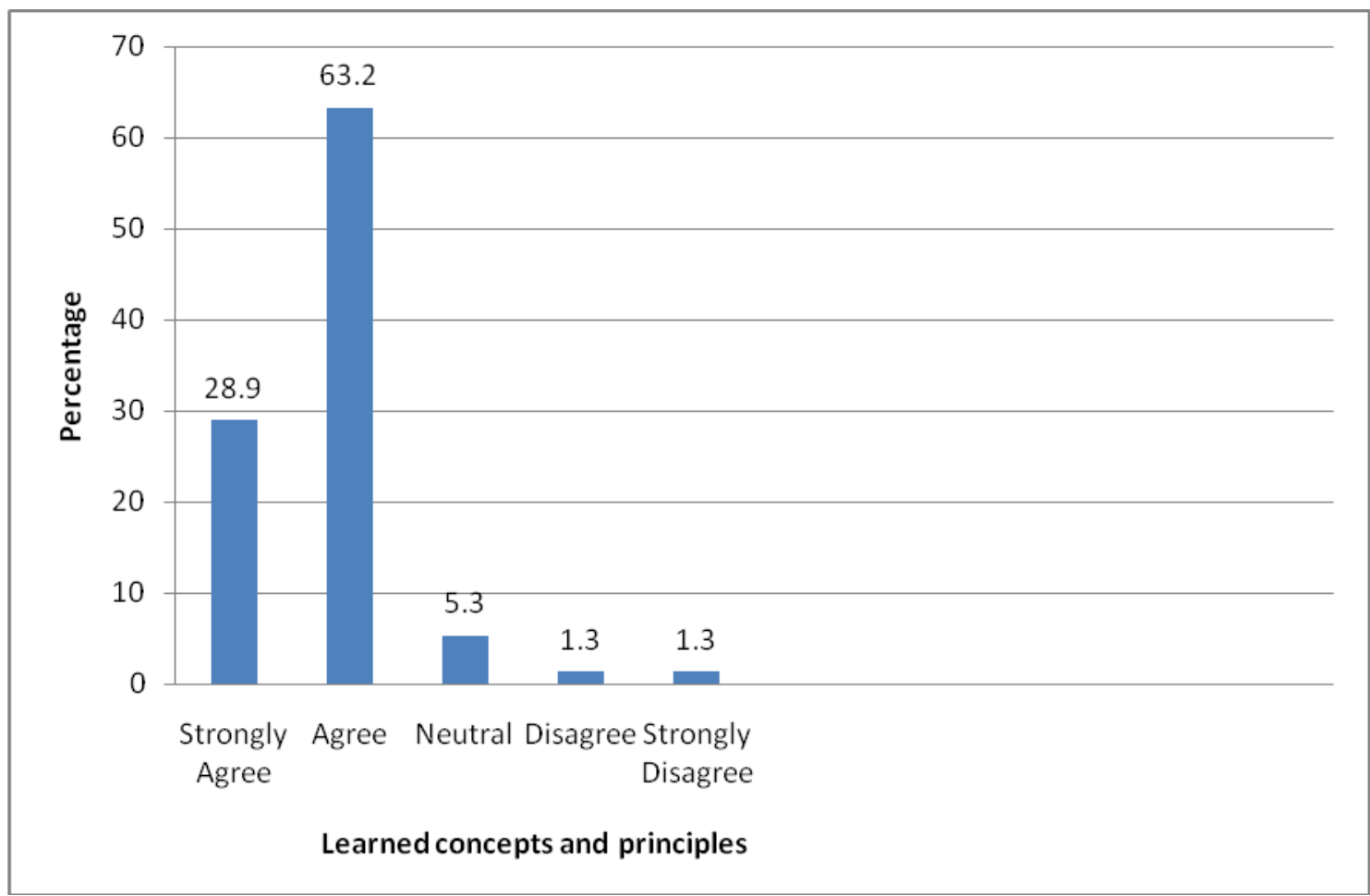




\section{Satisfaction}

When asked to indicate whether they were able to learn through the medium of CMC, slightly over 60 percent of the respondents agreed they were able to learn through the medium of CMC, while only one 1 student disagreed while 12 students were neutral. Figure 20 presents the breakdown of these results.

Figure 20: I was able to learn through the medium of CMC.

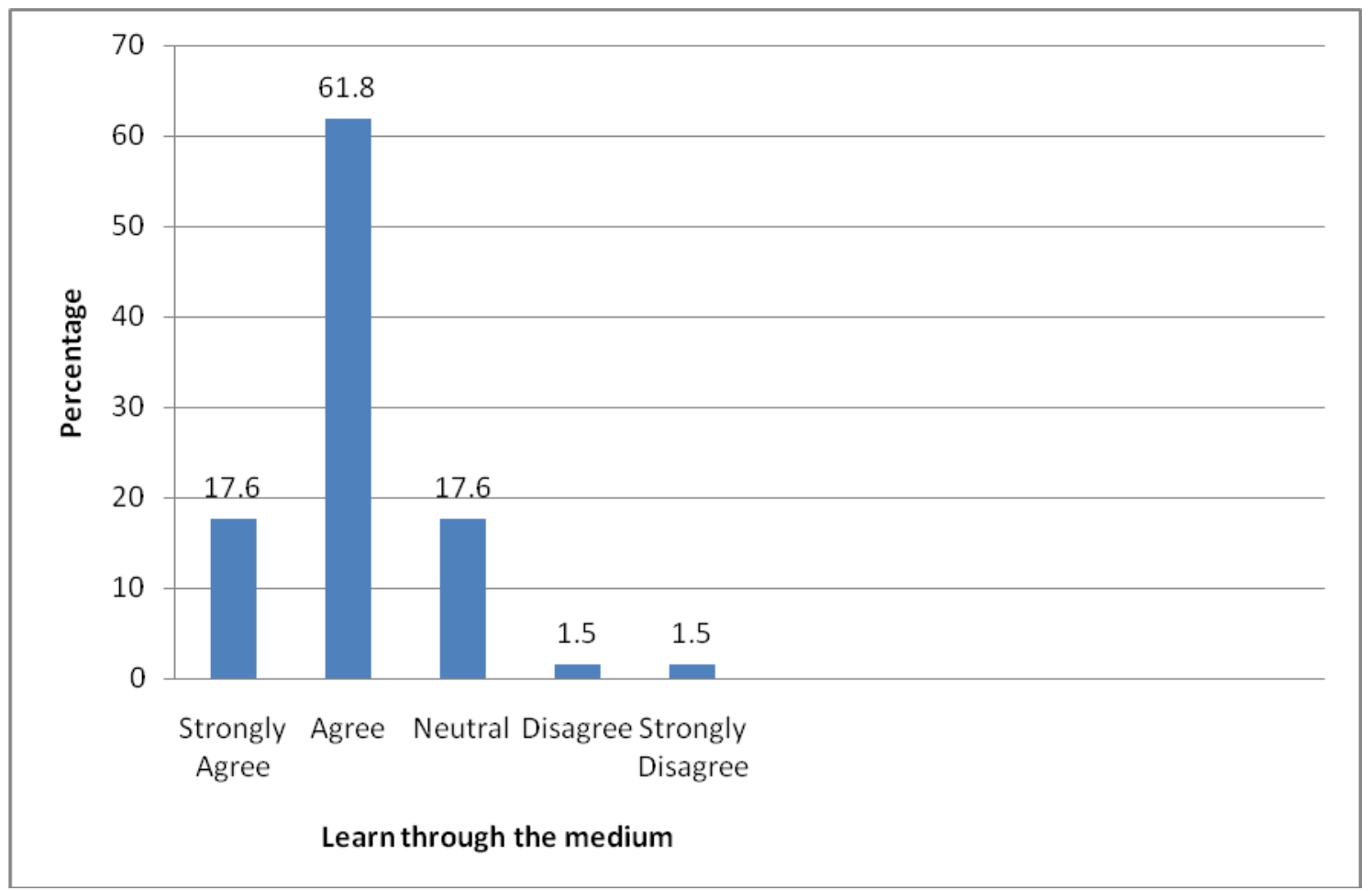

With respect to whether they were able to learn from the online discussions, a lot of the respondents, more than half of the participants agreed they were able to learn from the online discussions, while $2.8 \%$ disagreed and 6 or $8.5 \%$ remained neutral. Figure 21 presents the breakdown of these results. 
Figure 21: I was able to learn from the online discussions.

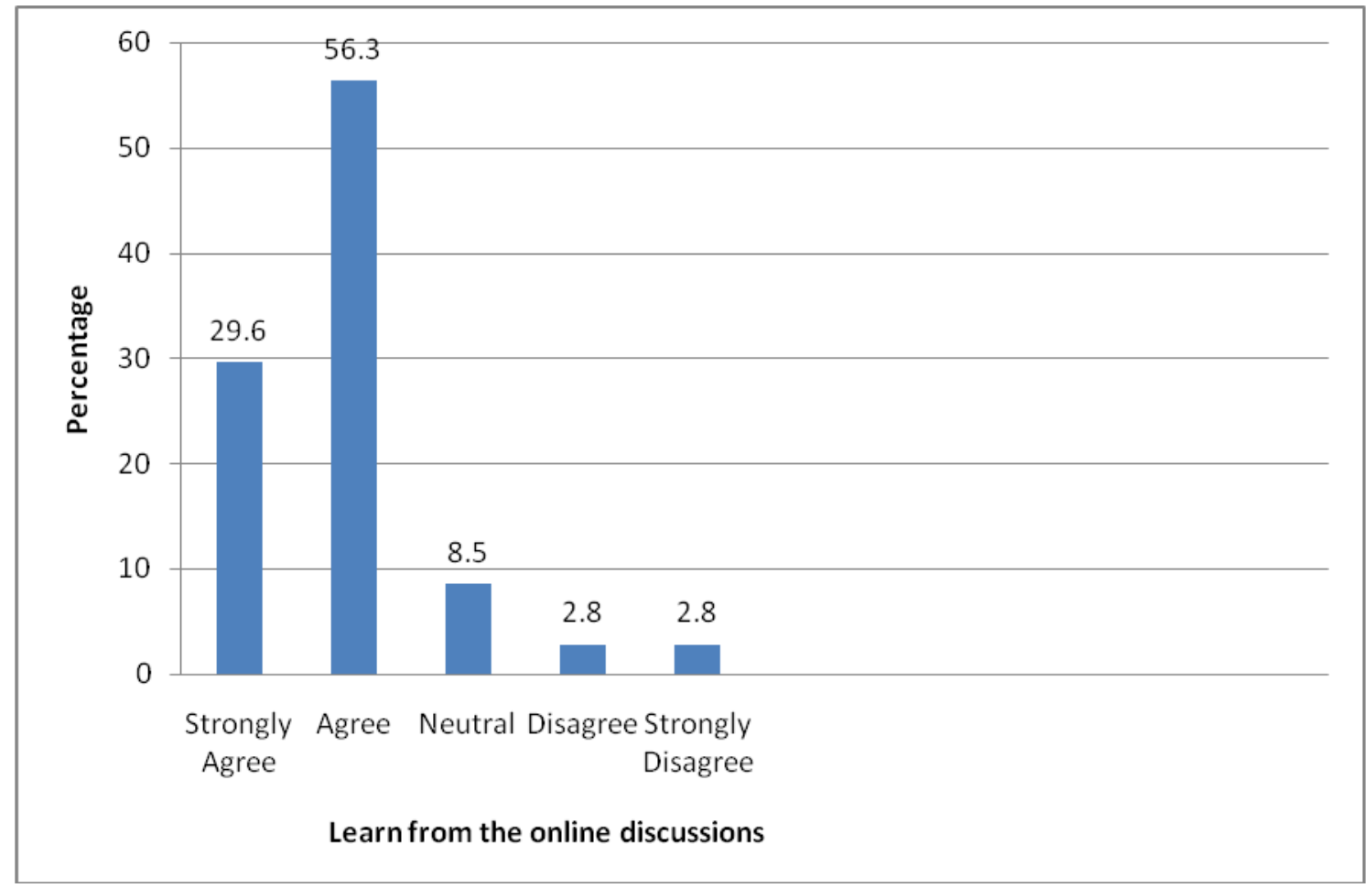

Pertaining to whether they felt motivated to explore content related questions, just over 60 percent of the respondents agreed that they felt motivated to explore content related questions, while $5.7 \%$ disagreed and 11 or $14.3 \%$ were neutral. Figure 22 presents the breakdown of these results. 
Figure 22: I felt motivated to explore content related questions.

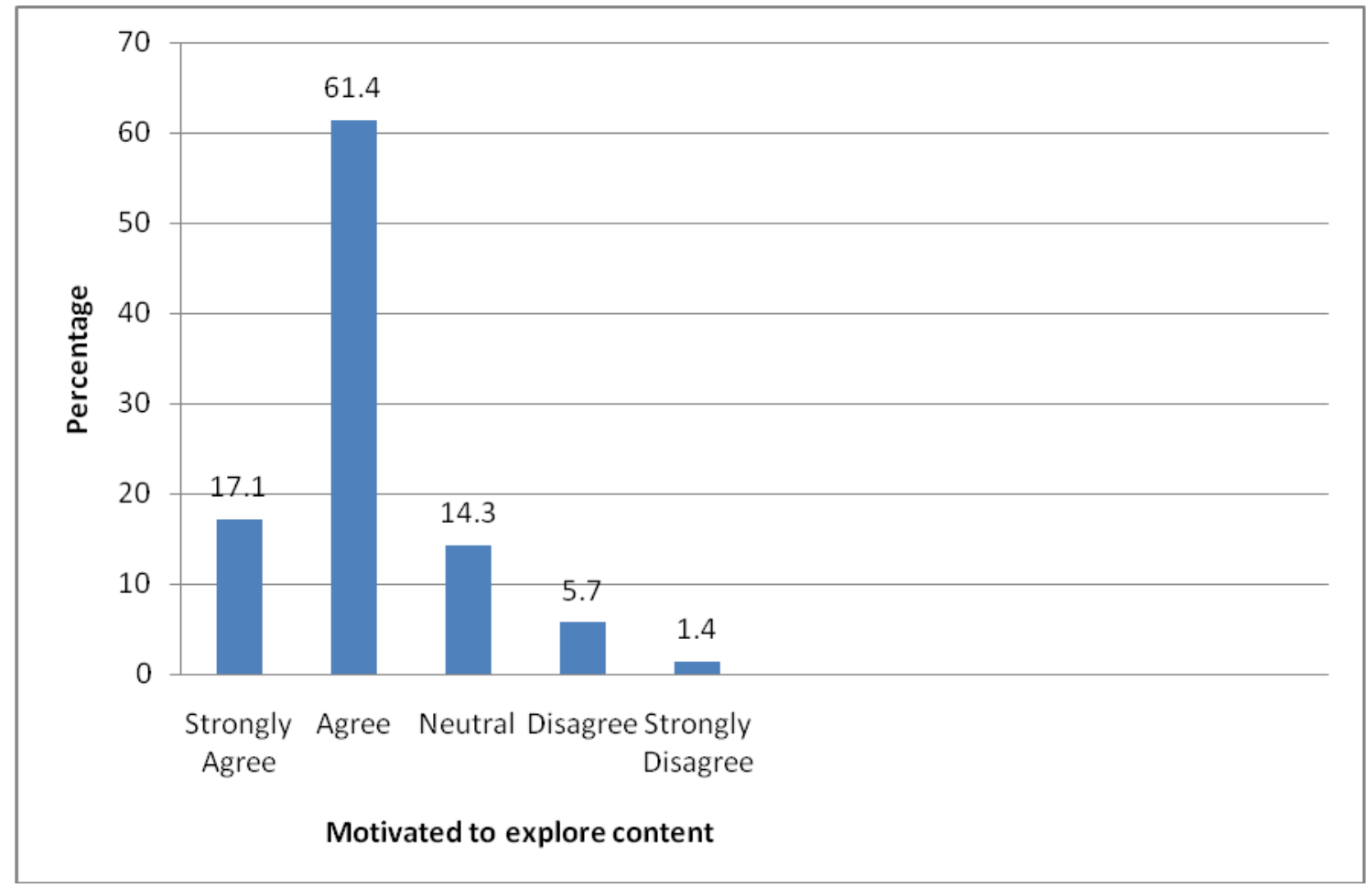

When asked to indicate whether they utilized a variety of information sources to explore problems posed in this course, a total of 49 of the respondents or $71 \%$ of the participants agreed that they utilized a variety of information sources to explore problems posed in this course, while $1(1.4 \%)$ disagreed and $6(8.7 \%)$ were neutral. Figure 23 presents the breakdown of these results. 
Figure 23: I utilized a variety of information sources to explore problems posed in this course.

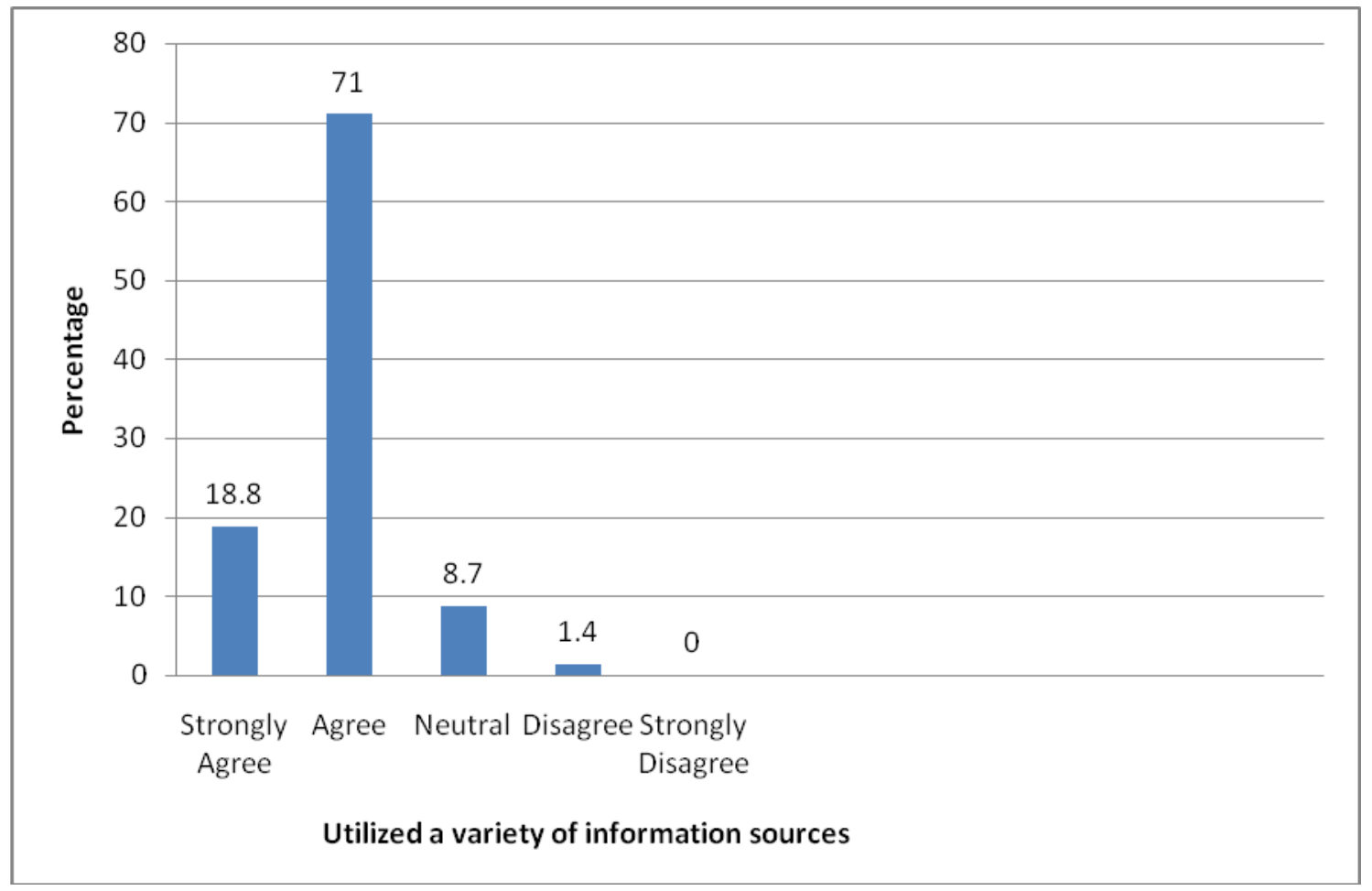

On the subject of whether they were stimulated to do additional reading or research on topics discussed in the online special education course, just over 50 percent of the respondents agreed that they were stimulated to do additional reading or research on topics discussed in the online special education course, while $8.5 \%$ disagreed and 10 or $14.1 \%$ remained neutral. Figure 24 presents the breakdown of these results. 
Figure 24: I was stimulated to do additional reading or research on topics discussed in the online special education course.

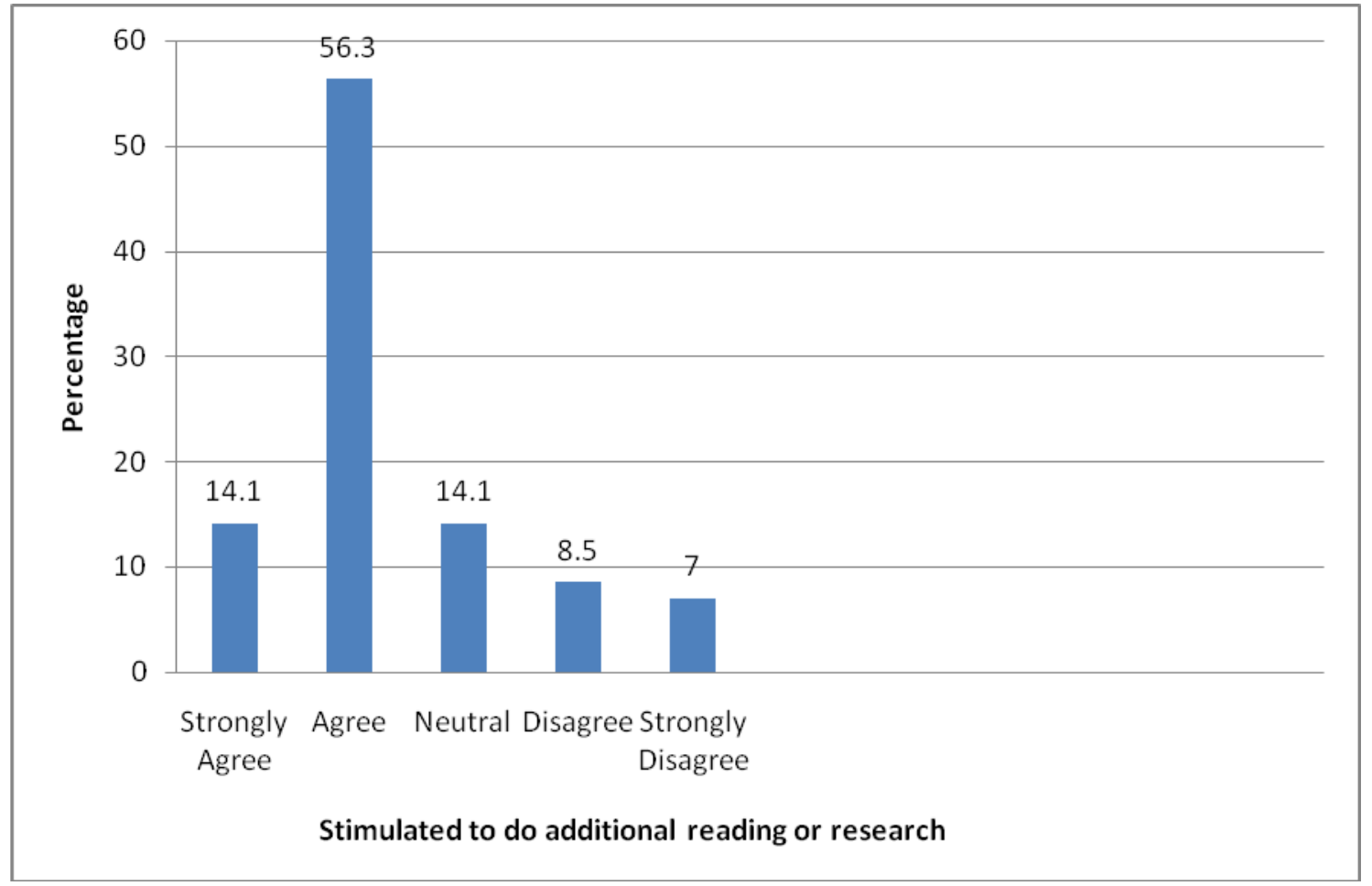

With regards to whether they learned to value other points of view, more than half of the participants agreed that they learned to value other points of view; while 1 respondent disagreed while 13 or $18.3 \%$ remained neutral. Figure 25 presents the breakdown of these results. 
Figure 25: I learned to value other points of view.

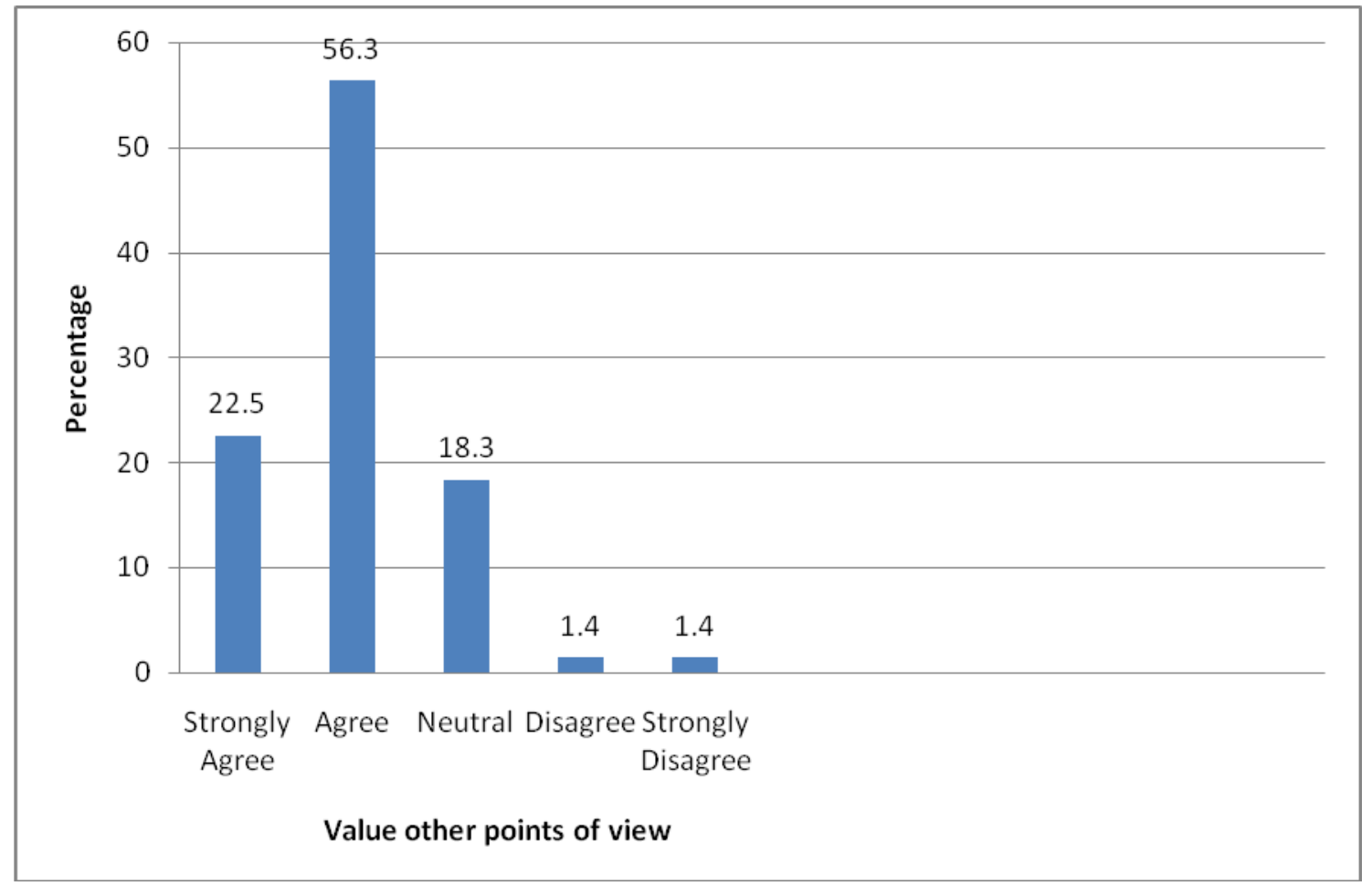

With respect to whether based on their experience with the online special education course, if they would like to participate in another online course in the future, nearly $60 \%$ agreed that they would like to participate in another online course in the future, while $2.8 \%$ disagreed and 7 or $9.9 \%$ remained neutral. Figure 26 presents the breakdown of these results. 
Figure 26: As a result of my experience with the online special education course, I would like to participate in another online course in the future.

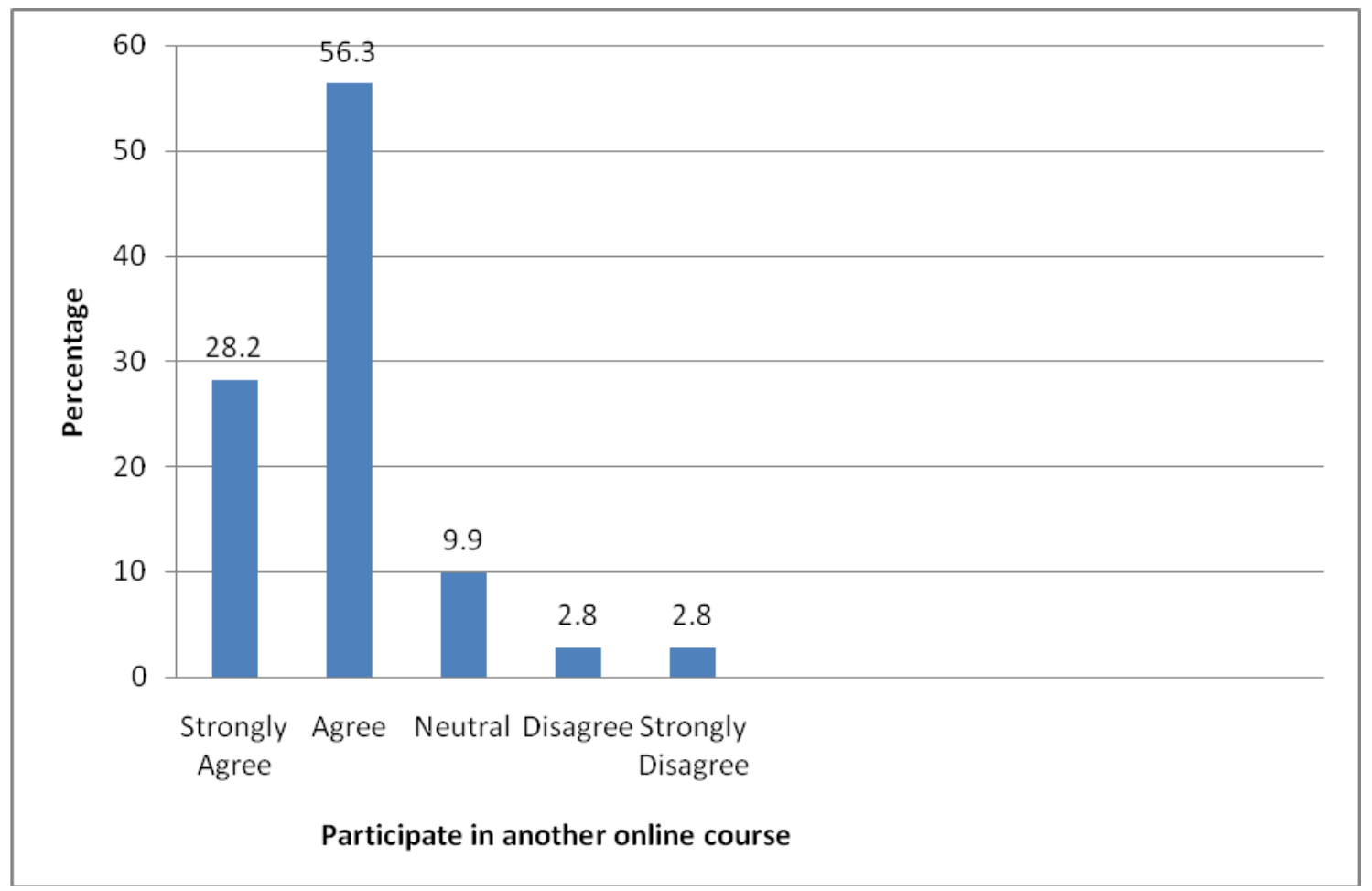

On the subject of whether the online course was a useful learning experience, a total of 42 of the respondents or $60 \%$ respondents agreed that the online course was a useful learning experience, while $4.3 \%$ disagreed and 2 or $2.9 \%$ were neutral. Figure 27 presents the breakdown of these results. 
Figure 27: The online course was a useful learning experience.

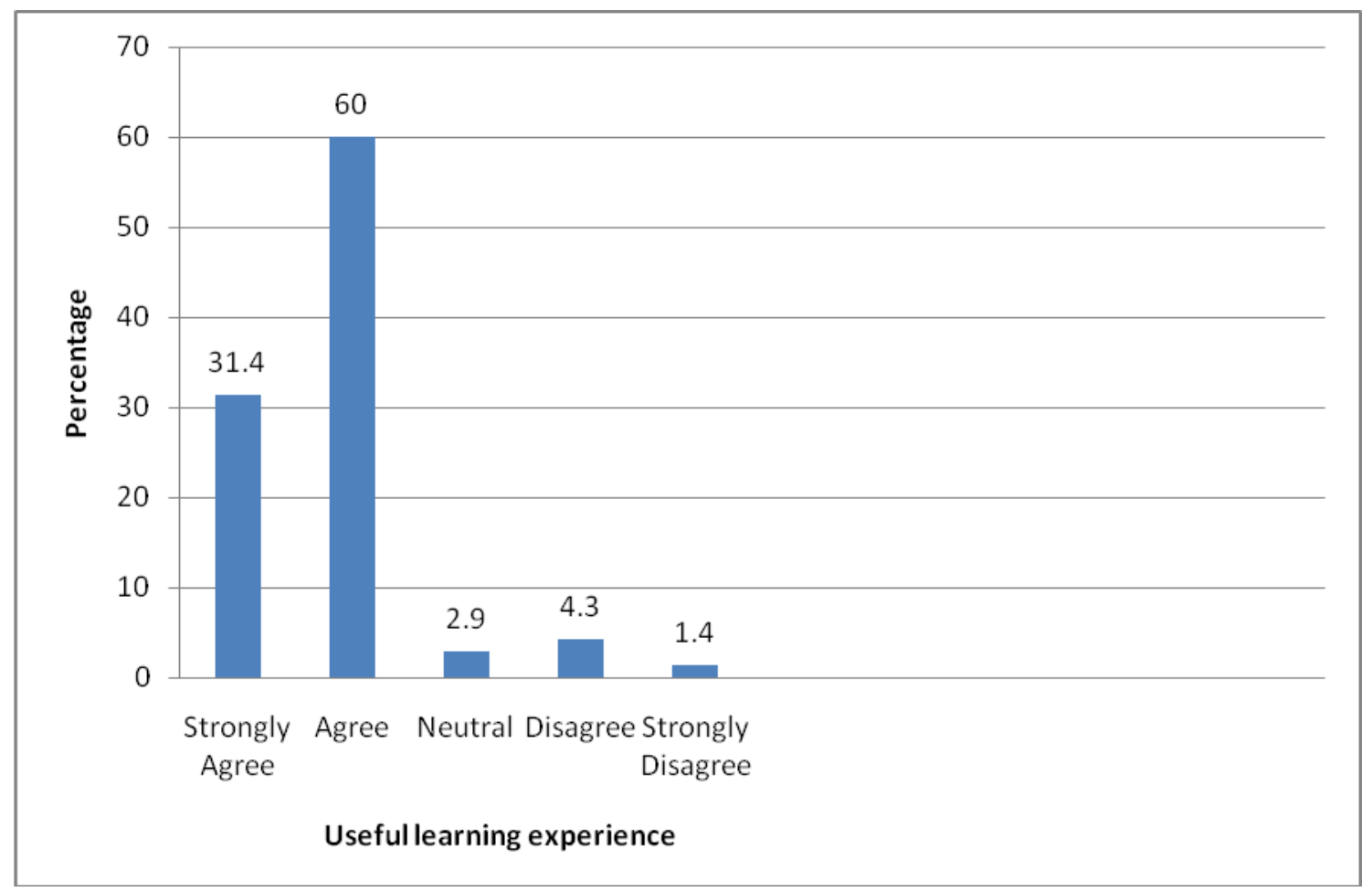

When asked to indicate whether based on their participation in the online course, they made acquaintances electronically in other parts of the country/world, it should be noted that slightly over $40 \%$ of the respondents agreed that based on their participation in the online course, they made acquaintances electronically in other parts of the country/world, while $23.9 \%$ disagreed and 11 or $15.5 \%$ remained neutral. Figure 28 presents the breakdown of these results. 
Figure 28: As a result of my participation in the online course, I made acquaintances electronically in other parts of the country/world.

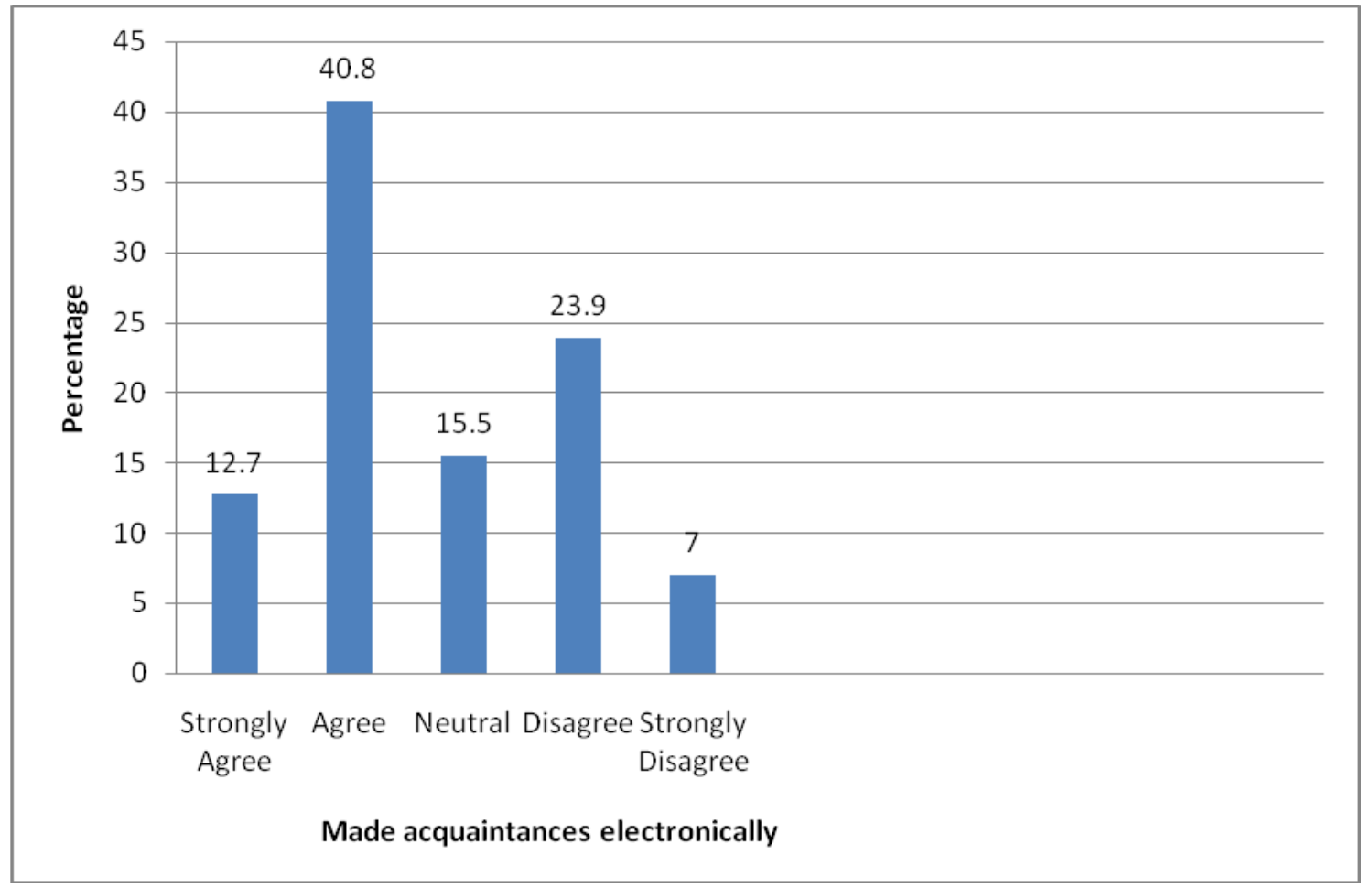

Regarding to whether the diversity of topics in the online course prompted them to participate in the discussions, over half of the participants agreed that diversity of topics in the online course prompted them to participate in the discussions, while $9.9 \%$ disagreed and 10 or $14.1 \%$ were neutral. Figure 29 presents the breakdown of these results. 
Figure 29: The diversity of topics in the online course prompted me to participate in the discussions.

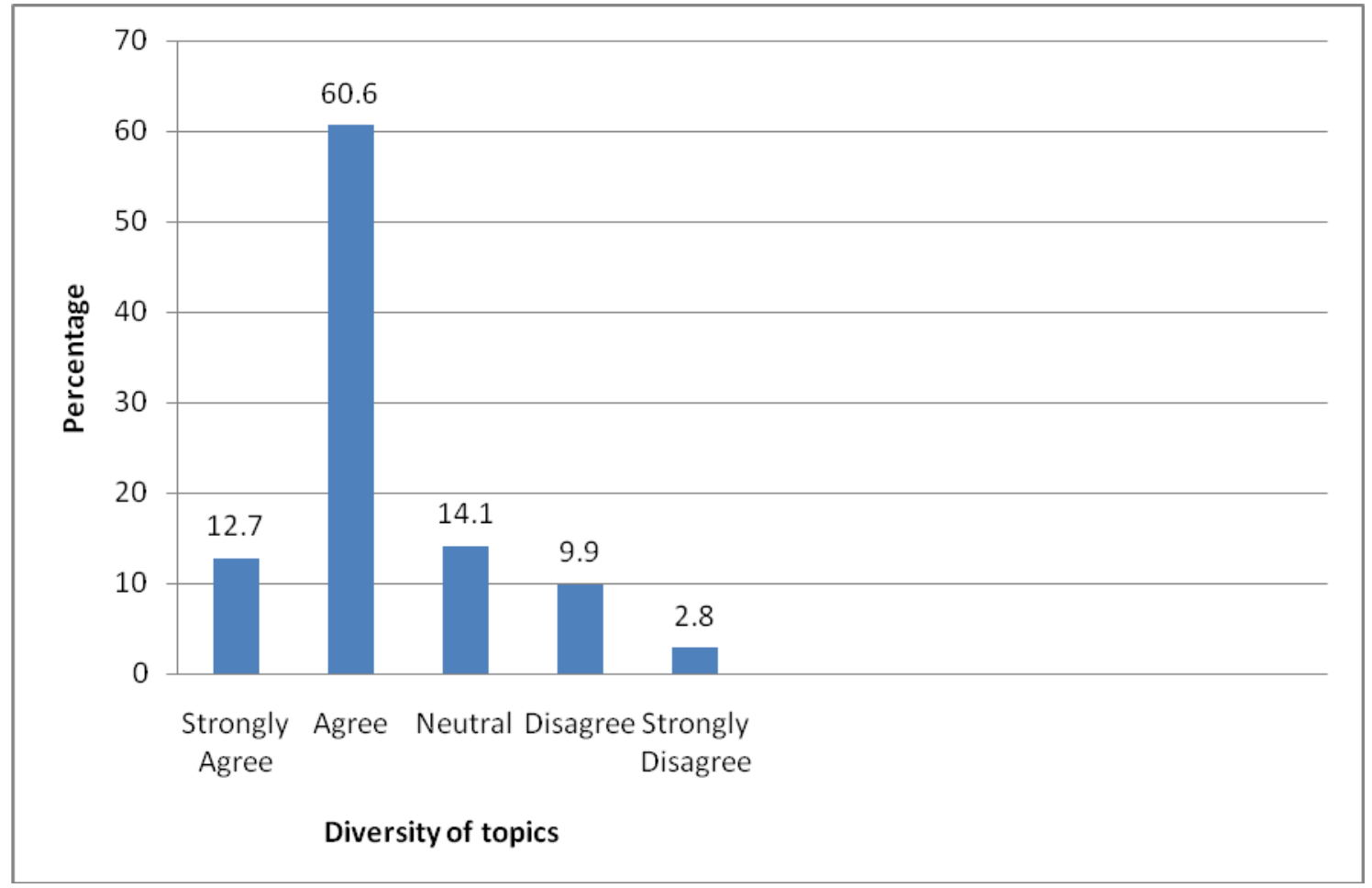

On the subject of whether they put a great deal of effort to learn the $\mathrm{CMC}$ system to participate in the online course, slightly over 40 percent of the respondents agreed that they put a great deal of effort to learn the CMC system to participate in the online course, while $11.3 \%$ disagreed and 17 or $23.9 \%$ remained neutral. Figure 30 presents the breakdown of these results. 
Figure 30: I put a great deal of effort to learn the CMC system to participate in the online course.

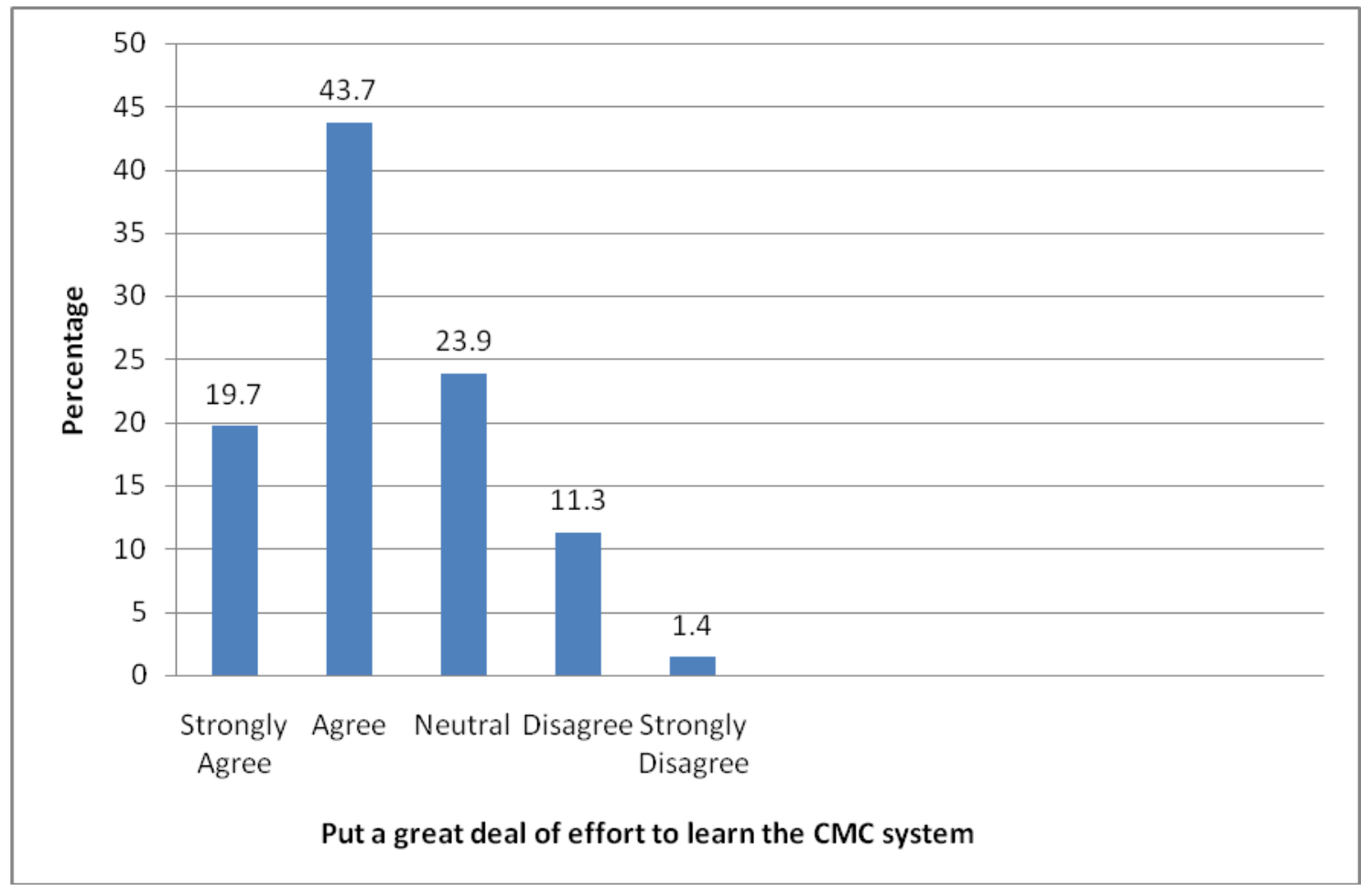

When asked to indicate what specific grade (before they began this course) did they expect to earn upon completion of the course, 62 of the respondents or $76.5 \%$ indicated that they expected to receive an $A$ grade, while 10 of the respondents or $12.3 \%$ indicated that they expected to receive a $B$ grade. Only one of the respondents indicated that they expected to receive a Pass. None of the students expected to earn a C, D, F, Fail or Incomplete. When asked what final grade they anticipated to receive in this course based on their performance thus far, 60 of the respondents or $74.1 \%$ indicated that they expected to receive an $A$ grade, while 12 of the respondents or $14.8 \%$ indicated that they expected to receive a $B$ grade. Only one student indicated that they expected to receive a Pass. None of the students expected to earn a C, D, F, Fail or Incomplete. 8 respondents skipped this question. 
When asked to rate the importance of welcome messages in this course, more than $50 \%$ of the participants indicated that it was an important tool, whereas $7.1 \%$ indicated that it was an unimportant tool, while 11 of the respondents or $15.7 \%$ did not use the tool. Figure 31 presents the breakdown of these results.

\section{Interactive Elements}

Figure 31: Welcome messages

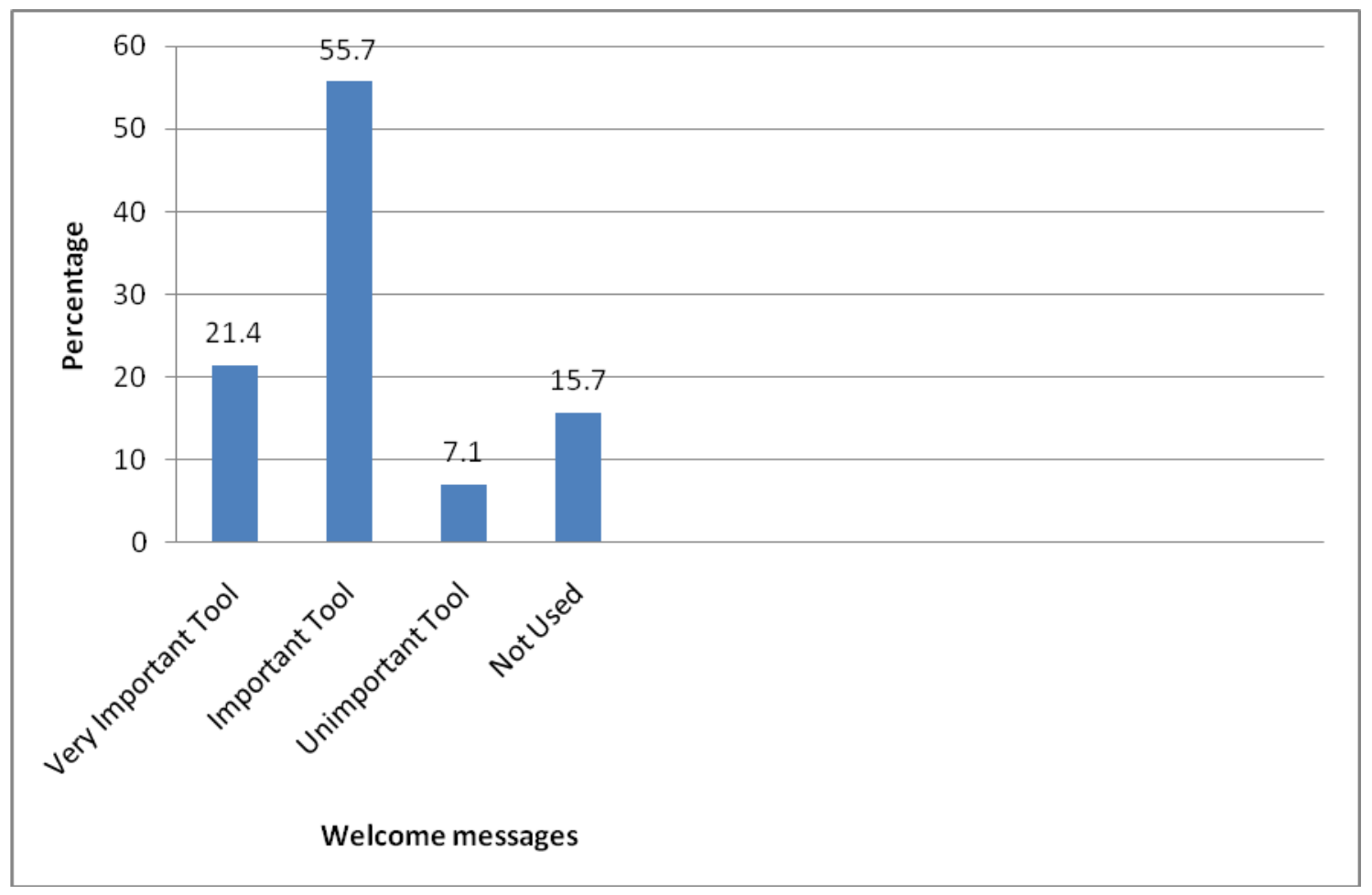

When asked to rate the importance of ice-breaker conversation piece in this course, many of the respondents, $33.8 \%$ of the participants indicated that it was an important tool, whereas 13 of the respondents or $18.3 \%$ indicated that it was an unimportant tool, while 23 of the respondents or $32.4 \%$ did not use the tool. Figure 32 presents the breakdown of these results. 
Figure 32: Ice-breaker

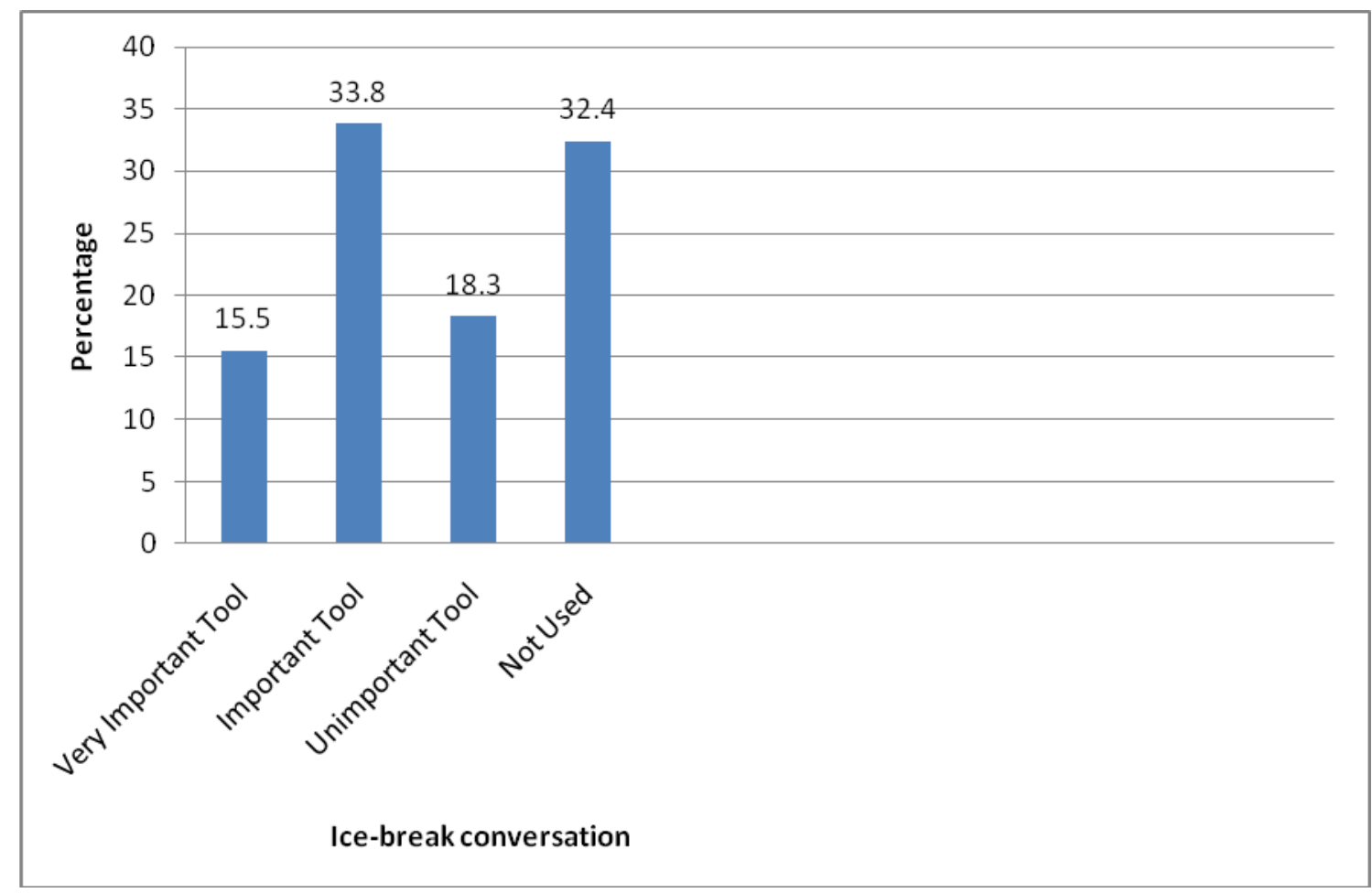

The participant ratings on the importance of student profiles and biographies in this course indicated that just over $50 \%$ of the respondents thought it was an important tool, while $22.9 \%$ indicated that it was an unimportant tool, while 5 respondents did not use the tool. Figure 33 presents the breakdown of these results. 
Figure 33: Student profiles and biographies

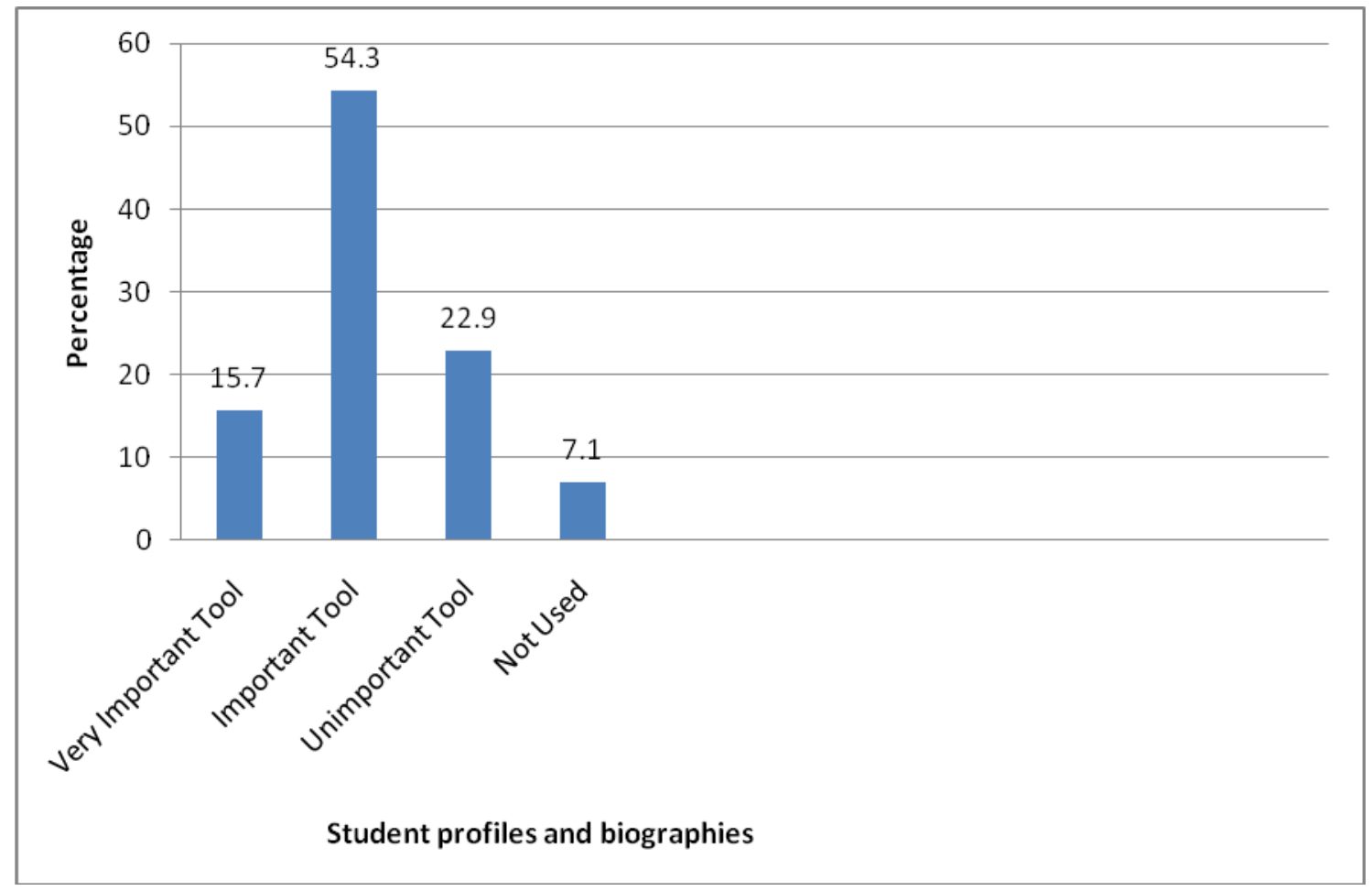

Approximately $3 / 4$ of the participants indicated that it was important to address other students' using their names in this course, while 6 of the respondents or $8.2 \%$ indicated that it was an unimportant tool. Only one participant did not use the tool. Figure 34 presents the breakdown of these results. 
Figure 34: Addressing students' using their names

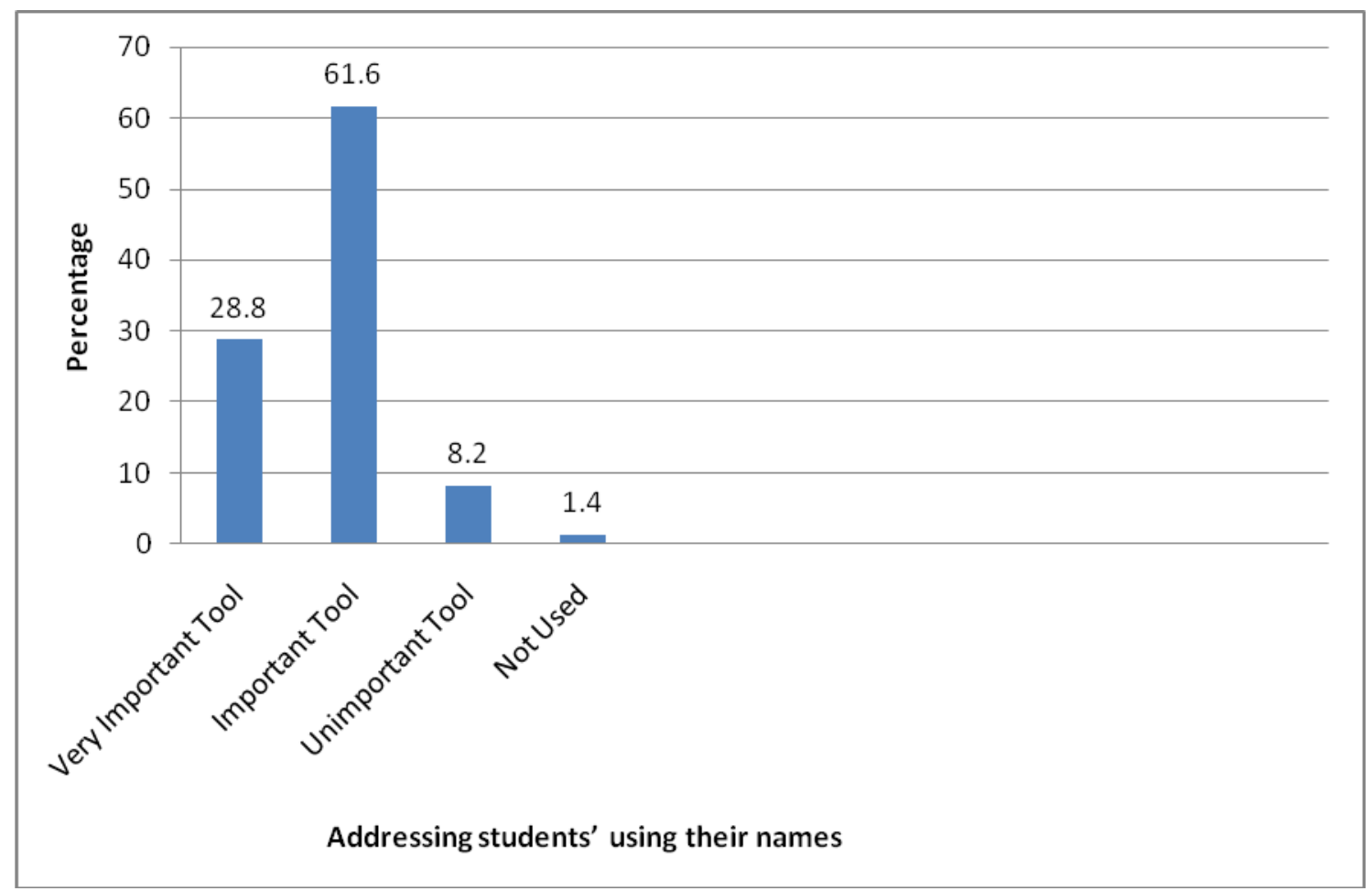

According to $38 \%$ of the participants, they found a social area in the discussion board (Sandbox) in this course, to be an important tool, while $18.3 \%$ indicated that it was an unimportant tool, while 18 of the respondents or $25.4 \%$ did not use the tool. Figure 35 presents the breakdown of these results. 
Figure 35: Social area in the discussion board (Sandbox)

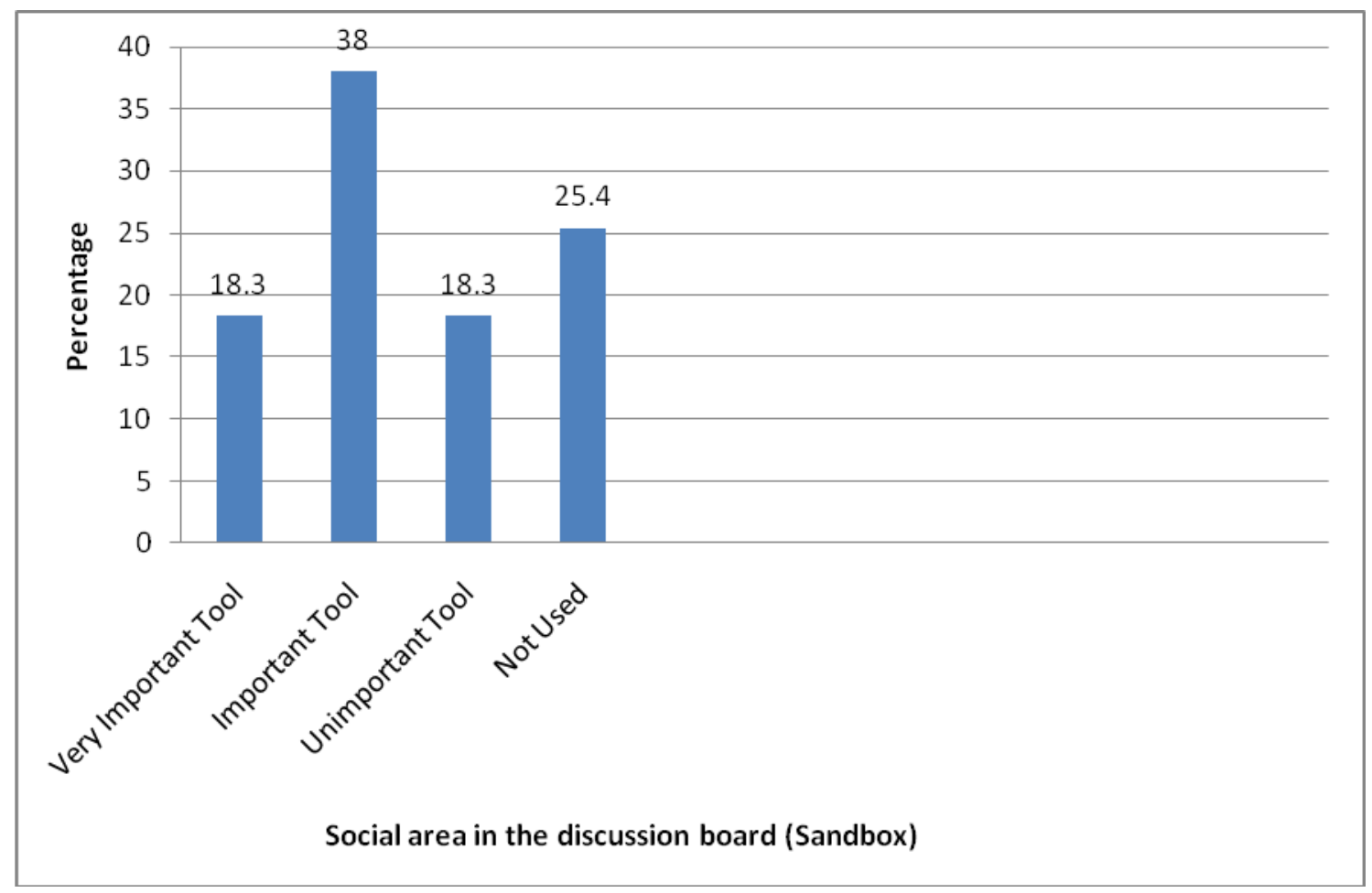

When asked to rate the importance of audio in this course, approximately two-thirds of the respondents indicated that the audio was important. Only around 5\% indicated that it was an unimportant tool. Only 1 student did not use the tool. Figure 36 presents the breakdown of these results. 
Figure 36: Audio

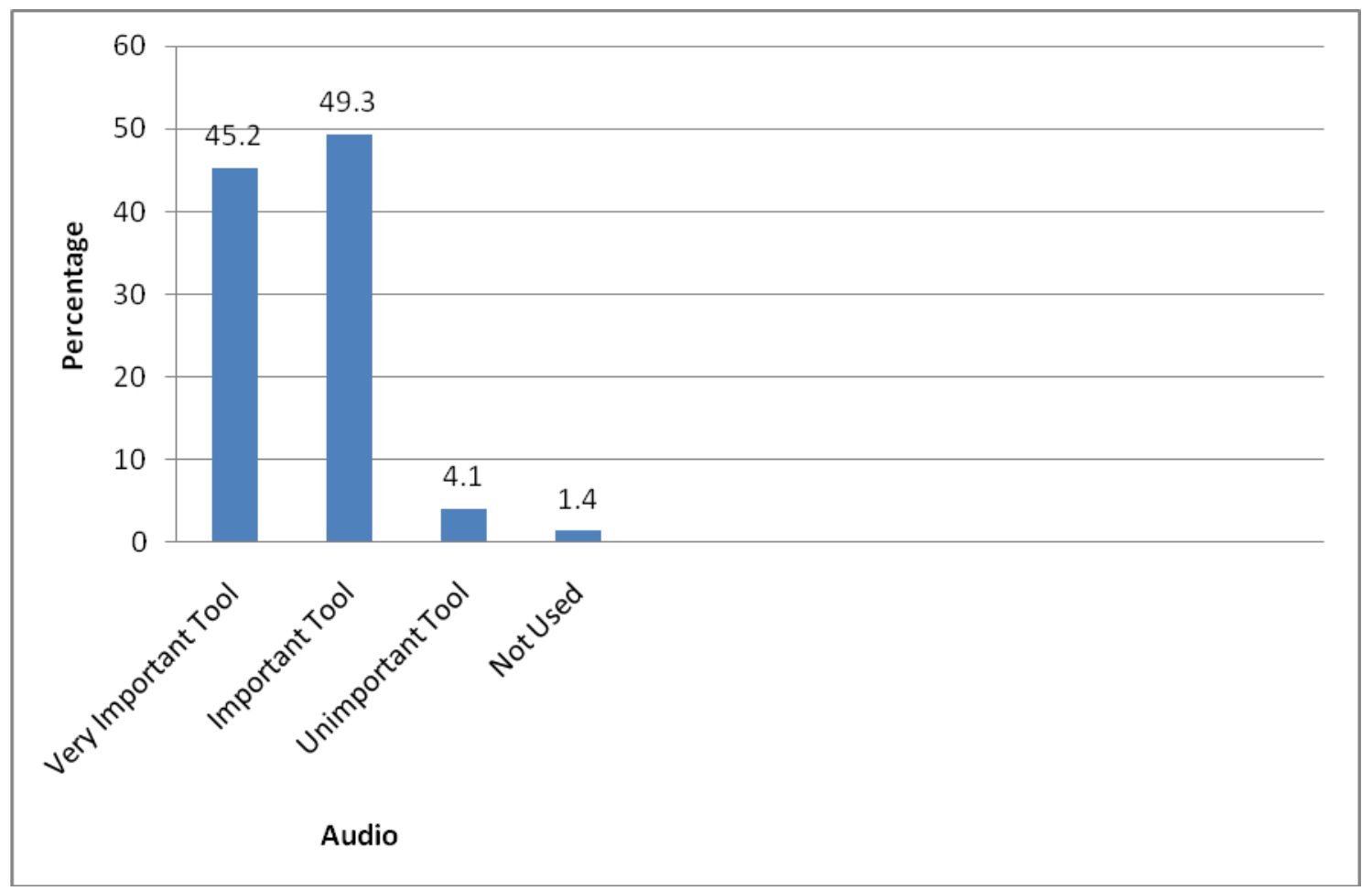

Rating indications on the importance of video in this course showed that slightly over $28 \%$ of the participants indicated that it was an important tool, while $11 \%$ indicated that it was an unimportant tool, while 17 of the respondents or $23.3 \%$ did not use the tool. Figure 37 presents the breakdown of these results. 
Figure 37: Video using Wimba

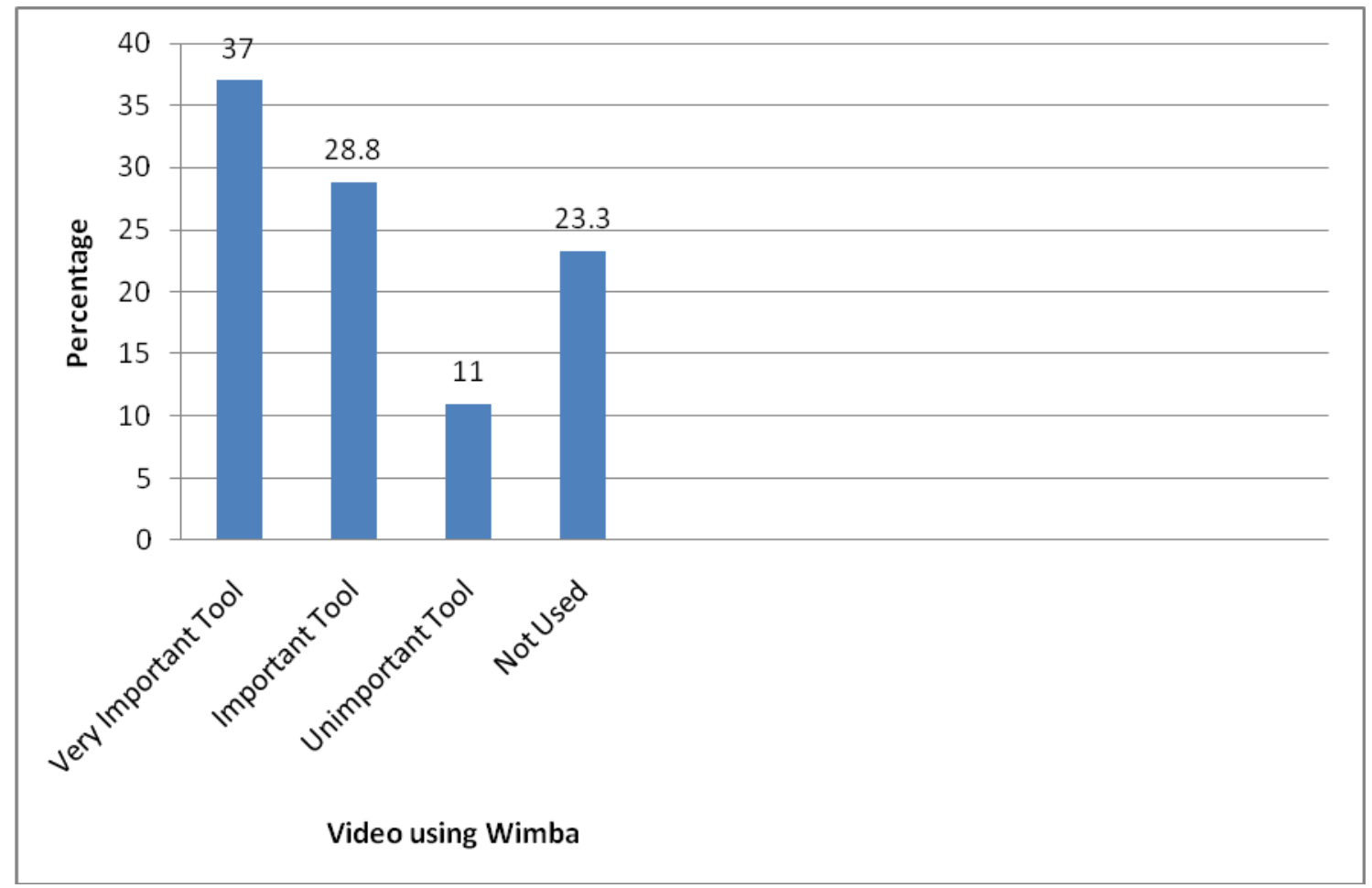

Based on the survey rating on the importance of using the chat feature in this course, close to half of the respondents indicated that it was an important tool, while 2 of the respondents indicated that it was an unimportant tool while 8 of the respondents did not use the tool. Figure 38 presents the breakdown of these results. 
Figure 38: Use of text-based chat

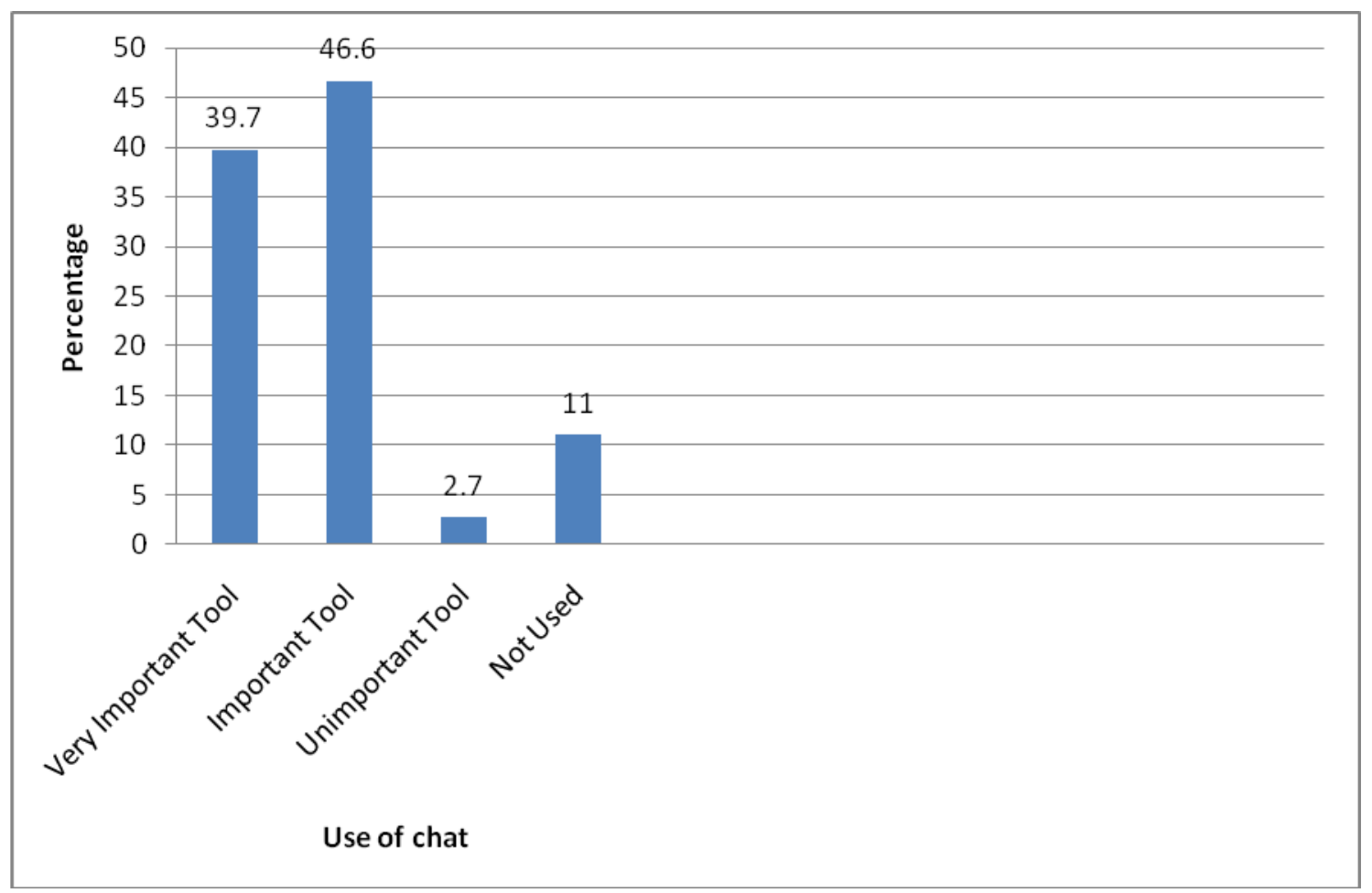

\section{Research Question One}

A standard multiple regression analysis was performed between the dependent variable (perceived learning) and the independent variable (the number of interactive elements and social presence). Analysis was performed using SPSS Regression. Regression will be best when each independent variable is strongly correlated with the dependent variable but uncorrelated with other independent variables. Table 5 displays that a simple correlation of $R=0.759$ (The correlation between the dependent variable and independent variables) with the two predictors, the number of interactive elements and social presence accounting for $56 \%$ of variance in perceived learning represented by Adjusted $R^{2}=0.563$. The Adjusted R Square indicated the proportion of variance in the dependent variable 
explained by the independent variable. This model shows that the difference between the Adjusted $R^{2}$ and $R^{2}$ is $.576-.563=.013$, about $1.3 \%$. The impact of $R^{2}$ is tested using an $F$ ratio. In this model, $R^{2}$ changed from zero to .576 . Due to the change in the amount of variance, there was a rise in an F-ratio of 44.110 which is significant with a probability less than $.001(p<.001)$.

Analysis of variance (ANOVA) was also performed on the data to show whether the regression equation was significant. If the Sig value is $<0.05$, then it means there is a significant regression equation. As shown in Table 6, the Sig value of .000 illustrated the regression equation was significant and we can reject the null hypothesis $(\mathrm{H} 0)$. According to the results there is a statistically significant regression model when trying to predict student's perceived learning from a combination of their social presence score and number of interactive elements in the course. In other words, this meant that when looking at the entire regression, there was a positive correlation between perceived learning and the two independent variables (number of interactive elements and social presence). In other words, this meant that when looking at the entire regression, social presence had a greater than chance relationship with how students perceived learning.

The next section of the model results was the coefficients. The $b$-values demonstrate the relationship between perceived learning and each predictor. A positive value indicates that there is a positive relationship between the outcome and the predictor whereas if the coefficient was negative, the relationship will be negative as well. The $b$-values demonstrate the degree to which each predictor affects the outcome as long as all other predictors are constant. From Table 5, social presence $(b=.820)$ had a positive relationship with perceived learning. The number of interactive elements $(b=-.008)$ had a negative relationship with 
perceived learning. So what this means is that social presence was significantly related to how the students perceived their learning and interactive elements were not significantly related to how the students perceived their learning. The standard error values show to what degree these values differ from each sample and whether the standard errors can be used to establish whether the $b$-value differs considerably from zero. For this model, social presence $(t(65)=9.089, \mathrm{p}<.001)$ was a significant predictor of perceived learning whereas the number of interactive elements $(t(65)=-.229, \mathrm{p}<.001)$ was not a significant predictor of the perceived learning.

Table 5 Perceived Learning

Model Summary

\begin{tabular}{rrrrr}
\hline \hline Model & $\mathrm{R}$ & $\mathrm{R}$ Square & $\begin{array}{r}\text { Adjusted R } \\
\text { Square }\end{array}$ & $\begin{array}{r}\text { Std. Error of the } \\
\text { Estimate }\end{array}$ \\
\hline & & & & .42976 \\
\hline
\end{tabular}

a. Predictors: (Constant), Number of Interactive Elements, Social Presence Mean Score

\begin{tabular}{llccccc}
\multicolumn{7}{c}{ ANOVA $^{\mathbf{b}}$} \\
\hline \hline Model & & Sum of Squares & df & Mean Square & F & Sig. \\
& & & & & & \\
\hline 1 & Regression & 16.294 & 2 & 8.147 & 44.110 & $.000^{\text {a }}$ \\
& Residual & 12.005 & 65 & .185 & & \\
& Total & 28.299 & 67 & & & \\
\hline \hline
\end{tabular}

a. Predictors: (Constant), Number of Interactive Elements, Social Presence Mean Score

b. Dependent Variable: Perceived Learning Mean Score

Coefficients $^{\mathrm{a}}$ 


\begin{tabular}{|c|c|c|c|c|c|c|}
\hline \multicolumn{2}{|c|}{ Model } & \multicolumn{2}{|c|}{$\begin{array}{c}\text { Unstandardized } \\
\text { Coefficients }\end{array}$} & \multirow{2}{*}{$\begin{array}{c}\begin{array}{c}\text { Standardized } \\
\text { Coefficients }\end{array} \\
\text { Beta }\end{array}$} & \multirow[b]{2}{*}{$\mathrm{t}$} & \multirow[b]{2}{*}{ Sig. } \\
\hline & & B & Std. Error & & & \\
\hline \multirow[t]{3}{*}{1} & (Constant) & 1.002 & .366 & & 2.735 & .008 \\
\hline & $\begin{array}{l}\text { Social Presence Mean } \\
\text { Score }\end{array}$ & .820 & .090 & .764 & 9.089 & .000 \\
\hline & $\begin{array}{l}\text { Number of Interactive } \\
\text { Elements }\end{array}$ & -.008 & .035 & -.019 & -.229 & .819 \\
\hline
\end{tabular}

a. Dependent Variable: Perceived Learning Mean Score

Research Question Two

A standard multiple regression analysis was performed between the dependent variable (satisfaction) and the independent variable (the number of interactive elements and social presence). Analysis was performed using SPSS Regression.

Regression will be best when each independent variable is strongly correlated with the dependent variable but uncorrelated with other independent variables. Table 6 displays that a simple correlation of $R=0.814$ (The correlation between the dependent variable and independent variables) with the two predictors, the number of interactive elements and social presence accounting for $65 \%$ of variance in satisfaction represented by Adjusted $R^{2}=.652$. This model shows that the difference between the Adjusted $R^{2}$ and $R^{2}$ is $.662-.652=.010$, about $1 \%$. This indicates that if the model was drawn from a population instead of a sample it would account for roughly $1 \%$ less variance in the outcome. The impact of $R^{2}$ is tested using an $F$-ratio. In this model, $R^{2}$ changed from zero to .662. Due to the change in the amount of variance, there was a rise in an F-ratio of 62.812 which is significant with a probability less than $.001(p<.001)$.

Analysis of variance (ANOVA) was also performed on the data to show whether the regression equation was significant. As shown in Table 6, the Sig value of .000 illustrated the 
regression equation found a significant result and we can reject the null hypothesis $(\mathrm{H} 0)$ that there is no statistically significant regression model when trying to predict student's satisfaction from a combination of their social presence score and number of interactive elements in the course. In other words, this meant that when looking at the entire regression, there was a positive correlation between satisfaction and the two independent variables (number of interactive elements and social presence).

The next section of the model results was the coefficients. The $b$-values demonstrate the relationship between relationship satisfaction and each predictor. A positive value indicates that there is a positive relationship between the outcome and the predictor whereas if the coefficient was negative, the relationship will be negative as well. The $b$-values demonstrate the degree to which each predictor affects the outcome as long as all other predictors are constant. From Table 6 , social presence $(b=.921)$ had a positive relationship with satisfaction. This value indicated that that social presence is related 0.921 to satisfaction. The number of interactive elements $(b=-.001)$ had a negative relationship with satisfaction. This value indicated that the number of interactive elements is not related to satisfaction. The standard error values show to what degree these values differ from each sample and whether the standard errors can be used to establish whether the $b$-value differs considerably from zero. For this model, social presence $(t(64)=10.788, \mathrm{p}<.001)$ was a significant predictor of satisfaction whereas the number of interactive elements $(t(65)=-.032, \mathrm{p}<.001)$ did not significantly contribute to the prediction of the students' satisfaction. 
Table 6 Satisfaction

Model Summary

\begin{tabular}{cccrr}
\hline \hline Model & $\mathrm{R}$ & R Square & $\begin{array}{r}\text { Adjusted R } \\
\text { Square }\end{array}$ & $\begin{array}{r}\text { Std. Error of the } \\
\text { Estimate }\end{array}$ \\
\hline 1 & $.814^{\mathrm{a}}$ & .662 & .652 & .40682 \\
\hline \hline
\end{tabular}

a. Predictors: (Constant), Number of Interactive Elements, Social Presence Mean Score

\begin{tabular}{llccccc}
\multicolumn{7}{c}{ ANOVA $^{\mathbf{b}}$} \\
\hline \hline Model & & Sum of Squares & df & Mean Square & F & Sig. \\
& & & & & & \\
\hline 1 & Regression & 20.791 & 2 & 10.396 & 62.812 & $.000^{\text {a }}$ \\
& Residual & 10.592 & 64 & .166 & & \\
& Total & 31.384 & 66 & & & \\
\hline \hline
\end{tabular}

a. Predictors: (Constant), Number of Interactive Elements, Social Presence Mean Score

b. Dependent Variable: Perceived Satisfaction Mean Score

\section{Coefficients $^{\text {a }}$}

\begin{tabular}{|c|c|c|c|c|c|c|}
\hline \multicolumn{2}{|c|}{ Model } & \multicolumn{2}{|c|}{$\begin{array}{l}\text { Unstandardized } \\
\text { Coefficients }\end{array}$} & \multirow{2}{*}{$\begin{array}{c}\begin{array}{c}\text { Standardized } \\
\text { Coefficients }\end{array} \\
\text { Beta } \\
\end{array}$} & \multirow[b]{2}{*}{$\mathrm{t}$} & \multirow[b]{2}{*}{ Sig. } \\
\hline & & B & Std. Error & & & \\
\hline \multirow[t]{3}{*}{1} & (Constant) & .335 & .347 & & .965 & .338 \\
\hline & $\begin{array}{l}\text { Social Presence Mean } \\
\text { Score }\end{array}$ & .921 & .085 & .815 & 10.788 & .000 \\
\hline & $\begin{array}{l}\text { Number of Interactive } \\
\text { Elements }\end{array}$ & -.001 & .033 & -.002 & -.032 & .974 \\
\hline
\end{tabular}

a. Dependent Variable: Perceived Satisfaction Mean Score 
For both regression analyses, the investigator utilized the default (Enter) option in SPSS, in which "All predictors are forced into the model simultaneously." (Field, 2009, pg. 212). Reliabilities were respectable for the scales employed. Alpha values yielded 0.89 for the Social Presence items, 0.95 for Perceived Learning items, and 0.94 for Satisfaction items. Table 7: Alpha values.

Case Processing Summary
\begin{tabular}{|ll|r|r|}
\hline & \multicolumn{1}{|c|}{$N$} & \multicolumn{1}{c|}{$\%$} \\
\hline Cases & Valid & 75 & 92.6 \\
& Excluded $^{a}$ & 6 & 7.4 \\
& Total & 81 & 100.0 \\
\hline
\end{tabular}

a. Listwise deletion based on all variables in the procedure.

Reliability Statistics

\begin{tabular}{|c|r|}
\hline $\begin{array}{c}\text { Cronbach's } \\
\text { Alpha }\end{array}$ & N of Items \\
\hline .887 & 9 \\
\hline
\end{tabular}

Case Processing Summary

\begin{tabular}{|ll|r|r|}
\hline & & \multicolumn{1}{|c|}{$N$} & \multicolumn{1}{c|}{$\%$} \\
\hline Cases & Valid & 75 & 92.6 \\
& Excluded $^{a}$ & 6 & 7.4 \\
& Total & 81 & 100.0 \\
\hline
\end{tabular}

a. Listwise deletion based on all variables in the procedure.

Reliability Statistics

\begin{tabular}{|r|r|}
\hline $\begin{array}{c}\text { Cronbach's } \\
\text { Alpha }\end{array}$ & N of ltems \\
\hline .952 & 6 \\
\hline
\end{tabular}

Case Processing Summary

\begin{tabular}{|ll|r|r|}
\hline & \multicolumn{1}{|c|}{$N$} & \multicolumn{1}{c|}{$\%$} \\
\hline \multirow{2}{*}{ Cases } & Valid & 67 & 82.7 \\
& Excluded $^{a}$ & 14 & 17.3 \\
& Total & 81 & 100.0 \\
\hline
\end{tabular}

a. Listwise deletion based on all variables in the procedure.

Reliability Statistics

\begin{tabular}{|r|r|}
\hline $\begin{array}{c}\text { Cronbach's } \\
\text { Alpha }\end{array}$ & N of ltems \\
\hline .936 & 11 \\
\hline
\end{tabular}

As part of a check for the assumption of linearity, plots were produced for each of the two main regression analyses conducted in which standardized residuals were plotted against 
standardized predicted values of the dependent variable. For the regression involving perceived learning as the dependent variable, the following plot was obtained.

Figure 39: Perceived Learning Assumption Linearity Plot

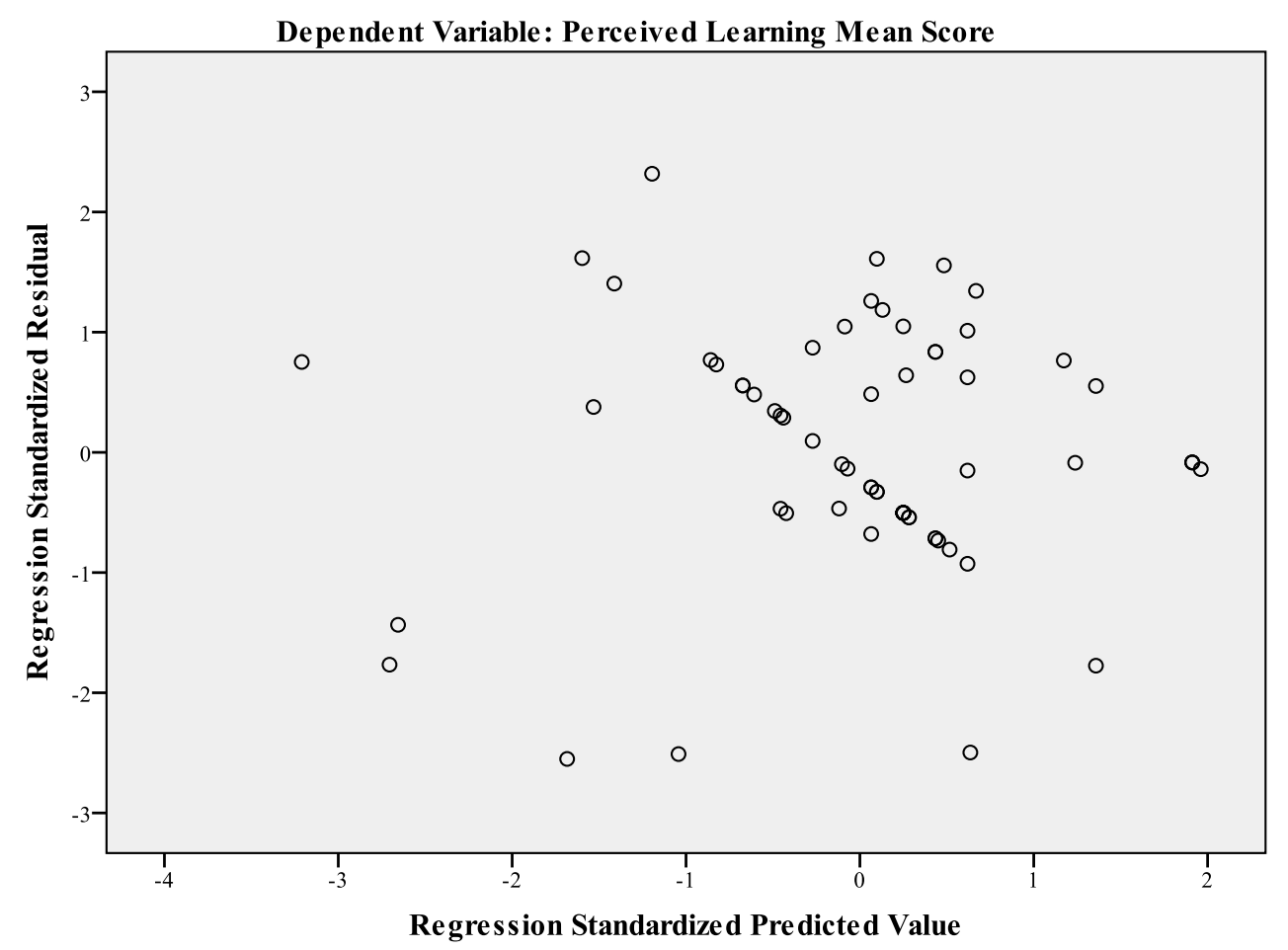

Although the distribution of scores is not ideal, the plot does not seem to indicate the existence of either a nonlinear relationship or heteroscedasticity. According to Field (2009) heteroscedasticity "occurs when the residuals at each level of the predictor variable(s) have unequal variances. Put another way, at each point along any predictor variable, the spread of residuals is different" (p. 732).

As part of a check for the assumption of linearity, plots were produced for each of the 2 main regression analyses conducted in which standardized residuals were plotted against standardized predicted values of the dependent variable. For the regression involving satisfaction as the dependent variable, the following plot was obtained. 
Figure 40: Perceived Learning Assumption Linearity Plot

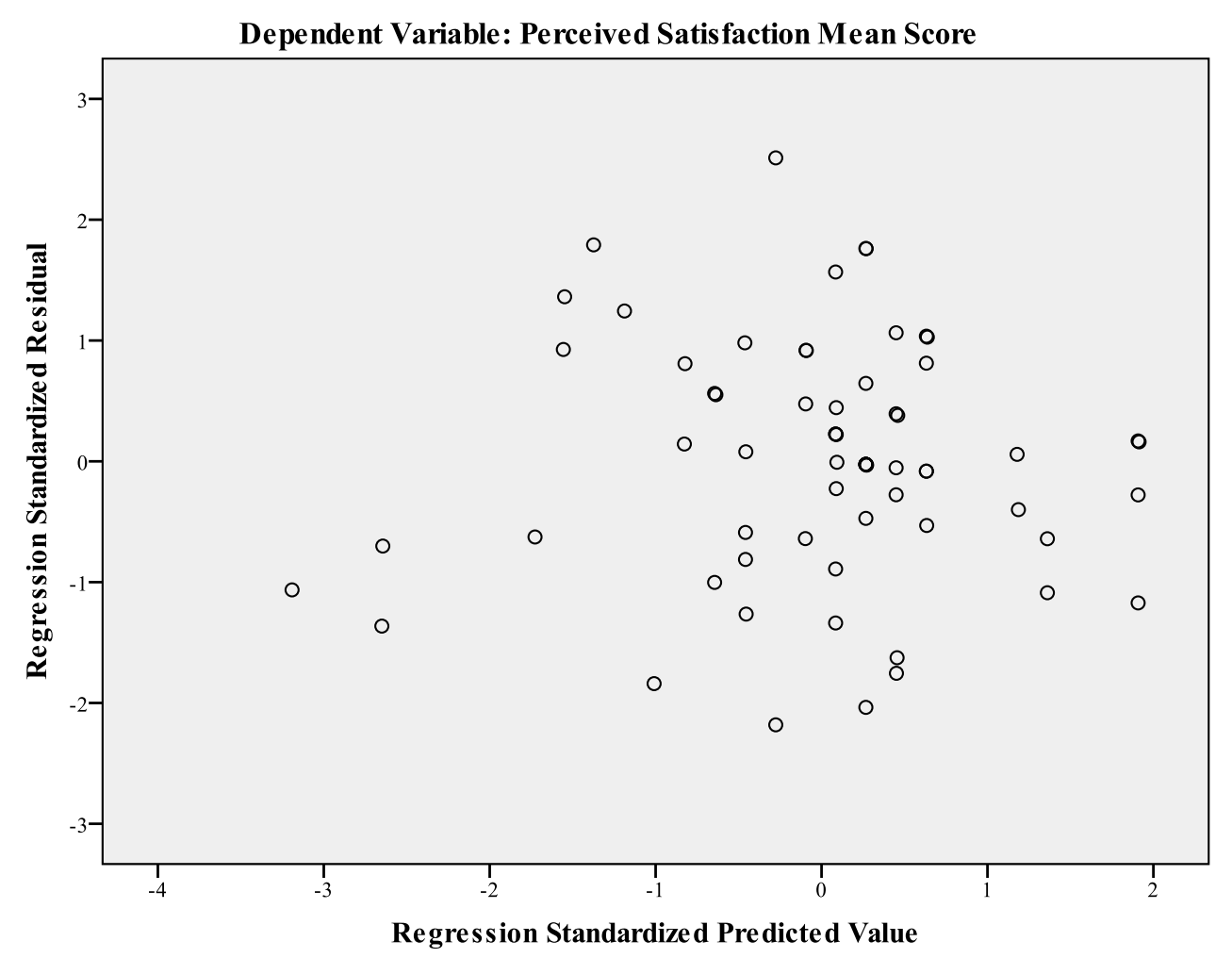

Although the distribution of scores is not ideal, the plot does not seem to indicate the existence of either a nonlinear relationship or heteroscedasticity. Ideally, regression analyses involve independent variables that are not highly correlated with one another, yet where each is highly correlated with the dependent variable. In both regressions conducted in this study, there were low correlations among the independent variables, yet each of these correlated highly to the dependent variable. 
Table 8: Correlations

\begin{tabular}{|c|c|c|c|c|c|}
\hline \multicolumn{6}{|c|}{ Correlations } \\
\hline & & $\begin{array}{c}\text { Social } \\
\text { Presence } \\
\text { Mean Score }\end{array}$ & $\begin{array}{c}\text { Perceived } \\
\text { Learning } \\
\text { Mean Score }\end{array}$ & $\begin{array}{c}\text { Perceived } \\
\text { Satisfaction } \\
\text { Mean Score }\end{array}$ & $\begin{array}{l}\text { Number of } \\
\text { Interactive } \\
\text { Elements }\end{array}$ \\
\hline \multirow{3}{*}{$\begin{array}{l}\text { Social Presence Mean } \\
\text { Score }\end{array}$} & Pearson Correlation & 1 & $.758^{* *}$ & $.809^{* *}$ & $.276^{*}$ \\
\hline & Sig. (2-tailed) & & .000 & .000 & .023 \\
\hline & $\mathrm{N}$ & 76 & 76 & 71 & 68 \\
\hline \multirow{3}{*}{$\begin{array}{l}\text { Perceived Learning Mean } \\
\text { Score }\end{array}$} & Pearson Correlation & $.758^{* *}$ & 1 & $.777^{* *}$ & .191 \\
\hline & Sig. (2-tailed) & .000 & & .000 & .118 \\
\hline & $\mathrm{N}$ & 76 & 76 & 71 & 68 \\
\hline \multirow{3}{*}{$\begin{array}{l}\text { Perceived Satisfaction } \\
\text { Mean Score }\end{array}$} & Pearson Correlation & $.809^{* *}$ & $.777^{* *}$ & 1 & .221 \\
\hline & Sig. (2-tailed) & .000 & .000 & & .073 \\
\hline & $\mathrm{N}$ & 71 & 71 & 71 & 67 \\
\hline \multirow{3}{*}{$\begin{array}{l}\text { Number of Interactive } \\
\text { Elements }\end{array}$} & Pearson Correlation & $.276^{*}$ & .191 & .221 & 1 \\
\hline & Sig. (2-tailed) & .023 & .118 & .073 & \\
\hline & $\mathrm{N}$ & 68 & 68 & 67 & 68 \\
\hline
\end{tabular}

**. Correlation is significant at the 0.01 level (2-tailed).

*. Correlation is significant at the 0.05 level (2-tailed).

\section{Summary of the Data Analysis}

This chapter presented the results of the study on the effects of social presence on students' perceived learning and satisfaction in online courses. Data for this study was collected at a major higher education institution located in a Mid-Atlantic state. Regression analysis was used to determine how strong is the relationship between the student's perceived learning, satisfaction and social presence, and the relative importance of social presence towards that relationship while looking a number of interactive elements. According to the findings, social presence was a strong predictor of students' perceived learning and satisfaction. In both research questions, the results showed that interactive elements only did not have a significant relationship with students' perceived learning and satisfaction. The following chapter discusses the significance of the study, limitations and recommendations for further research. 


\section{CHAPTER V: DISCUSSION}

\section{Overview}

As learners seek for inexpensive alternative ways of earning higher education, there is a need for institutions of higher learning to understand the effectiveness of these courses and how to better plan, design, develop, manage, and deliver them in a way that will improve how the students learn as well as their satisfaction. The aim of this study was to investigate the effects of social presence on students' perceived learning and satisfaction in online courses. The rationale for this chapter is to discuss the significance of the study, limitations of this study, implications, recommendations for further research and a conclusion. This study adopted a quantitative method to collect and analyze data. The data was collected from a targeted population of 160 graduate students enrolled in special education online courses at a major higher education institution located in a Mid-Atlantic state. Out of the 160 graduate students, $81(50.63 \%)$ participated in this study. The participants were requested to complete a survey at the end of the course, asking them a series of questions concerning their general experience in respect to social presence, perceived learning, satisfaction and interactive elements in the course.

\section{Discussion}

This section discusses the findings of the data analysis performed in this study. The research questions were: Research Question 1, examined whether we can predict in a statistically significant fashion using linear regression students' perceived learning in a course based on their perceived level of social presence and number of interactive elements in the course. In Research Question 2 examined whether we can predict in a statistically 
significant fashion using linear regression students' satisfaction in a course based on their perceived level of social presence and number of interactive elements in the course.

For Research Question 1, the regression equation was significant. This illustrated that the regression equation was significant hence rejecting the null hypothesis (Ho) that there is no statistically significant regression model when trying to predict student's perceived learning from a combination of their social presence score and number of interactive elements in the course. The results indicated $56 \%$ of variance in perceived learning represented by Adjusted $R^{2}=0.563$ which demonstrated clearly that there is a strong relationship involving students' perceived learning and social presence. These findings correspond with the results of previous studies. The results correspond to previous finding that there is a positive relationship between social presence and perceived learning. A similar study conducted by Picciano (2002), established a positive correlation of .67 among students' perceived learning and social presence. Likewise, Richardson and Swan (2003) conducted a study which established a variability of $42 \%$ in the perceived learning as predicted based on social presence among the learners. Research by Swan and Shih (2005) also established a positive relationship of .70 among students' perceived learning and social presence. Most recently, Hornik and Tupchiy (2006) also conducted a study which demonstrated a positive correlation of .38 between students' perceived learning and social presence.

For Research Question 2, the regression equation was significant. This illustrated that the regression equation was significant hence rejecting the null hypothesis (Ho) that there is no statistically significant regression model when trying to predict student's satisfaction from a combination of their social presence score and number of interactive elements in the course. The results indicated $65 \%$ of variance in satisfaction represented by Adjusted $R^{2}=$ 
.652 which demonstrated clearly that there is a strong correlation between students' satisfaction and social presence? These findings also match with the results of previous studies which found that there is a positive relationship between social presence and satisfaction. A study conducted by Gunawardena and Zittle (1997) predicted a positive relationship between students' satisfaction and social presence. This study established a variability of 58\% in the students' satisfaction as predicted based on social presence hence signifying that social presence was a strong predictor of students' satisfaction in a computermediated environment.

For both research questions, the results show that interactive elements alone did not have a statistically significant relationship on students' perceived learning and satisfaction. Consequently the technology by itself does not significantly effect how students learn. What matters is the way the technology is used to support the social aspects of the learning process. It is imperative to note that technology is merely a tool that can be used to deliver instruction in an efficient and timely manner. As stated by Kearsley (1998), "While technology certainly plays a role in distance education, it is far from the being the most significant element. Yet, it is frequently the technology that receives all the attention, often to the exclusion of curriculum design, learner support, appropriate administrative procedures, etc. This is one of the major reasons why distance learning is often unsuccessful. Educators fail to understand that distance education is really about creating a different kind of structure for learning and teaching -- not the use of technology." (p. 5). This study reiterates what Barker (2003) wrote that "Technology is merely a tool for course delivery, and as with any tool, faculty members must have confidence in their skills for using it and confidence that the tool promotes student learning” (p. 24). 
In order for the technology to enhance learning, it is imperative that the right instructional strategies are applied to accomplish the intended learning outcome. Excellence in instruction can be achieved when technology is used as a tool to ascertain novel avenues for attaining intended learning outcomes. Online education can be seen as an academic advancement and a means of communication that allows engagement among the learners. Huang (2002) suggests that "learning should involve interaction with other people or environments, which fosters potential development through instructors' guidance or in collaboration with more peers" (p.7). With the use of technology, instructors are able to develop different and quality courses as well as develop a unique relationship with their students. 


\section{Conclusions}

As institutions of higher learning progressively implement online courses, more and more questions arise pertaining to the barriers and challenges of online learning. One particular challenge has been finding ways to develop and increase relations among students in an online learning environment. The increasing research in social presence reveals that there is a need for institutions of higher education to better understand social presence and how it can be used to improve the learning and instructional experience. Garrison et al. (2001) assert that social presence permits participants within an online learning community to project their individuality into the online learning community. Based on Tu \& McIsaac (2002) social presence also establishes a learning community as well as sense of connection which is typically lacking in online courses.

Aragon (2003) points out that social presence is a key aspect in the learning experience in addition to building social presence in an online learning community. Social presence is also very important for the students' satisfaction as well as perceived learning. Social presence creates an environment where members of the learning community feel they are community with other people as opposed to the technology (Short et al., 1976). The decrease in communication channels can result to a decrease of social presence and vice versa. As stated by Rovai, Ponton, Wighting, and Baker (2007) "feelings of isolation and lack of direct teacher contact in distance learning environments can result in the belief that the student does not belong to a scholarly community, which may also contribute to student attrition."

Aragon (2003) points out that the formation of social presence in a learning community improves connections among the participants and at the same time scatters the 
feeling of loneliness. Swan and Shih (2005) believe that there is a direct association between the enhanced social presence and the students' satisfaction. As per Mykota and Duncan (2007) the main significance of social presence is its role of maintaining cognitive presence and the more the students perceive their interaction in the learning community as enjoyable and fulfilling, they become inclined to stay in the cohort of learners for the length of the program and as a result social presence becomes a contributor to the learning experience.

A decade into the new century, more and more higher learning institutions are using technology to enhance their students learning in online courses as well as using it to increase social presence within this environment. The use of these innovative technologies allows the students to effortlessly communicate among themselves along with other learners worldwide. Vrasidas and McIsaac (1999) said "social presence could be promoted in a computermediated communication (CMC) setting by employing strategies that encourage interaction." (p.25). As we go into the future, educators ought to appropriately use both the existing and new technologies to facilitate an environment where the learners are motivated and encouraged to interact more.

Online courses offer an innovative environment for communication among students and instructors and at the same time allows the instructors to develop courses, which are student-centered and allow teamwork. Even though online learning allows easy access, anytime from anywhere, it has to be appropriately designed to engage the students in order to promote the desired learning. The objective of any instruction is help the students learn and retain the information that is being presented to them. It is for that reason; educators must clearly understand the principles of learning as well as how students learn in order to develop the appropriate learning materials. This is particularly important in an online environment 
where both the instructors and students are physically separated. The learning material used is designed based on sound learning principles. Although this study shows that social presence played a very significant role in the students' perceived learning and satisfaction whereas the interactive elements did not affect how students learn, it is imperative for educators to know how to create a learning environment where all these key areas work simultaneously.

\section{Significance of the Study}

Given the issue of social presence in an online learning environment, it was imperative to investigate whether it plays a role in students' perceived learning and satisfaction. The results of this study will increase the universal knowledge of this topic in numerous ways:

1. Subsequent to reading the literature it showed that modest research has been done on the function of social presence regarding students' perceived learning and satisfaction. For that reason, this research will be a complement to the increasing number of studies on this topic while also providing a research example for future researchers. In addition, it will play a role for others enhancing their understanding social presence in Computer Mediated Communication (CMC).

2. The results will assist institutions of higher learning officials and instructors to strategize suitable interventions and tactics that can help incorporate social presence in online courses.

\section{Limitations}

The following are some of the limitations that were related to this study: 
1. The sample of this study was limited to the number of students enrolled in online courses at a major higher education institution located in a Mid-Atlantic state. Therefore, there is a need to conduct further studies to establish whether the same results will be generated with a different population.

2. Due to the scale of the study, an appraisal was not done to find out if there were pre-existing relationships among the participants given that they were from the same university. It is therefore imperative to conduct further studies to establish if the outcome of this study can be generalized to online courses with students who do not know each other.

3. Another possible limitation of this study was that the sample size was to some extent small. Having a larger sample size would have increased the robustness of the data analyses and might have produced different results.

4. In addition, the participants in this study were all special education students. Further studies with students in different subjects should be administered to see if these results extend outside special education courses and students.

5. The data collected was student reports for all variables so there was no independent verification of their reports and therefore dependent on the students' ability to accurately report. This introduces the possibility of reliability and validity concerns for the resulting data.

\section{Implications}

Results from this research emphasize the significance of social presence in an online learning environment, specifically in enhancing students' learning experience and satisfaction. The study results present substantiation as to why there is a need for educators to 
use the existing and new technologies correctly to promote social presence. Both the instructional designer and instructors need to develop courses that encourage social presence among the learners, the learners and instructor hence leading to student satisfaction. Given that social presence plays a major role in students' perceived learning and satisfaction, there is a need for the educators to design the courses in such a way that intentionally encourages students to interact and engage while at the same time making sense of the information being disseminated to them. Clearly, the finding of this study showed that even though a majority of higher learning institutions focus more on the technology, it is the way that that technology is used that really affects the students. What really matters is how the students use the technology to communicate rather than the technology itself.

\section{Recommendations for Further Research}

My recommendation for further research is to use both a mixed research methodology to merge the use of quantitative and qualitative methods. The benefit of using a mixed research methodology is that both survey questions and in-person interviews can be used to gather information and individual perspectives. Additionally, further studies with an adequate sample size should be used in order to generalize the results. In addition, further research should use a more diverse population, which includes students from different academic fields as well as undergraduate students. Future research also needs to look at the roles instructors play in creating social presence in online courses and what instructional strategies and principles they use and whether these strategies affect students' perceived learning and satisfaction. Future studies should also be conducted to establish whether the social presence influence instructors' efficiency as well as their satisfaction with the courses they teach. With the steady development of new technologies, further research should also be conducted to 
look at emerging interactive elements such as social networking technologies e.g. Facebook, MySpace, Twitter, Ning, etc.

\section{Summary}

This study looked into to investigate and review the role that social presence plays in how students perceived learning and satisfaction in a computer-mediated communication environment. According to the findings of this study, there is a relationship between students' perceived learning and social presence. When it comes to satisfaction there is a relationship between students' satisfaction and social presence. The results also showed that interactive elements alone did not did not have effect on students' perceived learning and satisfaction hence confirming that technology by itself did not affect how students learn. The literature review for this study supports that social presence plays a major role in how students' learning and whether or not they are satisfied with course. On the other hand, the results of this research showed that the technology did not sway the students' perceived learning or satisfaction. Therefore this confirms that the technology by itself does not enhance learning rather how it is used and applied. 


\section{References}

Ajayi, L. (2009). An Exploration of Pre-Service Teachers' Perceptions of Learning to Teach while Using Asynchronous Discussion Board. Educational Technology \& Society, 12 (2), 86-100.

Alavi, M., Marakas, G., and Yoo, Y. 2002. "A Comparative Study of Technologies for Distance Learning, "Information Systems Research, 13(4), 404-415.

Allen, I. E., \& Seaman, J. (2003, September). Sizing the opportunity: The quality and extent of online education in the United States, 2002 and 2003. Retrieved June 3, 2008, from The Sloan Consortium: http://www.sloanc.org/resources/sizing_opportunity.pdf

Anderson, T., Garrison, D., \& Archer, W. (1999). Assessing social presence in asynchronous text-based computer. The Journal of Distance Education, 14(2), 50-71.

Anderson, T., Rourke, L., Garrison, D., \& Archer, W. (2001). Assessing teaching presence in instructional computer conferences. Journal of Asynchronous Learning Networks, 5(2).

Aragon, S. R. (2003). Creating social presence in online environments. New Directions for Adult and Continuing Education, (100), 57-68.

Arbaugh, J. Ben (2000). "Virtual classroom characteristics and student satisfaction with internet-based MBA courses.” Journal of Management Education, 24(1), 3254.

Arbaugh, B., Cleveland-Innes, M., Diaz, S. Ice, P., Garrison, D.R., Richardson, J.C, 
Shea, P. \& Swan, K. (2008). Developing a Community of Inquiry instrument: Testing a measure of the Community of Inquiry framework using a multi-institutional sample. The Internet and Higher Education, 11(3-4), 133-136.

Association, A. P. (1997). Learner-centered psychological principles: Guidelines for school redesign and reform. Washington, DC: American Psychological Association and the Mid-continent Regional Education Laboratory.

Barker, A. (2003). Faculty development for teaching online educational and technological issues. The Journal of Continuing Education in Nursing, 34(6), 273278.

Benbunan-Fich, R., \& Hiltz, S. R. (1999). Effects of asynchronous learning networks: results of a field experiment comparing groups and individuals. Journal of Group Decision and Negotiation, 8(5), 409-426.

Berge, Z. L. (1996). The role of the online instructor/facilitator. Retrieved December 5, 2008, from eModerators: http://www.emoderators.com/moderators/teach_online.html

Berge, Z., \& Collins, M. (1995, February 1). Computer-Mediated Communication and the Online Classroom: Overview and Perspectives. Retrieved May 28, 2008, from Computer-Mediated Communication Magazine: http://www.december.com/cmc/mag/1995/feb/berge.html

Bibeau, S. (2001). Social presence, isolation, and connectedness in online teaching and learning. Journal of Instruction Delivery Systems, 15(3), 35-39.

Bos, N., \& Shami, S. (2006). Adapting a face-to-face role-playing simulation for online play. Educational Technology Research \& Development, 54(5), 493-521.

Bradshaw, P., Powell, S., \& Terrell, I. (2002). Learning, community and technology: 
Ultralab's recent experience. APU Learning and Teaching Conference (pp. 1-14). Danbury: Ultralab.

Conrad, D. (2005). Building and maintaining community in cohort-based online learning. Journal of Distance Education, 20(1), 1 - 20.

Clark, H. H., \& Brennan, S. E. (1991). Grounding in communication. In L. B. Resnick, J. M. Levine, \& S. D. Teasley, Perspectives on socially shared (pp. 127-149). Washington, DC: American Psychological Association.

Cohen, A. (1999). Instructional technology and distance learning through the Internet. Educational Media International, 36(3), 218-229.

Cronbach, L.J., 1971. Test validation. Educational measurement. In: Thorndike, R.L. (Ed.), American Council on Education, second ed., Washington, pp. 443-507

D'Angelo, J. M., \& Woosley, S. A. (2007). Technology in the Classroom: Friend or Foe. Education, 127(4), 462-471.

Daft, R.L. \& Lengel, R.H. (1986). Organizational information requirements, media richness and structural design. Management Science 32(5), 554-572.

December, J. (1997). Notes on defining of computer-mediated communication. Journal of Computer-Mediated Communication, 3, 1.

Dede, C. (1996). Emerging technologies in distance education for business. Journal of Education for Business, 71(4), 197-204.

Dede, C. (1996). The evolution of distance education: Emerging technologies and distributed learning. American Journal of Distance Education, 10 (2), 4-36.

Diane, C. M. (1990). The Relationships among Teacher Immediacy Behaviors, Student Motivation, and Learning. Communication Education, 39(4), 323-40. 
Driscoll, M. (1998). Web-based training: Using technology to design adult learning experiences. San Francisco: Jossey-Bass Pfeiffer.

Eastmond, D. V. (1995). Alone but together: Adult distance study through computer conferencing. Cresskill. New Jersey: Hampton Press.

Field, A. (2009). Discovering Statistics Using SPSS. 3d edition. London: Sage Publications.

Fox, J. (1998, January 21). Distance education: is it good enough? Retrieved June 16, 2008, from The University Concourse: http://www.theuniversityconcourse.com/III,4,1-211998/Fox.htm

Garrison, D. R., \& Anderson, T. (2003). E-Learning in the 21st century: A framework for research and practice. New York, New York: Routledge.

Garrison, R., Anderson, T., \& Archer, W. (2001). Critical thinking, cognitive presence, and computer conferencing in distance education. American Journal of Distance Education, 15(1), 7-23.

Garrison, D. R., Anderson, T., \& Archer, W. (2001). Critical thinking, cognitive presence and computer conferencing in distance education. American Journal of Distance Education, 15(1), 7-23.

Garrison, D. R., Anderson, T., \& Archer, W. (2000). Critical Inquiry in a Text-Based Environment: Computer Conferencing in Higher Education. Internet and Higher Education, 2(3), 87-105.

Garrison, R. D. (1997). Computer conferencing: the post-industrial age of distance education. Open \& Distance Education and eLearning, 3-11.

Geoghegan, W. H. (1994). Whatever happened to instructional technology? $22^{\text {nd }}$ 
Annual Conference of the International Business Schools Computing Association, Baltimore, MD.

Gunawardena, C. N., \& Zittle, F. J. (1997). Social presence as a predictor of satisfaction within a computer-mediated conferencing environment. American Journal of Distance Education, 11(3), 8-26.

Hackman, M. Z., \& Walker, K. B. (1990). Instructional communication in the televised classroom: The effects of system design and teacher immediacy on student learning and satisfaction. Communication Education, 196-206.

Hara, N., \& Kling, R. (2000). Students' distress with a web-based distance education course. Information, Communication and Society, 3(4), 557-579.

Harasim, L. M. (1990). Online education: Perspectives on a new environment. New York, New York: Praeger Publishers.

Hardey, M. (2002). Life beyond the Screen: Embodiment and Identity through the Internet. Sociological Review, 50(4), 570-585.

Hawisher, G. E., \& Pemberton, M. A. (1997). Writing across the curriculum encounters asynchronous learning networks or WAC meets up with ALN. Retrieved March 5, 2008, from http://www.sloan-c.org/

Hiltz, S. R. (1994). The Virtual classroom: Learning without limits via computer. Norwood: Ablex.

Hiltz, S. R., \& Wellman, B. (1997). Asynchronous learning networks as a virtual classroom. Communications of the ACM, 40(9), 44-49.

Hirschheim, R. (2005). The internet-based education bandwagon: Look before you leap. Communications of the ACM, 48(7), 97-101. 
Hornik, S., \& Tupchiy, A. (2006). Culture's impact on technology mediated learning: The role of horizontal and vertical individualism and collectivism. Journal of Global Information Management, 14(4), 31-56.

Hrastinski, S. (2008). Asynchronous and synchronous learning. Educause Quarterly, 31(4), $51-55$.

Huang, H. (2002). Toward constructivism for adult learners in online learning environments. British Journal of Educational Technology, 33(1), 27-37. Retrieved January 2, 2011, from Wiley Online Library.

IM, Y., \& Lee, O. (2003). Pedagogical Implications of Online Discussion for Preservice Teacher Training. Journal of Research on Technology in Education, 14 (2), 155170.

Isaac, S., \& Michael, W. B. (1995). Handbook in research and evaluation. (3rd ed.). San Diego, CA: EdITS Pub.

Jiang, M., \& Ting, E. (2000). A Study of Factors Influencing Students' Perceived Learning in a Web-Based Course Environment. International Journal of Educational Telecommunications, 6 (4), 317-338.

Kahn, T. (1999). A New Model of Education: Designing Virtual Communities for Creativity and Learning. Retrieved September 15, 2010 from, from edutopia: http://www.edutopia.org/designing-virtual-communities-creativity-and-learning

Kearsley, G., \& Lynch, W. (1994). Educational Technology Leadership Perspectives. Englewood Cliffs, NJ: Educational Technology Publications.

Kearsley, G. (1998). Educational technology: A critique. Educational Technology. Retrieved January 21, 2010 from http://home.sprynet.com/ gkearsley/critique.htm 
King, F. B., Young, M.F., Drivere-Richmond, K., \& Schrader, P.G. (2004). Defining distance learning and distance education. Retrieved January 31, 2010 from http://www.editlib.org/f/17786

Leh, A. (2001). Computer-Mediated Communication and Social Presence in a Distance Learning Environment. International Journal of Educational Telecommunications , 7 (2), 109-128.

Lipman, M. (2003). Thinking in Education. (2nd ed.). Cambridge: Cambridge University Press.

Lock, J. V., \& Clark, W. B. (2004, December). Pushing the envelope of technology integration. Paper presented in Best Practices in E-Learning: Showcase, University of Calgary, Calgary, AB.

Lowenthal, P. R. (2009, October). Social presence: What is it? Does it make a difference? Paper presented at the 2009 AECT International Convention, Louisville, KY. Retrieved January 31, 2010 from http://www.aect.org/events/review/PropResults.asp?submit=View+Full+Proposal.\&p $\underline{\text { ropid }=287}$

McFadden, A. C., Marsh, G. E., \& Price, B. J. (1999). Why Do Educators Embrace HighCost Technologies? Retrieved May 28, 2008, from Online Journal of Distance Learning Administration: http://www.westga.edu/ distance/mcfadden24.html McFadzean, E., \& McKenzie, J. (2001). Facilitating virtual learning groups: A practical approach. Journal of Management Development, 20 (6), 470-494.

McKeachie, W. J., Pintrich, P. R., Lin, Y.-G., \& Smith, D. A. (1986). Teaching and 
Learning in the College Classroom: A Review of the Research Literature. Ann Arbor, Michigan: The Regents of the University of Michigan.

Moore, M. G., \& Kearsley, G. (1996). Distance education: A systems view. Belmont: Wadsworth Publishing Company.

Munroe, J. (1998). Presence at a Distance: The Educator-Learner Relationship in Distance Education. University Park, PA: Study of Distance Education Pennsylvania State University.

Mykota, D., \& Duncan, R. (2007). Learning characteristics as predictors of online social presence. Canadian Journal of Education, 30(1), 157-170.

Mynatt, E.D., Adler, A., Ito, M. and O’Day, V. (1997), “Design for network communities", Proceedings of the ACM Conference on Human Factors in Computing Systems (CHI '97), ACM Press, New York, NY, pp. 210-17.

Newberry, B. (2001). Media Richness, Social Presence and Technology Supported Communication Activities in Education. Retrieved June 24, 2008, from Technology Enriched Learning: http://www.learngen.org/resources/module/lgend101_norm1/200/210/211_3.html

Newby, T. J., Stepich, D. A., Lehman, J. D., \& Russell, J. D. (2000). Instructional technology for teaching and learning: Designing instruction, integrating computers, and using media (2nd ed.). Upper Saddle River, NJ: Merrill Prentice Hall.

Pacific Policy Research Center. (2010). 21st Century Skills for Students and Teachers. Honolulu: Kamehameha Schools, Research \& Evaluation Division.

Palloff, R. M., \& Pratt, K. (1999). Building Online Learning Communities in 
Cyberspace: Effective Strategies for the Online Classroom. San Francisco: Jossey Bass.

Picciano, A. (2002). Beyond Student Perceptions: Issues of Interaction, Presence, and Performance in an Online Course. Journal of Asynchronous Learning Networks, 6 (1), 21-40.

Preece, J. (2000). Online communities. Designing usability,supporting sociability. Chichester: Wiley \& Sons, Ltd.

Pritchard, J. (July 2008) Good Practice in Safeguarding Adults: Working Effectively in Adult Protection. London: Jessica Kingsley Publishers.

Procter, M. (2000, April). The Instructor's Role in Online Conferencing:Do I Want to Do This? Retrieved June 26, 2008, from Teaching, Learning and Research in Today's University, University of Toronto: http://www.utoronto.ca/writing/conferencing.html

Rester, C.H., \& Edwards, R. (2007). Effects of sex and settings' interpretations of teachers' excessive use of immediacy. Communication Education, 56, 34-53.

Richardson, J. C., \& Swan, K. (2003). Examining social presence in online courses in relation to students' perceived learning and satisfaction. Journal of Asynchronous Learning Networks, 7(1), 68-88.

Roberson, T., \& Klotz, J. (2002). How can instructors and administrators fill the missing link in online instruction? Online Journal of Distance Learning Administration, 5(4). Retrieved November 12, 2009, from http://www.westga.edu/ distance/ojdla/winter54/roberson54.htm

Romiszowski, A.J. \& Mason, R. (1996). Computer-Mediated Communication. In D. H. 
Jonassen (Ed.). Handbook of Research for Educational Communications and Technology. New York: Prentice Hall International.

Rourke, L. A., Terry, G., D, R., \& Archer, W. (1999). Assessing Social Presence in an Asynchronous Text-Based Computer Conferencing. Journal of Distance Education, 14(2), 50-71.

Rourke, L., Anderson, T., Garrison, D. R., \& Archer, W. (2001). Assessing social presence in asynchronous, text-based computer conferences. Journal of Distance Education, 14(3), 51-70.

Rovai, A. (2001). Building Sense of Community at a Distance. International Review of Research in Open and Distance Learning, 3(1).

Rovai, A. (2002). Development of an instrument to measure classroom community. The Internet and Higher Education, 5(3), 197-211.

Rovai, A., \& Jordan, H. (2004). Blended learning and sense of community: A comparative analysis with traditional and fully online graduate courses. The International Review of Research in Open and Distance Learning, 5(2). Retrieved January 13, 2010, from: http://www.irrodl.org/index.php/irrodl/article/view/192/795

Rovai, A. P., Ponton, M. K., Wighting, M. J., \& Baker, J. D. (2007). A comparative analysis of student motivation in traditional classroom and e-learning courses. International Journal on E-Learning, 6(3), 413-432.

Ruberg, L. F., Moore, D. M., \& Taylor, C. D. (1996). Student participation, interaction, and regulation in a computer-mediated communication environment: A qualitative study. Journal of Educational Computing Research, 14(3), 243-268.

Rupert, M., Hassas, S., Li, C., \& Sherwood, J. (2007). Simulation of Online Communities 
Using MAS Social and Spatial Organisations. World Academy of Science, Engineering and Technology, 355-360. Retrieved November 12, 2009, from http://www.waset.org/journals/waset/v30/v30-67.pdf

Russo, T., \& Benson, S. (2005). Learning with invisible others: Perceptions of online presence and their relationship to cognitive and affective learning. Educational Technology \& Society, 8(1), 54-62.

Salmon, G. (2004). E-Moderating: The key to teaching and learning online (2 ed.). New York: RoutledgeFalmer.

Saenz, B. L. (2002). Student perceptions of social presence and its value in an asynchronous web-based master's instructional program. Unpublished doctoral dissertation, Virginia Polytechnic Institute and State University, Blacksburg. Retrieved November 12, 2009, from http://scholar.lib.vt.edu/theses/available/etd05232002-095013/unrestricted/blsETD.pdf

Santoro, G. M. (1995). What is computer mediated communication? In Z. Berge, \& M. Collins, Computer-mediated communication and the online classroom in distance learning (pp. 11-27). Cresskill, New Jersey: Hampton Press.

Scardamalia, M., \& Berieter, C. (2003). Knowledge Building. Encyclopedia of Education , 2nd Edition. New York: Macmillan.

Scott, I. (2010). Accreditation of prior learning in pre-registration nursing programmes 2: The influence of prior qualifications on perceived learning during the foundation year. Nurse Education Today, 438-442.

Sergiovanni, T. J. (1996). Leadership for the Schoolhouse: How is it different? Why is it important? San Francisco: Jossey-Bass. 
Sherry, L. (1996). Issues in distance learning. Retrieved November 11, 2009, from: http://carbon.cudenver.edu/ 1sherry/pubs/issues

Shin, N. (2002). Beyond Interaction: The Relational Construct of "Transactional Presence.". Open Learning, 17 (2), Open Learning.

Short, J., Edergn, W., \& Bruce, C. (1976). The Social Psychology of Telecommunications . New York: John Wiley \& Sons.

Sloan (n.d.). The 5 Pillars of Quality Online Education. The Sloan Consortium. Retrieved March 24, 2011 from http://old.sloanconsortium.org/5pillars

Sotillo, S. M. (2000). Discourse functions and syntactic complexity in synchronous and asynchronous communication. Language Learning and Technology, 4 (1), 82-119.

Swan, K. (2005). A constructivist model for thinking about learning online. Retrieved October 20, 2008, from http://www.kent.edu/rcet/Publications/upload/constructivist\%20theory.pdf

Swan, K., Shea, P., Fredericksen, E., Pickett, A., Pelz, W., \& Maher, G. (2000). Building Knowledge Building Communities: Consistency, contact and communication in the virtual classroom. Journal of Educational Computing Research, 23 (4), 359 - 383.

Swan, K., \& Shih, L. F. (2005). On the nature and development of social presence in online course discussions. Journal of Asynchronous Learning Networks, 9(3), 115136.

Sweeney, J.C., \& Ingram. D. (2001). A Comparison of Traditional and Web-Based Tutorials in Marketing Education: An Exploratory Study. Journal of Marketing Education, 23(1), 55-62.

Tallent-Runnels, M. K., Thomas, J. A., Lan, W. Y., Cooper, S., Ahern, T. C., Shaw, S. M, \& 
Liu, X. (Spring 2006). Teaching courses online: A review of the research. Review of Educational Research, 76(1), 93-135.

Tiangha, T. (2003, November 20). Blended learning: wave of the future? Retrieved July 3, 2008, from Gauntlet News: http://gauntlet.ucalgary.ca/a/story/6848

Tu, C.-H. (2001). How Chinese Perceive Social Presence: An Examination of Interaction in Online Learning Environment. Educational Media International, 38 (1), 4560.

Tu, C.H., \& McIsaac, M. (2002). The Relationship of Social Presence and Interaction in Online Classes. American Journal of Distance Education, 16 (3), 131 - 150.

Vrasidas, C. \& McIsaac, M. S. (1999). Factors influencing Interaction in an Online Course. American Journal of Distance Education, 13 (3), 22-36. Retrieved December 13, 2010, from http://www.cait.org/vrasidas/pubs/AJDE_Vrasidas.pdf.

Wegerif, R. (1998). The Social Dimension of Asynchronous Learning Networks. Journal of Asynchronous Learning Networks, 2 (1), 34-49.

Whiteman, J. A. (2002). Interpersonal Communication in Computer Mediated Learning. Orlando: University of Central Florida.

Wilen-Daugenti, T. (2008, August). 21st Century Trends for Higher Education. Retrieved September 12, 2010, from http://www.cisco.com/web/about/ac79/docs/wp/21st_Century_Top_Trends_POV_08 11.pdf

Woods, R., \& Keeler, J. (2001). The effect of instructor's use of audio e-mail messages on student participation in and perceptions of online learning: A preliminary case study. Open Learning, 7(5(3), 263-278. 
Winograd, D. (2002). Guidelines for moderating online educational computer conferences. TechTrends, 46 (5), 53-57.

Yoakam, M., \& Franklin, N. (1999). Distance learning: A guide to system planning and implementation. Bloomington: Indiana University, School of Continuing Studies.

Yoon, S. W. (2003). Examination of member behaviors, group processes, and development-shaping forces of virtual learning teams. Urbana-Champaign, Illinois: Unpublished doctoral dissertation, Department of Human Resources Education, University of Illinois, Urbana-Champaign. 
Appendices

Appendix A: Survey Instrument 


\section{The Effect of Social Presence on Students' Perceived Leaming and}

\section{Social Presence Survey}

Dear Participant,

Thank you for taking part in a research study investigating the effect of social presence on students' perceived learning and satisfaction in online courses. Social presence is defined by Garrison, Anderson and Archer (2000) as 'the ability of participants in a community of inquiry to project themselves socially and emotionally, as "real" people (i.e. their full personality), through the medium of communication being used" (p. 94). This research study is being conducted by Joseph Nyachae, with supervision of Dr. Terence Ahem, in the Department of Technology, Learning and Culture at WVU. This research is being conducted in partial fulfillment of the requirements for my dissertation. Your participation in this project is greatly appreciated and will take approximately 20-30 minutes to complete.

Your involvement in this project will be kept as confidential as legally possible. All data collected will be reported in the aggregate. In order to participate in this research you must be 18 years or older. I will not ask any information that should lead back to your identity as a participant. Your participation is completely voluntary. You may skip any question that you do not wish to answer and you may discontinue at any time. Your decision to participate or not to participate in this research will have no effect on your class standing or final course grade. West Virginia University's Institutional Review Board acknowledgement of this project is on file.

I hope that you will participate in this research study, as it could be beneficial in understanding effect of social presence on students' perceived learning and satisfaction in online courses. Thank you very much for your time. Should you have any questions about this letter or the research project, please feel free to contact Joseph Nyachae at (304) 319-1227 or by e-mail at nyandusi@yahoo.com. You can also contact my Advisor and Chairman of my research committee Dr. Terence Ahern at the email address Terence.Ahern@mail.wvu.edu

Thank you in advance for your time and help with this study.

Sincerely,

Joseph Nyachae

1. Please enter your age in years in the box below.

2. Please enter in the box below the Course Instructor for which you are taking this survey:

3. Please enter in the space below the Course Name for which you are taking this survey.

4. Please indicate your gender:

Male

Female 


\section{The Effect of Social Presence on Students' Perceived Learning and}

5. Please enter the degree program in which you are currently enrolled (if you are enrolled in more than one program simultaneously, please enter the higher degree program):

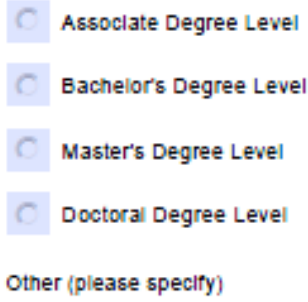

6. In the space below, please enter the approximate number of college credits you have completed towards your current degree of study.

7. Is this your first semester taking an online course?

$$
\begin{aligned}
& \text { Yes } \\
& \text { No }
\end{aligned}
$$

8. Please choose the number of online college courses (at any degree level) that you have taken. Include any online courses in which you are currently enrolled.
1
2
3
4
5 to 7
8 to 10
11 to 15
16 to 20
21 to 25
More than 25 
The Effect of Social Presence on Students' Perceived Learning and

2. Social Presence Survey ... ctd.

9. For each of the following questions, please choose the descriptor that best describes your level of agreement with the statement.

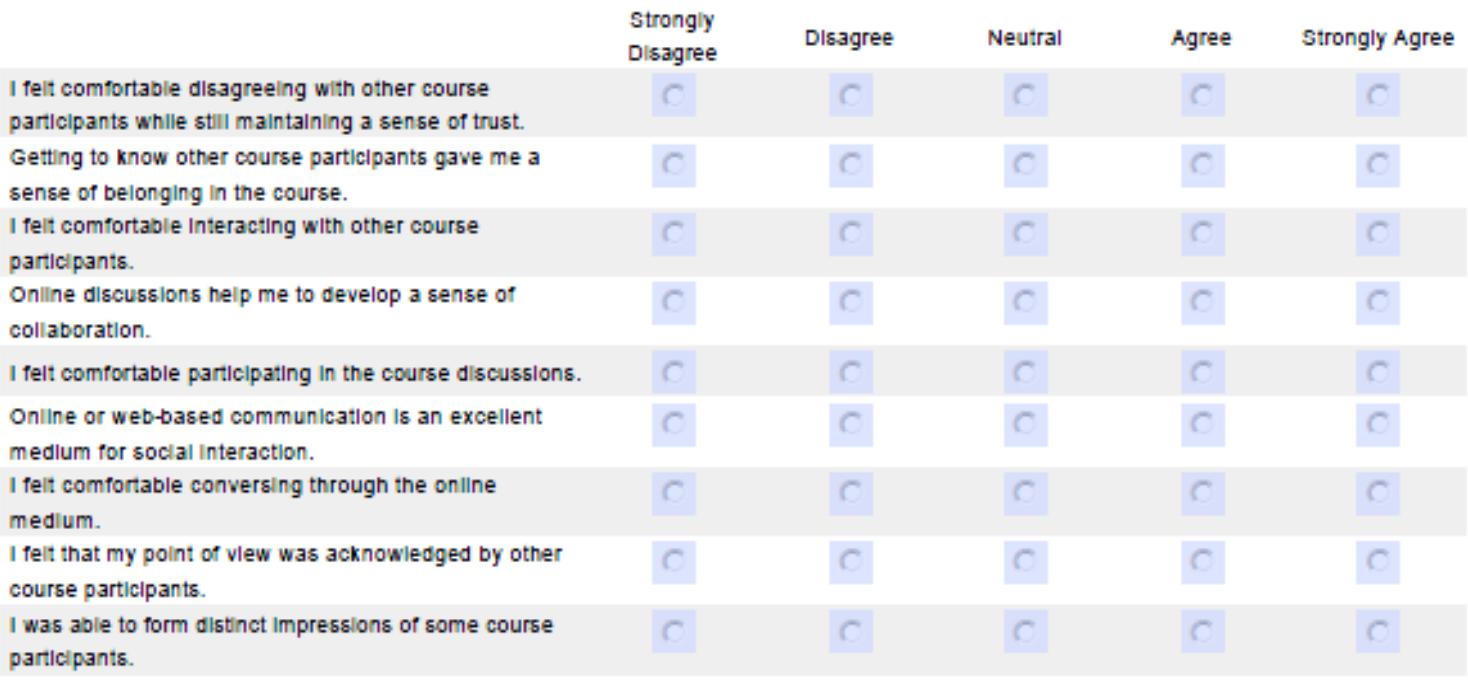

10. For each of the following questions, please choose the descriptor that best describes your level of agreement with the statement.

\begin{tabular}{|c|c|c|c|c|c|}
\hline & $\begin{array}{l}\text { Strongly } \\
\text { Disagree }\end{array}$ & Disagree & Neutral & Agree & Strongly Agree \\
\hline $\begin{array}{l}\text { I gained a good understanding of the basic concepts of } \\
\text { the material. }\end{array}$ & $\mathrm{C}$ & C & $\mathrm{C}$ & c & C \\
\hline 1 learned concepts and principles in this course. & C & $C$ & $\mathrm{C}$ & $c$ & $\mathrm{C}$ \\
\hline I learned to Identify the central issues of the course. & $c$ & $c$ & $c$ & C & $c$ \\
\hline $\begin{array}{l}\text { I learned to interrelate the Important Issues in the } \\
\text { course materlal. }\end{array}$ & C & $\mathrm{C}$ & $\mathrm{C}$ & $\mathrm{C}$ & $\mathrm{C}$ \\
\hline $\begin{array}{l}\text { I developed the ablity to communicate clearly about } \\
\text { the subject. }\end{array}$ & $\mathrm{C}$ & $\mathrm{C}$ & C & C & $\mathrm{C}$ \\
\hline $\begin{array}{l}\text { I Improved my ablity to integrate facts and develop } \\
\text { generallzations from the course materlal. }\end{array}$ & $\mathrm{C}$ & C & $\mathrm{C}$ & C & C \\
\hline
\end{tabular}




\section{The Effect of Social Presence on Students' Perceived Leaming and}

\section{Social Presence Survey ... ctd.}

11. For each of the following questions, please choose the descriptor that best describes your level of agreement with the statement.

\begin{tabular}{|c|c|c|c|c|c|}
\hline & $\begin{array}{l}\text { Strongly } \\
\text { Disagree }\end{array}$ & Dlsagree & Neutral & Agree & Strongly Agree \\
\hline $\begin{array}{l}\text { I was stlmulated to do additional reading or research on } \\
\text { toplcs discussed in the online speclal education course. }\end{array}$ & $\mathrm{C}$ & $\mathrm{C}$ & $c$ & $\mathrm{C}$ & 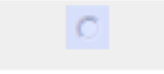 \\
\hline 1 learned to value other points of view. & $\mathrm{C}$ & $\mathrm{C}$ & $c$ & $\mathrm{C}$ & $\mathrm{C}$ \\
\hline $\begin{array}{l}\text { As a result of my participation in the online course, I } \\
\text { made acquaintances electronically in other parts of the } \\
\text { country/worid. }\end{array}$ & $\mathrm{C}$ & $\mathrm{C}$ & $\mathrm{C}$ & $\mathrm{C}$ & $C$ \\
\hline I was able to learn from the online discussions. & $\mathrm{C}$ & $\mathrm{C}$ & $c$ & $c$ & 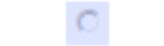 \\
\hline $\begin{array}{l}\text { I utllized a varlety of Information sources to explore } \\
\text { problems posed in this course. }\end{array}$ & $\mathrm{C}$ & $\mathrm{C}$ & $\mathrm{C}$ & $\mathrm{C}$ & C \\
\hline I felt motlvated to explore content related questions. & $\mathrm{C}$ & $\mathrm{C}$ & $c$ & $c$ & $\mathrm{C}$ \\
\hline $\begin{array}{l}\text { As a result of my experlence with the online special } \\
\text { education course, I would IIke to participate In another } \\
\text { online course in the future. }\end{array}$ & $\mathrm{C}$ & $\mathrm{C}$ & $\mathrm{C}$ & C & $\mathrm{C}$ \\
\hline The online course was a useful learning experlence. & $\mathrm{C}$ & $\mathrm{C}$ & $\mathrm{C}$ & $\mathrm{C}$ & $\mathrm{C}$ \\
\hline I was able to learn through the medlum of CMC. & $\mathrm{C}$ & C & $c$ & $\mathrm{C}$ & $\mathrm{C}$ \\
\hline $\begin{array}{l}\text { The diversity of topics in the online course prompted } \\
\text { me to participate in the discussions. }\end{array}$ & $\mathrm{C}$ & $\mathrm{C}$ & $\mathrm{C}$ & $\mathrm{C}$ & $\mathrm{C}$ \\
\hline $\begin{array}{l}\text { I put a great deal of effort to learn the CMC system to } \\
\text { particlpate in the online course. }\end{array}$ & C & C & $c$ & $c$ & $\mathrm{C}$ \\
\hline
\end{tabular}




\section{The Effect of Social Presence on Students' Perceived Leaming and}

4. Social Presence Survey ... ctd.

* 12. Before you began this course, what specific grade did you expect to earn upon completion of the course:
A
B
c
D
F
Pass
Fall
Incomplete
Other (please specify)

* 13. Based on your performance thus far, what final grade do you anticipate to receive in this course?

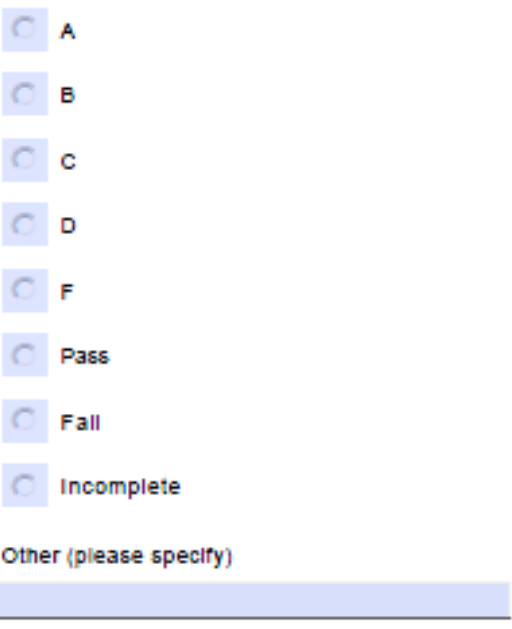




\section{The Effect of Social Presence on Students' Perceived Leaming and}

14. During this course, you had several online tools available to you on eCampus for accessing information and for communicating with colleagues and the instructor. Please use the following scale to rate the importance of each of these tools. If you did not use the tool, please choose "Not Used."

Not Used

Weicome messages

Ice-break conversation

Student proflles and blographles

Addressing students' using their names

Soclal area in the discussion board (Sandbox)

Audlo

Video using wimba

Use of chat

15. Please use the space below to offer any additional comments and/or concerns related to this online survey. 


\title{
Appendix B: IRB Cover Letter Sent to Participants
}

\section{West Virginia University}

\author{
College of Human Res ources and Education
}

\section{IRB Cover Letter Sent to Participants}

Dear Participant,

This letter is a request for you to take part in a research study investigating the effect of social presence on students' perceived learning and satisfaction in online courses. Social presence is defined by Garrison, Anderson and Archer (2000) as "the ability of participants in a community of inquiry to project themselves socially and emotionally, as "real" people (i.e. their full personality), through the medium of communication being use d" ( $p$. 94). This rese arch study is being conducted by Joseph Nyachae, with supervision of Dr. Terence Ahem, in the Department of Technology, Learning and Culture at WVU. This research is being conducted in partial fulfillment of the requirements for my dissertation. Your participation in this project is greatly appreciated and will take approximately 20-30 minutes to complete.

Your involvement in this project will be kept as confidential as legally possible. All data collected will be reported in the aggregate. In order to participate in this research you must be 18 years or ol der. I will not ask any information that should lead back to your identity as a participant. Your participation is completely voluntary. You may skip any question that you do not wish to answer and you may discontinue at any time. Your decision to participate or not to participate in this research will have no effect on your class standing or final course grade. West Virginia University's Institutional Review Board acknowledgement of this project is on file.

I hope that you will participate in this research study, as it could be beneficial in understanding effect of social presence on students' perceived learning and satisfaction in online courses. Thank you very much for your time. Should you have any questions about this letter or the research project, please feel free to contact Joseph Nyachae at (304) 319-1227 or by e-mail at nyandusi@yahoo.com. You can also contact my Advisor and Chairm an of my rese arch committee Dr. Terence Ahern at the email address

Terence.Ahern@mail.wvu.edu

Your expediency in returning the Web-based questionnaire will be greatly appreciated. If you are interested in receiving a summary of the results of this study, please contact me.

Here is a link to the survey:

http:/www. survevmonkev.com/s/Social Presence

Thank you in advance for your time and help with this study.

Sincerely,

Joseph Nyachae

Phone: 304-293-3049

Fax 304-293-9424

Department of Technology, Leaming \& Culture

Instructional Design \& Technology, Educational Psychology, and

Child Development \& Family Studies

504/ 506/507 Allen Hal

POBox 6122

Morgantown, WV 26506-6122

Equal OpportunitydAfirmative Adtion Institution 
Appendix C: Cover Letter Sent to Faculty Requesting Assistance in Sending Survey to

\author{
Students
}

Dear Faculty Member,

I would like to request for your assistance in my doctoral research. My research topic is, "The Effect of Social Presence on Students' Perceived Learning and Satisfaction in Online Courses".

Social presence is defined by Garrison, Anderson and Archer (2000) as "the ability of participants in a community of inquiry to project themselves socially and emotionally, as "real" people (i.e. their full personality), through the medium of communication being used" (p. 94). Social presence is an important topic, which must be addressed in distance education, because human beings naturally want to sense that they are needed, they play a role in something and not isolated. In a learning environment, the learners need to be aware of each other's presence for the learning to be more productive. Social presence is something, which is sometimes overlooked by many institutions of higher learning when implementing online education in their curriculum. This can be due to financial constraints and time. The purpose of the study is to investigate the effects of social presence on students' perceived learning and satisfaction in online courses. Results from this kind of study could assist higher learning institutions, instructors and instructional designers to better plan, design, develop, manage, and deliver quality online courses in a way that will improve how students perform as well as their satisfaction.

Participation in the survey is online and simple. The target sample is graduate students enrolled in special education online courses. The students will be emailed an attachment from their instructor and directed to a website link. The students will simply click on the link and it will lead them to a set of questions. When they are done answering the questions, they will submit the questionnaire online. The survey takes approximately 20 to 30 minutes to complete. Students may skip any question that they do not wish to answer and they may discontinue at any time. Participation in this study is absolutely voluntary. Their decision to participate or not to participate in this research will have no effect on their class standing or final course grade. The results of this survey will be confidential.

I am therefore requesting your assistance in emailing your students the attached cover letter that will direct them to the website to complete the online survey. Here is a link to the survey: http://www.surveymonkey.com/s/3QMZSQ6

If you have any questions about this study please contact me at the email address nyandusi@yahoo.com You can also contact my Advisor and Chairman of my research committee Dr. Terence Ahern at the email address Terence.Ahern@mail.wvu.edu or the West Virginia Office of Research Compliance at irb@mail.wvu.edu

Thank you in advance for your assistance.

Yours sincerely, Joseph 


\section{Appendix D: Follow-Up E-Mails to Survey Participants}

\section{Dear Faculty Member,}

Could you please send the reminder below to the students that have not yet responded to the survey? I am extremely grateful for all your assistance.

Thank you in advance.

Joseph

\section{Dear Participant,}

This letter is a request to those who have not already participated in this research study, please could you take 15 minutes to give us your feedback at the following link:

\section{http://www.surveymonkey.com/s/Social Presence}

Thanks very much to everyone who has already completed the survey - your input will be beneficial in understanding the effect of social presence on students' perceived learning and satisfaction in online courses. Your expediency in returning the Web-based questionnaire will be greatly appreciated.

Thank you in advance for your time and help with this study.

Sincerely, Joseph Nyachae 
Appendix E: Supplemental Tables from Chapter 4

\section{$\underline{\text { Social Presence }}$}

Table 9: Getting to know other course participants gave me a sense of belonging in the course.

\begin{tabular}{lcc}
\hline $\begin{array}{l}\text { Getting to know other } \\
\text { course participants }\end{array}$ & Frequency & Percentage \\
\hline Strongly Agree & 11 & 14.5 \\
Agree & 41 & 53.9 \\
Neutral & 12 & 15.8 \\
Disagree & 10 & 13.2 \\
Strongly Disagree & 2 & 2.6 \\
Total & 76 & 100 \\
Missing & 5 & \\
\hline Total & 81 & 100 \\
\hline
\end{tabular}

Table 10: I was able to form distinct impressions of some course participants.

\begin{tabular}{lcc}
\hline $\begin{array}{l}\text { Form distinct } \\
\text { impressions }\end{array}$ & Frequency & Percentage \\
\hline Strongly Agree & 10 & 13.2 \\
Agree & 50 & 65.8 \\
Neutral & 11 & 14.5 \\
Disagree & 2 & 2.6 \\
Strongly Disagree & 3 & 3.9 \\
Total & 76 & 100 \\
Missing & 5 & 100 \\
\hline Total & 81 & \\
\hline
\end{tabular}


Table 11: Online or web-based communication is an excellent medium for social interaction.

\begin{tabular}{lcc}
\hline $\begin{array}{l}\text { Excellent medium for } \\
\text { social interaction }\end{array}$ & Frequency & Percentage \\
\hline Strongly Agree & 9 & 11.8 \\
Agree & 39 & 51.3 \\
Neutral & 19 & 25.0 \\
Disagree & 7 & 9.2 \\
Strongly Disagree & 2 & 2.6 \\
Total & 76 & 100 \\
Missing & 5 & 100 \\
\hline Total & 81 & \\
\hline
\end{tabular}

Table 12: I felt comfortable conversing through the online medium.

\begin{tabular}{lcc}
\hline $\begin{array}{l}\text { Comfortable } \\
\text { Conversing }\end{array}$ & Frequency & Percentage \\
\hline Strongly Agree & 19 & 25.0 \\
Agree & 43 & 56.6 \\
Neutral & 8 & 10.5 \\
Disagree & 6 & 7.9 \\
Strongly Disagree & 0 & 0.0 \\
Total & 76 & 100 \\
Missing & 5 & 100 \\
\hline Total & 81 & \\
\hline
\end{tabular}


Table 13: I felt comfortable participating in the course discussions.

\begin{tabular}{lcc}
\hline $\begin{array}{l}\text { Comfortable } \\
\text { Participating }\end{array}$ & Frequency & Percentage \\
\hline Strongly Agree & 13 & 17.1 \\
Agree & 49 & 64.5 \\
Neutral & 8 & 10.5 \\
Disagree & 6 & 7.9 \\
Strongly Disagree & 0 & 0.0 \\
Total & 76 & 100 \\
Missing & 5 & \\
\hline Total & 81 & 100 \\
\hline
\end{tabular}

Table 14: I felt comfortable interacting with other course participants.

\begin{tabular}{lcc}
\hline Comfortable Interacting & Frequency & Percentage \\
\hline Strongly Agree & 15 & 19.7 \\
Agree & 47 & 61.8 \\
Neutral & 12 & 15.8 \\
Disagree & 1 & 1.3 \\
Strongly Disagree & 1 & 1.3 \\
Total & 76 & 100 \\
Missing & 5 & 100 \\
\hline Total & 81 & \\
\hline
\end{tabular}


Table 15: I felt comfortable disagreeing with other course participants while still maintaining a sense of trust.

\begin{tabular}{lcc}
\hline Comfortable Disagreeing & Frequency & Percentage \\
\hline Strongly Agree & 15 & 11.8 \\
Agree & 47 & 56.6 \\
Neutral & 12 & 15.8 \\
Disagree & 11 & 14.5 \\
Strongly Disagree & 1 & 1.3 \\
Total & 76 & 100 \\
Missing & 5 & 100 \\
\hline Total & 81 & \\
\hline
\end{tabular}

Table 16: I felt that my point of view was acknowledged by other course participants.

\begin{tabular}{lcc}
\hline $\begin{array}{l}\text { Point of view was } \\
\text { acknowledged }\end{array}$ & Frequency & Percentage \\
\hline Strongly Agree & 13 & 17.3 \\
Agree & 53 & 70.7 \\
Neutral & 8 & 10.7 \\
Disagree & 1 & 1.3 \\
Strongly Disagree & 0 & 0.0 \\
Total & 75 & 100 \\
Missing & 6 & 100 \\
\hline Total & 81 & \\
\hline
\end{tabular}


Table 17: Online discussions help me to develop a sense of collaboration.

\begin{tabular}{lcc}
\hline $\begin{array}{l}\text { Point of view was } \\
\text { acknowledged }\end{array}$ & Frequency & Percentage \\
\hline Strongly Agree & 10 & 13.2 \\
Agree & 47 & 61.8 \\
Neutral & 12 & 15.8 \\
Disagree & 5 & 6.6 \\
Strongly Disagree & 2 & 2.6 \\
Total & 76 & 100 \\
Missing & 5 & 100 \\
\hline Total & 81 & \\
\hline
\end{tabular}




\section{$\underline{\text { Perceived Learning }}$}

Table 18: I learned to interrelate the important issues in the course material

\begin{tabular}{lcc}
\hline $\begin{array}{l}\text { Interrelate the important } \\
\text { issues }\end{array}$ & Frequency & Percentage \\
\hline Strongly Agree & 14 & 18.7 \\
Agree & 51 & 68.0 \\
Neutral & 4 & 5.3 \\
Disagree & 6 & 8.0 \\
Strongly Disagree & 0 & 0.0 \\
Total & 75 & 100 \\
Missing & 6 & 100 \\
\hline Total & 81 & \\
\hline
\end{tabular}

Table 19: I gained a good understanding of the basic concepts of the material.

\begin{tabular}{lcc}
\hline $\begin{array}{l}\text { Understanding of the } \\
\text { basic concepts }\end{array}$ & Frequency & Percentage \\
\hline Strongly Agree & 18 & 23.7 \\
Agree & 52 & 68.4 \\
Neutral & 2 & 2.6 \\
Disagree & 4 & 5.3 \\
Strongly Disagree & 0 & 0.0 \\
Total & 76 & 100 \\
Missing & 5 & 100 \\
\hline Total & 81 & \\
\hline
\end{tabular}


Table 20: I learned to identify the central issues of the course.

\begin{tabular}{lcc}
\hline Identify the central issues & Frequency & Percentage \\
\hline Strongly Agree & 24 & 31.6 \\
Agree & 44 & 57.9 \\
Neutral & 4 & 5.3 \\
Disagree & 4 & 5.3 \\
Strongly Disagree & 0 & 0.0 \\
Total & 76 & 100 \\
Missing & 5 & 100 \\
\hline Total & 81 & \\
\hline
\end{tabular}

Table 21: I developed the ability to communicate clearly about the subject.

\begin{tabular}{lcc}
\hline $\begin{array}{l}\text { Developed the ability to } \\
\text { communicate }\end{array}$ & Frequency & Percentage \\
\hline Strongly Agree & 13 & 17.1 \\
Agree & 53 & 69.7 \\
Neutral & 6 & 7.9 \\
Disagree & 4 & 5.3 \\
Strongly Disagree & 0 & 0.0 \\
Total & 76 & 100 \\
Missing & 5 & 100 \\
\hline Total & 81 & \\
\hline
\end{tabular}


Table 22: I improved my ability to integrate facts and develop generalizations from the course material.

\begin{tabular}{lcc}
\hline $\begin{array}{l}\text { Integrate facts and } \\
\text { develop generalizations }\end{array}$ & Frequency & Percentage \\
\hline Strongly Agree & 17 & 22.4 \\
Agree & 50 & 65.8 \\
Neutral & 6 & 7.9 \\
Disagree & 3 & 3.9 \\
Strongly Disagree & 0 & 0.0 \\
Total & 76 & 100 \\
Missing & 5 & 100 \\
\hline Total & 81 & \\
\hline
\end{tabular}

Table 23: I learned concepts and principles in this course.

\begin{tabular}{lcc}
\hline $\begin{array}{l}\text { Learned concepts and } \\
\text { principles }\end{array}$ & Frequency & Percentage \\
\hline Strongly Agree & 22 & 28.9 \\
Agree & 48 & 63.2 \\
Neutral & 4 & 5.3 \\
Disagree & 1 & 1.3 \\
Strongly Disagree & 1 & 1.3 \\
Total & 76 & 100 \\
Missing & 5 & 100 \\
\hline Total & 81 & \\
\hline
\end{tabular}




\section{$\underline{\text { Satisfaction }}$}

Table 24: I was able to learn through the medium of CMC.

\begin{tabular}{lcc}
\hline $\begin{array}{l}\text { Learn through the } \\
\text { medium }\end{array}$ & Frequency & Percentage \\
\hline Strongly Agree & 12 & 17.6 \\
Agree & 42 & 61.8 \\
Neutral & 12 & 17.6 \\
Disagree & 1 & 1.5 \\
Strongly Disagree & 1 & 1.5 \\
Total & 68 & 100 \\
Missing & 13 & \\
\hline Total & 81 & 100 \\
\hline
\end{tabular}

Table 25: I was able to learn from the online discussions.

\begin{tabular}{lcc}
\hline $\begin{array}{l}\text { Learn from the online } \\
\text { discussions }\end{array}$ & Frequency & Percentage \\
\hline Strongly Agree & 21 & 29.6 \\
Agree & 40 & 56.3 \\
Neutral & 6 & 8.5 \\
Disagree & 2 & 2.8 \\
Strongly Disagree & 2 & 2.8 \\
Total & 71 & 100 \\
Missing & 10 & \\
\hline Total & 81 & 100 \\
\hline
\end{tabular}


Table 26: I felt motivated to explore content related questions.

\begin{tabular}{lcc}
\hline $\begin{array}{l}\text { Motivated to explore } \\
\text { content }\end{array}$ & Frequency & Percentage \\
\hline Strongly Agree & 12 & 17.1 \\
Agree & 43 & 61.4 \\
Neutral & 10 & 14.3 \\
Disagree & 4 & 5.7 \\
Strongly Disagree & 1 & 1.4 \\
Total & 70 & 100 \\
Missing & 11 & 100 \\
\hline Total & 81 & \\
\hline
\end{tabular}

Table 27: I utilized a variety of information sources to explore problems posed in this course.

\begin{tabular}{lcc}
\hline $\begin{array}{l}\text { Utilized a variety of } \\
\text { information sources }\end{array}$ & Frequency & Percentage \\
\hline Strongly Agree & 13 & 18.8 \\
Agree & 49 & 71.0 \\
Neutral & 6 & 8.7 \\
Disagree & 1 & 1.4 \\
Strongly Disagree & 0 & 0.0 \\
Total & 69 & 100 \\
Missing & 12 & 100 \\
\hline Total & 81 & \\
\hline
\end{tabular}


Table 28: I was stimulated to do additional reading or research on topics discussed in the online special education course.

\begin{tabular}{lcc}
\hline $\begin{array}{l}\text { Stimulated to do } \\
\text { additional reading or } \\
\text { research }\end{array}$ & Frequency & Percentage \\
\hline Strongly Agree & 10 & 14.1 \\
Agree & 40 & 56.3 \\
Neutral & 10 & 14.1 \\
Disagree & 6 & 8.5 \\
Strongly Disagree & 5 & 7.0 \\
Total & 71 & 100 \\
Missing & 10 & 100 \\
\hline Total & 81 & \\
\hline
\end{tabular}

Table 29: I learned to value other points of view.

\begin{tabular}{lcc}
\hline $\begin{array}{l}\text { Value other points of } \\
\text { view }\end{array}$ & Frequency & Percentage \\
\hline Strongly Agree & 16 & 22.5 \\
Agree & 40 & 56.3 \\
Neutral & 13 & 18.3 \\
Disagree & 1 & 1.4 \\
Strongly Disagree & 1 & 1.4 \\
Total & 71 & 100 \\
Missing & 10 & 100 \\
\hline Total & 81 & \\
\hline
\end{tabular}


Table 30: As a result of my experience with the online special education course, I would like to participate in another online course in the future.

\begin{tabular}{lcc}
\hline $\begin{array}{l}\text { Participate in another } \\
\text { online course }\end{array}$ & Frequency & Percentage \\
\hline Strongly Agree & 20 & 28.2 \\
Agree & 40 & 56.3 \\
Neutral & 7 & 9.9 \\
Disagree & 2 & 2.8 \\
Strongly Disagree & 2 & 2.8 \\
Total & 71 & 100 \\
Missing & 10 & \\
\hline Total & 81 & 100 \\
\hline
\end{tabular}

Table 31: The online course was a useful learning experience.

\begin{tabular}{lcc}
\hline $\begin{array}{l}\text { Useful learning } \\
\text { experience }\end{array}$ & Frequency & Percentage \\
\hline Strongly Agree & 22 & 31.4 \\
Agree & 42 & 60.0 \\
Neutral & 2 & 2.9 \\
Disagree & 3 & 4.3 \\
Strongly Disagree & 1 & 1.4 \\
Total & 70 & 100 \\
Missing & 11 & \\
\hline Total & 81 & 100 \\
\hline
\end{tabular}


Table 32: As a result of my participation in the online course, I made acquaintances electronically in other parts of the country/world.

\begin{tabular}{lcc}
\hline $\begin{array}{l}\text { Made acquaintances } \\
\text { electronically }\end{array}$ & Frequency & Percentage \\
\hline Strongly Agree & 9 & 12.7 \\
Agree & 29 & 40.8 \\
Neutral & 11 & 15.5 \\
Disagree & 17 & 23.9 \\
Strongly Disagree & 5 & 7.0 \\
Total & 71 & 100 \\
Missing & 10 & 100 \\
\hline Total & 81 & \\
\hline
\end{tabular}

Table 33: The diversity of topics in the online course prompted me to participate in the discussions.

\begin{tabular}{lcc}
\hline Diversity of topics & Frequency & Percentage \\
\hline Strongly Agree & 9 & 12.7 \\
Agree & 43 & 60.6 \\
Neutral & 10 & 14.1 \\
Disagree & 7 & 9.9 \\
Strongly Disagree & 2 & 2.8 \\
Total & 71 & 100 \\
Missing & 10 & 100 \\
\hline Total & 81 & \\
\hline
\end{tabular}


Table 34: I put a great deal of effort to learn the CMC system to participate in the online course.

\begin{tabular}{lcc}
\hline $\begin{array}{l}\text { Put a great deal of effort } \\
\text { to learn the CMC } \\
\text { system }\end{array}$ & Frequency & Percentage \\
\hline Strongly Agree & 14 & 19.7 \\
Agree & 31 & 43.7 \\
Neutral & 17 & 23.9 \\
Disagree & 8 & 11.3 \\
Strongly Disagree & 1 & 1.4 \\
Total & 71 & 100 \\
Missing & 10 & \\
\hline Total & 81 & 100 \\
\hline
\end{tabular}


$\underline{\text { Interactive Elements }}$

Table 35: Welcome messages

\begin{tabular}{lcc}
\hline Welcome messages & Frequency & Percentage \\
\hline Very Important Tool & 15 & 21.4 \\
Important Tool & 39 & 55.7 \\
Unimportant Tool & 5 & 7.1 \\
Not Used & 11 & 15.7 \\
Total & 70 & 100 \\
Missing & 11 & 100 \\
\hline Total & 81 & \\
\hline
\end{tabular}

Table 36: Ice-breaker

\begin{tabular}{lcc}
\hline Ice-break conversation & Frequency & Percentage \\
\hline Very Important Tool & 11 & 15.5 \\
Important Tool & 24 & 33.8 \\
Unimportant Tool & 13 & 18.3 \\
Not Used & 23 & 32.4 \\
Total & 71 & 100 \\
Missing & 10 & 100 \\
\hline Total & 81 & \\
\hline
\end{tabular}


Table 37: Student profiles and biographies

\begin{tabular}{lcc}
\hline $\begin{array}{l}\text { Student profiles and } \\
\text { biographies }\end{array}$ & Frequency & Percentage \\
\hline Very Important Tool & 11 & 15.7 \\
Important Tool & 38 & 54.3 \\
Unimportant Tool & 16 & 22.9 \\
Not Used & 5 & 7.1 \\
Total & 70 & 100 \\
Missing & 11 & 100 \\
\hline Total & 81 & \\
\hline
\end{tabular}

Table 38: Addressing students' using their names

\begin{tabular}{lcc}
\hline $\begin{array}{l}\text { Addressing students' } \\
\text { using their names }\end{array}$ & Frequency & Percentage \\
\hline Very Important Tool & 21 & 28.8 \\
Important Tool & 45 & 61.6 \\
Unimportant Tool & 6 & 8.2 \\
Not Used & 1 & 1.4 \\
Total & 73 & 100 \\
Missing & 8 & 100 \\
\hline Total & 81 & \\
\hline
\end{tabular}


Table 39: Social area in the discussion board (Sandbox)

\begin{tabular}{lcc}
\hline $\begin{array}{l}\text { Social area in the } \\
\text { discussion board } \\
\text { (Sandbox) }\end{array}$ & Frequency & Percentage \\
\hline Very Important Tool & 13 & 18.3 \\
Important Tool & 27 & 38.0 \\
Unimportant Tool & 13 & 18.3 \\
Not Used & 18 & 25.4 \\
Total & 71 & 100 \\
Missing & 10 & 100 \\
\hline Total & 81 & \\
\hline
\end{tabular}

Table 40: Audio

\begin{tabular}{lcc}
\hline Audio & Frequency & Percentage \\
\hline Very Important Tool & 33 & 45.2 \\
Important Tool & 36 & 49.3 \\
Unimportant Tool & 3 & 4.1 \\
Not Used & 1 & 1.4 \\
Total & 73 & 100 \\
Missing & 8 & 100 \\
\hline Total & 81 & \\
\hline
\end{tabular}


Table 41: Video using Wimba

\begin{tabular}{lcc}
\hline Video using Wimba & Frequency & Percentage \\
\hline Very Important Tool & 27 & 37.0 \\
Important Tool & 21 & 28.8 \\
Unimportant Tool & 8 & 11.0 \\
Not Used & 17 & 23.3 \\
Total & 73 & 100 \\
Missing & 8 & 100 \\
\hline Total & 81 & \\
\hline
\end{tabular}


Appendix F: Perceived Learning Regression Analysis Output

\section{Regression}

\begin{tabular}{|l|l|l|l|}
\hline Model & $\begin{array}{c}\text { Variables Entered/Removed } \\
\text { Variables } \\
\text { Entered }\end{array}$ & $\begin{array}{l}\text { Variables } \\
\text { Removed }\end{array}$ & Method \\
\hline 1 & $\begin{array}{l}\text { Social Presence } \\
\text { Mean Score, } \\
\text { Number of } \\
\text { Interactive } \\
\text { Elements }\end{array}$ & & \\
& & & \\
& & & \\
& & & \\
\hline
\end{tabular}

a. All requested variables entered.

b. Dependent Variable: Perceived Learning Mean Score

Model Summary

\begin{tabular}{|l|r|r|r|r|}
\hline Model & R & R Square & $\begin{array}{c}\text { Adjusted R } \\
\text { Square }\end{array}$ & $\begin{array}{c}\text { Std. Error of the } \\
\text { Estimate }\end{array}$ \\
\hline 1 & $.759^{\mathrm{a}}$ & .576 & .563 & .42976 \\
& & & & \\
& & & & \\
& & & & \\
& & & & \\
\hline
\end{tabular}

a. Predictors: (Constant), Social Presence Mean Score, Number of Interactive Elements 
ANOVA $^{b}$

\begin{tabular}{|ll|r|r|r|r|r|}
\hline \multicolumn{1}{|l|}{} & & Sum of Squares & df & Mean Square & F & Sig. \\
\hline 1 & Regression & 16.294 & 2 & 8.147 & 44.110 & $.000^{\mathrm{a}}$ \\
& Residual & 12.005 & 65 & .185 & & \\
& Total & 28.299 & 67 & & & \\
\hline
\end{tabular}

a. Predictors: (Constant), Social Presence Mean Score, Number of Interactive Elements

b. Dependent Variable: Perceived Learning Mean Score

Coefficients $^{\mathrm{a}}$

\begin{tabular}{|c|c|c|c|c|c|c|}
\hline \multirow{2}{*}{\multicolumn{2}{|c|}{ Model }} & \multicolumn{2}{|c|}{ Unstandardized Coefficients } & \multirow{2}{*}{$\begin{array}{l}\text { Standardized } \\
\text { Coefficients } \\
\text { Beta }\end{array}$} & \multirow[b]{2}{*}{$\mathrm{t}$} & \multirow[b]{2}{*}{ Sig. } \\
\hline & & $\mathrm{B}$ & Std. Error & & & \\
\hline \multirow[t]{5}{*}{1} & (Constant) & 1.002 & .366 & & 2.735 & .008 \\
\hline & Number of Interactive & -.008 & .035 & -.019 & -.229 & .819 \\
\hline & Elements & & & & & \\
\hline & Social Presence Mean & .820 & .090 & .764 & 9.089 & .000 \\
\hline & Score & & & & & \\
\hline
\end{tabular}

a. Dependent Variable: Perceived Learning Mean Score 


\section{Appendix G: Satisfaction Regression Analysis Output}

\section{Regression}

\begin{tabular}{|l|l|l|l|}
\hline \multicolumn{3}{|c|}{ Variables Entered/Removed $^{\text {b }}$} \\
\hline 1 & $\begin{array}{l}\text { Variables } \\
\text { Entered }\end{array}$ & $\begin{array}{l}\text { Variables } \\
\text { Removed }\end{array}$ & Method \\
\hline $\begin{array}{l}\text { Social Presence } \\
\text { Mean Score, } \\
\text { Number of } \\
\text { Interactive } \\
\text { Elements }\end{array}$ & & & Enter \\
& & & \\
& & & \\
\hline
\end{tabular}

a. All requested variables entered.

b. Dependent Variable: Perceived Satisfaction Mean

Score

Model Summary

\begin{tabular}{|l|r|r|r|r|}
\hline Model & $\mathrm{R}$ & $\mathrm{R}$ Square & $\begin{array}{c}\text { Adjusted R } \\
\text { Square }\end{array}$ & $\begin{array}{c}\text { Std. Error of the } \\
\text { Estimate }\end{array}$ \\
\hline 1 & $.814^{\mathrm{a}}$ & .662 & .652 & .40682 \\
& & & & \\
& & & & \\
& & & & \\
& & & & \\
\end{tabular}

a. Predictors: (Constant), Social Presence Mean Score, Number of Interactive Elements 
ANOVA $^{b}$

\begin{tabular}{|c|c|c|c|c|c|c|}
\hline \multicolumn{2}{|c|}{ Model } & Sum of Squares & $\mathrm{df}$ & Mean Square & $\mathrm{F}$ & Sig. \\
\hline \multirow[t]{3}{*}{1} & Regression & 20.791 & 2 & 10.396 & 62.812 & $.000^{\mathrm{a}}$ \\
\hline & Residual & 10.592 & 64 & .166 & & \\
\hline & Total & 31.384 & 66 & & & \\
\hline
\end{tabular}

a. Predictors: (Constant), Social Presence Mean Score, Number of Interactive Elements

b. Dependent Variable: Perceived Satisfaction Mean Score

Coefficients $^{\mathrm{a}}$

\begin{tabular}{|c|c|c|c|c|c|c|}
\hline \multirow{2}{*}{\multicolumn{2}{|c|}{ Model }} & \multicolumn{2}{|c|}{ Unstandardized Coefficients } & \multirow{2}{*}{$\begin{array}{l}\text { Standardized } \\
\text { Coefficients } \\
\text { Beta }\end{array}$} & \multirow[b]{2}{*}{$\mathrm{t}$} & \multirow[b]{2}{*}{ Sig. } \\
\hline & & $\mathrm{B}$ & Std. Error & & & \\
\hline \multirow[t]{5}{*}{1} & (Constant) & .335 & .347 & & .965 & .338 \\
\hline & Number of Interactive & -.001 & .033 & -.002 & -.032 & .974 \\
\hline & Elements & & & & & \\
\hline & Social Presence Mean & .921 & .085 & .815 & 10.788 & .000 \\
\hline & Score & & & & & \\
\hline
\end{tabular}

a. Dependent Variable: Perceived Satisfaction Mean Score 
Appendix H: Regression Analysis without Using Interactive Elements

If this predictive model were ever used to pragmatically predict Perceived Learning or Satisfaction, then one would re-conduct the regression analyses without using interactive elements as an Independent Variable, since this variable was not a significant predictor.

The resultant predictive models are:

PLMS $=(.787)($ Social Presence Mean Score $)+1.074$

Social Presence, in this model, explains $57 \%$ of the variance in perceived learning.

PSMS $=(.869)($ Social Presence Mean Score $)$

Social Presence, in this predictive model, explains $65 \%$ of Perceived Satisfaction.

\section{Regression}

\begin{tabular}{|l|c|c|l|}
\hline \multicolumn{3}{|c|}{ Variables Entered/Removed $^{\mathbf{b}}$} \\
\hline Model & Variables & Variables & \\
Entered & Removed & Method \\
\hline 1 & Social Presence \\
& Mean Score & & Enter \\
\hline
\end{tabular}

a. All requested variables entered.

b. Dependent Variable: Perceived Learning Mean Score

\begin{tabular}{|l|r|r|r|r|}
\hline \multicolumn{7}{|c|}{ Model Summary } \\
\hline Model & $\mathrm{R}$ & $\mathrm{R}$ Square & \multicolumn{1}{c|}{$\begin{array}{c}\text { Adjusted R } \\
\text { Square }\end{array}$} & $\begin{array}{c}\text { Std. Error of the } \\
\text { Estimate }\end{array}$ \\
\hline 1 & $.758^{\mathrm{a}}$ & .575 & .569 & .41727 \\
\hline
\end{tabular}

a. Predictors: (Constant), Social Presence Mean Score 
ANOVA $^{b}$

\begin{tabular}{|lr|r|r|r|r|r|}
\hline Model & & Sum of Squares & df & Mean Square & F & Sig. \\
\hline 1 & 17.418 & 1 & 17.418 & 100.039 & $.000^{\mathrm{a}}$ \\
Regression & 12.884 & 74 & .174 & & \\
& 30.302 & 75 & & & \\
Total & & & & & \\
\hline
\end{tabular}

a. Predictors: (Constant), Social Presence Mean Score

b. Dependent Variable: Perceived Learning Mean Score

\section{Coefficients $^{\mathrm{a}}$}

\begin{tabular}{|c|c|c|c|c|c|c|}
\hline \multirow{2}{*}{\multicolumn{2}{|c|}{ Model }} & \multicolumn{2}{|c|}{ Unstandardized Coefficients } & \multirow{2}{*}{$\begin{array}{c}\text { Standardized } \\
\text { Coefficients } \\
\text { Beta }\end{array}$} & \multirow[b]{2}{*}{$\mathrm{t}$} & \multirow[b]{2}{*}{ Sig. } \\
\hline & & B & Std. Error & & & \\
\hline \multirow[t]{2}{*}{1} & (Constant) & 1.074 & .304 & & 3.531 & .001 \\
\hline & Social Presence Mean Score & .787 & .079 & .758 & 10.002 & .000 \\
\hline
\end{tabular}

a. Dependent Variable: Perceived Learning Mean Score

\section{Regression}

\begin{tabular}{|l|c|c|l|}
\hline \multicolumn{3}{|c|}{ Variables Entered/Removed $^{\mathbf{b}}$} \\
\hline Model & $\begin{array}{c}\text { Variables } \\
\text { Entered }\end{array}$ & $\begin{array}{c}\text { Variables } \\
\text { Removed }\end{array}$ & Method \\
\hline 1 & Social Presence \\
& Mean Score & & Enter \\
\hline
\end{tabular}

a. All requested variables entered.

b. Dependent Variable: Perceived Satisfaction Mean

Score 


\begin{tabular}{|l|r|r|r|c|}
\hline Model & $\mathrm{R}$ & $\mathrm{R}$ Square & \multicolumn{1}{c|}{$\begin{array}{c}\text { Adjusted R } \\
\text { Square }\end{array}$} & $\begin{array}{c}\text { Std. Error of the } \\
\text { Estimate }\end{array}$ \\
\hline 1 & $.809^{\mathrm{a}}$ & .654 & .649 & .40232 \\
\hline
\end{tabular}

a. Predictors: (Constant), Social Presence Mean Score

\begin{tabular}{|c|c|c|c|c|c|c|}
\hline \multicolumn{7}{|c|}{ ANOVA $^{b}$} \\
\hline & & Sum of Squares & df & Mean Square & $\mathrm{F}$ & Sig. \\
\hline \multirow[t]{3}{*}{1} & Regression & 21.142 & 1 & 21.142 & 130.619 & $.000^{\mathrm{a}}$ \\
\hline & Residual & 11.168 & 69 & .162 & & \\
\hline & Total & 32.310 & 70 & & & \\
\hline
\end{tabular}

a. Predictors: (Constant), Social Presence Mean Score

b. Dependent Variable: Perceived Satisfaction Mean Score

\begin{tabular}{|c|c|c|c|c|c|c|}
\hline \multicolumn{7}{|c|}{ Coefficients $^{a}$} \\
\hline \multirow{2}{*}{\multicolumn{2}{|c|}{ Model }} & \multicolumn{2}{|c|}{ Unstandardized Coefficients } & \multirow{2}{*}{$\begin{array}{c}\begin{array}{c}\text { Standardized } \\
\text { Coefficients }\end{array} \\
\text { Beta }\end{array}$} & \multirow[b]{2}{*}{$\mathrm{t}$} & \multirow[b]{2}{*}{ Sig. } \\
\hline & & $\mathrm{B}$ & Std. Error & & & \\
\hline 1 & (Constant) & .542 & .293 & & 1.848 & .069 \\
\hline & Social Presence Mean Score & .869 & .076 & .809 & 11.429 & .000 \\
\hline
\end{tabular}

a. Dependent Variable: Perceived Satisfaction Mean Score

\section{Frequencies}


Statistics

Number of Interactive Elements

\begin{tabular}{|c|c|c|}
\hline $\mathrm{N}$ & Valid & 68 \\
\hline & Missing & 13 \\
\hline
\end{tabular}

\begin{tabular}{|c|c|c|c|c|c|}
\hline \multicolumn{6}{|c|}{ Number of Interactive Elements } \\
\hline & & Frequency & Percent & Valid Percent & $\begin{array}{c}\text { Cumulative } \\
\text { Percent }\end{array}$ \\
\hline \multirow[t]{8}{*}{ Valid } & 2.00 & 1 & 1.2 & 1.5 & 1.5 \\
\hline & 3.00 & 1 & 1.2 & 1.5 & 2.9 \\
\hline & 4.00 & 5 & 6.2 & 7.4 & 10.3 \\
\hline & 5.00 & 7 & 8.6 & 10.3 & 20.6 \\
\hline & 6.00 & 12 & 14.8 & 17.6 & 38.2 \\
\hline & 7.00 & 4 & 4.9 & 5.9 & 44.1 \\
\hline & 8.00 & 38 & 46.9 & 55.9 & 100.0 \\
\hline & Total & 68 & 84.0 & 100.0 & \\
\hline Missing & System & 13 & 16.0 & & \\
\hline Total & & 81 & 100.0 & & \\
\hline
\end{tabular}

Appendix I: Comments the Respondents Submitted In Response

Below are excerpts from the comments the respondents submitted in response to the additional comments section.

"On-line classes provide me with the opportunity to learn and interact with others while staying in the comfort of my own home. I liked the fact that I did not have to travel and could complete all of my work on-line." 
"Online courses have very beneficial to me. The most convenient class I have taken was a few years ago. The instructor recorded his lectures and we listened to them when we were able. The class did not meet at any specific time. We listened to the lectures at our convenience and, if we had questions, comments, etc., we could send the instructor an email or post info on the discussion board."

"The inability to do more research \& reading related to topics in the course is not because of non interest; it is due to lack of time due to completing assignments, required reading, working full time, and having a family."

"I honestly do not feel any relationship with my teachers or fellow students in an online class, unlike a real classroom. I do not feel that the introduction that they have us post is sufficient in having us get to know each other or encourage communication."

"I love online courses! They are a lot of work, but well worth it since it is so flexible."

"The due dates are not clear and the quizzes are only offered 1 evening of the week."

"I wish the instructor was more punctual and informative with responses to emails."

"I found "break-out rooms or sessions" during class very beneficial. I had an easier time with discussions using this method during live class sessions."

"Taking my coursework on line has opened a new window of opportunity for me and my family. I did not have to deal with driving time, and was able to observe in the local school district which has also been convenient. There has been a few of my peers that I grew to respect because they seemed like they were good students, but unfortunately it did seem to me like there were some students that did the minimum."

"I do not feel extremely comfortable expressing an opinion that is in conflict with the opinion of the professor. In addition, I feel that setting up the discussions with a graded portion for the discussions, while necessary I understand, poses an undue burden on those people who prefer to do work in advance. I have found myself needing to log in the day an assignment is due because a group person is late posting their portion of the discussion. I then feel compelled to write a quick not well thought out response for fear that my grade would be lowered for not posting before the midnight deadline. In previous online courses I was required to respond to a number of postings, but not necessarily every posting. This allowed me to think through and post something meaningful. This semester I find myself much more anxious because my group members are not posting their initial portion until last minute. And since I am required to respond to every posting from my group, I have been forced to check 2-3 times a day on the last day or two to be sure I do what I need to receive a high grade. Couple this with the fact that I am a HI-Tech grant participant, and need an A or B to be reimbursed and I find it unfair that my grade and thus my reimbursement is in another student's hands." 
"I prefer the typical classroom where I can get instant feedback to a question. I prefer having someone in person to ask a question to. These two classes that I have had have been the most stressful classes that I have ever had. I did not/ nor do I enjoy this class that I am currently taking. I am only taking online because it is not offered in class where I live."

"I have found that classes that required collaboration with other students for discussions and assignments increased the amount of social interaction. For example, Course 663 had several assignments in which you had to work with a partner in collaborating lesson plans (which was I did via phone conversations and email despite the fact my partner and I lived in the same county) and we had breakaway questions during the class, in which we were randomly put into groups, given a question to discuss and answer together and then share with the entire class. These types of assignments strongly encourage social interaction whereas Course 601, all assignments were individual and questions asked in class were asked of everyone with a response box to fill in. While all answers were visible, it was not what I would consider to be a "social interaction" with peers. Honestly the student profiles and biographies don't mean anything to me. It provides a face to a name and some background information but it is not the same as being in the same physical space. Social areas in the discussion boards are rarely used and when they are, not many people respond."

"I feel very comfortable with the online courses and they are very convenient for those of us who have full time teaching jobs and a family!"

"I feel that the online experience would be much more satisfying if there were a way for us to see each other. Even the use of avatars would fulfill this need to feel as if we are interacting with actual people and not just faceless voices and typing."

"I have really appreciated the offering of on-line classes because of my very tight schedule. They, also, offer interaction with other professionals that enhances my teaching skills and strategies as well as support and ideas."

\footnotetext{
John H. 